\title{
EXPLORATION OF HOW WOMEN MAKE TREATMENT DECISIONS AFTER A BREAST CANCER DIAGNOSIS
}

\author{
BY \\ Copyright 2011

\section{CHERYL ANN SPITTLER}

Submitted to the graduate degree program in Nursing and the Graduate Faculty of the University of Kansas in partial fulfillment of the requirements for the degree of Doctor of Philosophy.

Chairperson Marjorie Bott

Leonie Pallikkathayil

Wanda Bonnel

Jennifer Klemp

Bruce Kimler

Cindy Teel

Date Defended: April 13, 2011 
The Dissertation Committee for CHERYL ANN SPITTLER certifies that this is the approved version of the following dissertation:

EXPLORATION OF HOW WOMEN MAKE TREATMENT DECISIONS AFTER A BREAST CANCER DIAGNOSIS

Chairperson Marjorie Bott

Co-Chairperson Leonie Pallikkathayil

Date approved: April 13, 2011 


\begin{abstract}
Breast cancer is the most common type of cancer diagnosed in women. Although much research has been conducted on physical and psychosocial adjustment after the diagnosis of the disease, little is known about how women make treatment decisions following a breast cancer diagnosis. Therefore, this study examined the information needs women have after receiving the diagnosis of breast cancer, investigated how decisions are made about treatment options, and assessed the personal responses to the decisions made. A mixed methods approach using quantitative and qualitative data was used as the research design.
\end{abstract}

The sample consisted of 102 breast cancer survivors that had completed all forms of treatment for at least three months and less than five years were recruited from a Midwestern academic medical center and a Midwestern private plastic surgery practice setting. In Phase I participants completed a demographic participant information form and five questionnaires about informational needs, confidence and satisfaction with the decision, decisional regret, and conflict. In Phase II, 16 participants were purposively sampled from the 102 survivors to participate in a focus group session. Data analysis included frequencies and multiple regression for Phase I and qualitative content analysis for Phase II.

Findings from the study found that the women after being diagnosed with breast cancer viewed informational needs as very important in making treatment decisions. Confidence levels and satisfaction with the decisions made were reported as high and decisional conflict and regret were rated as low by the survivors. The regression model with the variables Widowed now, Confidence in Decision, Satisfaction with Decision, 
Decisional Conflict, and Decisional Regret significantly $(p=.01)$ accounted for $14 \%$ of the variance in informational needs. Two themes emerged from the study: Feelings, thoughts, and essential factors that impact treatment considerations and Tips for enhancing treatment consideration options. Important findings were the women's fear of dying and the need for hope.

This study has facilitated the understanding of how women make treatment decisions after being diagnosed with breast cancer. Implications for members of the treatment team are to provide the information with consideration of the patient's personal preferences that will assist women to make informed, confident, and satisfied decisions about treatment choices. 


\section{ACKNOWLEDGEMENTS}

I am so grateful for the expertise of all my dissertation committee members. This journey would not have been possible without the on-going advice, guidance, understanding, and patience of my co-chairs Dr. Marjorie Bott RN, PhD., and Dr. Leonie Pallikkathayil RN, PhD. Dr. Bott's knowledge of quantitative research and Dr. Pallikkathayil's wisdom and insight on the qualitative research process have been a valuable resource to me in the completion of this study. I am so thankful to have had the experience to work under these outstanding professors. I appreciate the advice and encouragement from Dr. Bonnel, Dr. Kimler, Dr. Klemp, and Dr. Teel.

I would like to acknowledge the assistance I received from Dr. Jennifer Klemp and Catie Knight at the University of Kansas Breast Cancer Survivorship Clinic. I appreciate all your help and persistence in recruitment of study participants. Also, Helen Schaag from the University of Kansas was instrumental in setting up the on-line surveys and keeping me updated and informed. The ease of the quantitative data collection would not have been possible without her hard work. I am so appreciative of all the breast cancer survivors who took time out of their busy lives to complete the on-line questionnaires and to those who were selected and participated in the focus group meetings.

Additionally, I am indebted to Dr. John Quinn MD, and all my co-workers at Quinn Plastic Surgery Center. Dr. Quinn's assistance in the recruitment process was a vital part in the completion of this study. Thanks to everyone at Quinn Plastic Surgery for your support and encouragement.

To my Mom and Dad, John and Arlene Bruner. Thank you so much for always believing in me. Both of you "knew I could do this" when I did not think it possible. You 
have been my biggest cheerleaders. Instilling the phrase "You never fail until you stop trying" in me has been a crucial component in all my life experiences and goals.

Lastly, my husband Leo and son Nicholas have been so understanding and caring throughout this entire educational undertaking. Without your support none of this could have been accomplished. I know that the time spent on this endeavor impacted both of your lives and I appreciate your tremendous encouragement and love. When I set out on this on-line educational adventure I had no idea how little I knew about computer skills and Nicholas I give you special thanks for all your help, time, and patience with technology support. 


\section{TABLE OF CONTENTS}

Acceptance Page

Abstract

Page

ii

Acknowledgments

iii

Table of Contents

V

List of Figures and Tables

ix

List of Appendices

Chapter One: Introduction

Study Purpose

Research Questions

Theoretical Framework

Theory Overview

Substruction

xi

xii

Definition of Terms

Summary

Chapter Two: Literature Review

Background

Decision Making

Assessing Informational Needs of Breast Cancer Patients

Decisional Conflict

Confidence and Decision Making

Decision Satisfaction

Decision Regret

Needs of Patients with Breast Cancer

Informational Needs

Physical Needs

Psychosocial Needs

Spiritual Needs

Impact of Technology

Research Gaps Identified

Understanding Decision Making.

Demographic Differences

Internet Use

Chapter Three: Methods $\quad 45$

Research Design $\quad 46$

Sample and Setting $\quad 47$

Measures $\quad 51$

Toronto Information Needs Questionnaire-Breast Cancer 51

Decisional Conflict Scale $\quad 54$

Confidence with Decision Scale $\quad 55$

Satisfaction with Decision Instrument $\quad 56$

Decision Regret Scale $\quad 56$

Data Collection Procedures $\quad 57$

Phase One Data Collection $\quad 58$ 
Phase Two Data Collection $\quad 59$

Data analysis Procedures $\quad 60$

$\begin{array}{lr}\text { Phase One Data Analysis } & 60\end{array}$

Phase Two Data Analysis $\quad 61$

Follow-Up Analysis $\quad 62$

Ethical Considerations $\quad 62$

$\begin{array}{ll}\text { Chapter Four: Results } & 64\end{array}$

Phase I Results $\quad 64$

Sample Characteristics $\quad 64$

Sample Descriptives $\quad 69$

Research Question One $\quad 69$

Research Question Two $\quad 71$

$\begin{array}{ll}\text { Research Question Three } & 72\end{array}$

$\begin{array}{ll}\text { Research Question Four } & 73\end{array}$

$\begin{array}{ll}\text { Research Question Five } & 74\end{array}$

$\begin{array}{lr}\text { Summary } & 78\end{array}$

Phase II Results $\quad 79$

$\begin{array}{ll}\text { Research Question Six } & 79\end{array}$

$\begin{array}{ll}\text { Sample } & 79\end{array}$

$\begin{array}{ll}\text { Study Themes } & 83\end{array}$

Follow-up Analysis $\quad 95$

Widowed Participants $\quad 95$

High versus Low Regret Individuals $\quad 97$

$\begin{array}{lr}\text { Satisfaction with Decision } & 98\end{array}$

Key theme Findings from Phase Two 100

$\begin{array}{ll}\text { Summary of Results } & 103\end{array}$

Chapter Five: Discussion $\quad 105$

Summary of Study Findings 105

Discussion 107

Theoretical Relevance 116

$\begin{array}{ll}\text { Clinical Implications } & 118\end{array}$

$\begin{array}{ll}\text { Strengths and Limitations } & 120\end{array}$

Recommendations for Future Research $\quad 122$

Conclusions 123

$\begin{array}{ll}\text { References } & 125\end{array}$

Appendices $\quad 134$ 


\section{FIGURES AND TABLES}

Chapter One

Figure 1. Substruction 12

Table 1. Questions to evaluate the process of effective decision-making

Chapter Three

Table 2. Operational Definitions of the TINQ-BC Subscales

Chapter Four

Table 3. Total Sample Demographics

Table 4. Description of Sample by Treatment Choices

Table 5. Descriptive Statistics for the TINQ, CDS, SWD, DCS and DRS

Table 6. Reliability Statistics for the TINQ subscales

Figure 2. Histogram of Confidence in Decision Scale

Table 7. Reliability Statistics for the Decisional Conflict Subscales

Table 8. Correlation Matrix

Table 9. Model Summary for the Regression Analysis

Table 10. Regression Coefficients

Table 11. Zero-order, Partial, and Part Correlations

Table 12. Demographic Characteristics of the Focus Group Participants

Table 13. Qualitative Findings: Themes and Categories

Table 14. Descriptive Statistics for the TINQ, CDS, SWD, DCS,

DRS, and Education, Tumor Stage, Time Since Diagnosis, Employment, and Support with Widowed Now and All Others 
For the High and Low Regret Individuals

Table 16. Descriptive Statistics for the TINQ, CDS, DCS, and the DRS With the High and Low Satisfaction Individuals

Table 17. Time Since Diagnosis in Relationship to Informational Needs $\left(\mathrm{TINQ}^{\mathrm{a}}\right)$

Table 18. Descriptive Statistics for the Disease Subscale and Concerns About Dying Item

Table 19. Descriptives of Support Subscale, Support Groups and Help with Feelings item for the Focus Group Sample and the Entire Sample

Table 20. Descriptives Statistics for Health Care Provider Support Items from TINQ ${ }^{\mathrm{a}}$; Who to Call with Questions, Who to Call After Treatment is Over, Who to Talk to About Specific Treatments with the Focus Group Sample Versus the Entire Sample 


\section{APPENDICES}

$\begin{array}{ll}\text { Appendix A Breast Cancer Websites } & 135\end{array}$

Appendix B Toronto Informational Needs Questionnaire-Breast Cancer 136

Appendix C Decisional Conflict Scale $\quad 141$

$\begin{array}{ll}\text { Appendix D Confidence with Decision } & 143\end{array}$

Appendix E Scale Satisfaction with Decision Instrument 144

Appendix F Decision Regret Scale $\quad 145$

Appendix G Letter to Breast Cancer Survivor 147

Appendix H Participant Information Form 149

Appendix I Participant Instruction Sheet 154

Appendix J Qualitative Interview Guide 155

Appendix K Focus Group Follow-up Email 157

$\begin{array}{ll}\text { Appendix L Coding Sheet } & 158\end{array}$ 


\section{CHAPTER ONE}

\section{INTRODUCTION}

Breast cancer is cited by the American Cancer Society as the most frequently diagnosed form of cancer in women. It is predicted that one in every eight females will develop breast cancer. Recent estimates indicate that in 2010 over 207,000 cases of breast cancer would be diagnosed in women in the United States. Approximately 1800 cases would be diagnosed in Kansas and 3900 in the state of Missouri. (American Cancer Society, 2009). The increase in the number of breast cancer diagnoses is primarily attributed to the ability to detect the disease in earlier stages by using improved diagnostic exams and procedures. Also, identifying women at high risk for the development of breast cancer through genetic testing such as BRCA1, BRCA2, (refer to Definition of Terms section for further explanation of these genetic mutations) and other risk factors have led to early diagnosis and treatment.

Based on the magnitude of the disease it is imperative that nurses are knowledgeable about risk factors, incidence, medical and surgical treatment options, as well as physical and psychosocial needs of breast cancer patients. Frequently, nurses are the health care team members who assume the role of educating patients on health care, disease prevention, and health promotion; nurses must be able to provide comprehensive care to women diagnosed with breast cancer.

Graydon et al. (1997) report that women diagnosed with breast cancer have an intense need for information regardless of the stage of their disease or where they are in the treatment process. Women routinely rely on health care providers to supply educational information about treatment options as well as give them psychosocial 
support. Holtzman and Timm (2005) conducted a study on women electing to have immediate breast reconstruction after the diagnosis of breast cancer and discovered that not all of the women's health care needs were being met. They found that nurses are prone to focus on physical needs of the patient and tend to neglect their emotional concerns. One of the primary roles of the nurse is to assist patients in expressing their needs, worries, desires, and preferences (Wujcik, 2008). Nurses must be able to recognize women's feelings of uncertainty about the disease process, prognosis, and treatment alternatives after the diagnosis of breast cancer. Some of the important concerns about breast health reported by women include: risk factors, available treatment options, ability to understand diagnostic tests, and health insurance coverage (Mangerich \& Stichler, 2008). Unclear information can result in poor decision making and dissatisfaction with treatment outcomes (LeBlanc, Kenny, O’Connor, \& Legate, 2009).

Jones and associates (2008) studied communication issues between healthcare providers and women diagnosed with breast cancer. The researchers found that little is known about informational continuity in this particular patient population. Informational continuity is defined by parameters of the patient's medical condition, circumstances of the illness, and preferences. Findings from the study indicated that informational continuity was affected by communication with and between healthcare providers and through shared decision making. Likewise, Sepucha, Belkora, Aviv, Mutchnick, and Esserman (2003) also studied information processing in women diagnosed with breast cancer. The researchers coined a term called "decision gap" in breast cancer patients. The author's state many decisions are made between the time of diagnosis and treatment that can substantially impact people's lives and numerous challenges can occur in the correct 
communication of information. Women often are overwhelmed by the vast amount of information introduced and available to them. Sepucha et al. also found that most women are unprepared and unsure of their role in making effective decisions before meeting with healthcare professionals. Educating patients prior to medical consultations is a potential way to foster patient participation and improve satisfaction in making informed health care decisions.

Information must be presented in an accurate, up to date, organized, and streamlined manner. Effectively communicating health care information to patients is an important initiative identified by our government to promote the health of United States citizens (Healthy People 2010). Initiative number eleven specifies the significance of communicating health care information to patients. Attributes listed as foundational for healthy communication encompass: accuracy and availability of information, a balance in presenting risks and benefits of treatment options, consistent information, assessment of cultural issues, using evidence-based practice, reachability, reliability, repetition of information, timeliness, and understandability of information to be communicated. Although health communication alone cannot amend all health care problems it does have the potential to help people understand their specific health-related issues along with available treatment options. The attributes cited by Healthy People 2010 are essential in providing women diagnosed with breast cancer up to date health care information and treatment options. This type of communication program can help in assessing and identifying patient needs, perceptions, and preferences and aid in effective decision making. 
Receiving a diagnosis of breast cancer and the number of treatment options available can be an extremely threatening and frightening event for most women (Galloway, Graydon et al. (1997). The disease jeopardizes physical and psychosocial well being in women (O’Brien, Whelan, Charles, Ellis, Gafni, Lovrics, Hasler, \& Dimitry, 2008). A patient's personal view strongly influences health care decision-making processes. Jones et al. (2007) found that the important themes in decision making include the patients actions, role of significant others, treatment decision choices, and communication with and between health care providers. Exploring a woman's existing ideas and mental images also may be helpful in improving communication and reducing misunderstanding about the diagnosis of breast cancer and treatment options (Harrow, Wells, Humphris, Taylor, \& Williams, 2008).

Depending on the type of breast cancer three surgical options are usually presented to the patient. The first option is a lumpectomy also known as breast conservation surgery (BCS). This surgery only involves the removal of the tumor and a small amount of surrounding breast tissue. The second option is the mastectomy surgery. One or both breasts may be removed during a mastectomy procedure depending on the patient's choice and stage of the tumor. Last, an option is to combine mastectomy with some type of breast reconstructive procedure. A mastectomy with reconstruction involves removal of all breast tissue unilaterally or bilaterally with the subsequent rebuilding of the breast mound (American Cancer Society, 2009). Throckmorton (2008) discovered that 43\% of women diagnosed with breast cancer were uncertain about surgical treatment options. However, Throckmorton reported that most women choose mastectomy or mastectomy with some sort of reconstructive procedure as opposed to breast conservation surgery. 
Zuckerman (2009) also posits current statistics reveal most women opt for breast reconstruction (84\%) compared to women choosing breast conservation $(16 \%)$. Other treatment options may include the need for chemotherapy, radiation, hormone treatment, or a combination of therapies.

Nurses ultimately must support the decisions women make about treatment options after their diagnosis in an effort to provide holistic care and nurture overall well being for patients and their significant others. Information on the disease process, diagnostic information, treatment choices, physical, and psychosocial needs have been identified as important aspects in providing comprehensive care (Redman, 2003). Lack of research in how women make decisions about breast cancer treatment options has been identified. The goals of this current study are to address these issues and help provide members of the treatment team with information to help breast cancer patients make satisfied treatment decisions.

\section{Study Purpose}

The purpose of this mixed methods study was to explore the decision making process of women diagnosed with breast cancer. The specific aims of this study were to: a) assess information needs women have after receiving the diagnosis of breast cancer; $b$ ) investigate how decisions about treatment options are made; and c) assess the personal responses to the decisions made.

The long term goals of the study were to advance the practice of nursing and nursing science by providing a better understanding of patients needs after a breast cancer diagnosis and to assist women in making informed health care decisions about available treatment options or alternative therapy. Additionally, there is a long term potential to 
decrease decisional conflict and regret and improve satisfaction with decisions made by women diagnosed with breast cancer and contribute to overall patient satisfaction, wellbeing, and adjustment post diagnosis.

\section{Research Questions}

The following questions were formulated to address the specific aims of the study:

1. What information about breast cancer, diagnostic tests, prognosis, treatment options, physical and psychosocial needs do women diagnosed with breast cancer report as being important in making informed decisions as measured by the Toronto Informational Needs Questionnaire-Breast Cancer (TINQ-BC) (Graydon et al., 1997)?

2. How confident are women about the decisions they made about breast cancer treatment as measured by the Confidence in Decision Scale (Estes \& Hosseini, 1988)?

3. How satisfied are women with the decisions they made about breast cancer treatment as measured by the Satisfaction with Decision Scale (Holmes-Rovner, Kroll, Schmitt, Rovner, Breer, Rothert, Padonu, \& Talarczyk, 1996)?

4. What is the degree of decisional conflict and regret if any that breast cancer survivors have about treatment choices made after being diagnosed with breast cancer as measured by the Decision Conflict Scale (O'Connor, 1993) and Decisional Regret Scale (DRS) (Brehaut, O’Connor, Wood, Hack, Siminoff, Gordon, Feldman-Stewart, 2003)? 
5. What is the relationship of demographic characteristics (marital status, educational level, and treatment choices), confidence in decisions, satisfaction with the decision, regret about the decision, and degree of decisional conflict to informational needs of 109 breast cancer survivors in making decisions about treatment options?

6. What considerations went into making decisions about treatment options after receiving a breast cancer diagnosis as shared by women in two focus groups?

\section{Theoretical Framework}

The theory of decisional conflict developed by Janis and Mann (1977) was used as a framework to guide the current study. Janis and Mann state decisional conflict occurs when there is uncertainty about a course of action. A state of uncertainty is exacerbated when making decisions involves unknown outcomes; are associated with a high degree of risks; when the ratio of benefits to loss must be assessed and evaluated; or remorse, guilt, or regret are possible consequences in making decisions involving tradeoffs. The theory can be applied to decisions related to things such as career choices, marital issues, healthrelated matters, community programs, large and small enterprises, government policies, or anything that involves multiple significant options. Signs of decisional conflict might encompass verbalization about choices, fear of the unknown or unwanted results, vacillation between treatment options, and delayed decision making that may cause moderate to severe stress. Uncertainty is increased when the person has a vague explanation about alternative treatments, lacks knowledge on the benefits and risks of the 
options, is unclear about personal values and feelings, lacks support in decision making, or is pressured to choose a course of action that is not personally understood or preferred.

\section{Theory Overview}

Decisional conflict theory originated from work by Janis and Mann (1977) and was based on previous research with people experiencing psychological stress. The authors define "stressful" events as any change that can induce a high degree of displeasing emotions (e.g. anxiety, guilt, or shame). Stressful situations can impact the person's usual patterns for information processing and decision making. The theory is founded on five basic assumptions. First, the degree of stress created by any conflict in decision making is a direct result of the potential ability to obtain certain goals set by the decision maker. The more unlikely the decision maker feels goals will be met and the more important the needs are to the decision maker the greater the likelihood for higher degrees of stress. Stress rises when the person feels there is a significant gain or loss that can occur based on certain decision alternatives. Second, new threats motivate people to consider a new plan of action. The amount of decisional stress experienced is a function of how much the person is committed to the current course of action. Third, decisional conflict can become severe when serious risks, hopelessness about the current situation, or the feeling that a better option is unavailable or unobtainable. The conflict can lead to defensive avoidance, which can be manifested by lack of a vigilant search, inattention, forgetfulness, selective attention to information, wishful thinking, or a distortion in the meaning of information. Things that cause a person to lose hope about a situation can occur when there is little or no information available or if important people in the persons most pertinent reference group feel that one of the choices is more preferable. Fourth, severe decisional conflict 
can materialize if the decision maker does not have enough time to find an acceptable or alternative course of action. Stress levels can become extremely elevated and a pattern of hypervigilance results. Hypervigilance can cause panic when there is a limited time to make decisions about imminent threats. Last, a moderate level of stress can actually be beneficial in assisting a decision maker to vigilantly search for different options or alternatives. This is based on the premise that the decision maker believes that it is possible to find a good solution to the problem.

Janis and Mann (1977) also present five coping patterns that are involved in the quality of decision making. Humans in response to threats or warnings that are felt to be harmful or dangerous can exhibit these coping patterns. The coping patterns include: a) unconflicted inertia, b) unconflicted change, c) defensive avoidance, d) hypervigilance, and e) vigilance. An explanation of the antecedent conditions, mediation processes, and consequences that make up the theory are described in further detail.

\section{Antecedent Conditions}

Communication variables are of utmost importance as antecedent conditions in the Janis and Mann (1977) model. Relevant sources for obtaining information can come from the media, private counselors, health care providers, family, friends, and significant others. The vast amount of decision making done by individuals is in response to the influences and encouragement or lack of reassurance that others place on the decision maker. Additional antecedent conditions may include unique personality variables or other pre-disposed characteristics of the individual. Previous exposure to similar situations that have resulted in negative consequences also can impact the way a person makes decisions. 
Specific antecedent conditions begin for the decision maker when an opportunity for challenging or negative feedback arises (e.g. breast cancer diagnosis). Further information needs to be obtained as to whether or not losses can occur if things continue to be the same or if changing the current path can increase the chance of loss with a negative occurrence. The decision maker also needs to be able to determine if more information is available or if there are untapped resources to gain other knowledge about the present situation. Finally, a decision maker needs to have the opportunity to gather information in a fashion that is not restricted by deadlines or time constraints.

\section{Mediating Processes}

The mediating factors incorporated in the model are actually a set of four questions that a decision maker must ask in order to choose options to respond to a situation or personal threat. First, the person must decide if the risks are serious if they do not choose a new course of action. Second, a person needs to ponder the impact of the risks if a change in current action is planned. Third, the decision maker needs to believe there is hope to find a better solution or more favorable options. Lastly, the decision maker needs to feel there is an adequate amount of time to search and contemplate different options or approaches.

\section{Consequences}

The concepts of unconflicted adherence, unconflicted change, defensive avoidance, hypervigilance, and vigilance are incorporated as consequences in the Janis and Mann (1977) theory of decisional conflict. Unconflicted adherence and unconflicted change can occur if the decision maker has a lack of interest in maintaining or changing the prevailing situation. Defensive avoidance may result if errors occur during the processing 
of new information and assimilation or when the disturbing news causes distortion in the individual's way of thinking or comprehending new knowledge. Cognitive abilities can become impaired when distressing information is given and can produce selective inattention or selective perception of emotionally disturbing issues. Hypervigilance may ensue when an individual cannot fulfill five of the necessary requirements to make effective decisions or if constant vacillation is present between different choices. The state of hypervigilance can involve a frantic search for new information or options and create a high level of anxiety and emotional arousal in which cognitive functioning is impaired and the chance of making effective decisions is highly compromised.

Vigilance is the preferred consequence for making informed and satisfied decisions. In this particular state the individual is sufficiently aroused to move forward, obtain information, and make effective decisions. The cognitive ability of the individual is at a level that is conducive for successful decision making and the likelihood for a satisfied and successful solution to the problem or threat is increased thus resulting in a decreased decisional conflict. Table 1 lists questions that may be helpful in evaluating vigilant decision-making processes. A substruction diagram is portrayed in Figure 1. Constructs and concepts associated with a breast cancer diagnosis are displayed. An operational system is presented to indicate how the variables of interest were measured. 
Figure 1. Substruction Diagram of Decisional Conflict

Potential Consequences of Decisional Conflict after a Breast Cancer Diagnosis Theoretical constructs:

Uncertainty in Decision Making $\rightarrow$ Decisional Conflict $\rightarrow$ Confidence with

Decision $\rightarrow$ Decision Satisfaction $\rightarrow$ Decision Regret

Concepts:

$\downarrow$

Needs of Breast Cancer Patients $\rightarrow$ Treatment Options $\rightarrow$ Decision Making Outcomes $\downarrow$
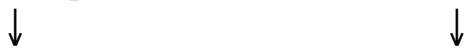

Disease, Tests, Treatment, Surgery, Radiation,

Physical \& Psychosocial needs

Chemotherapy, or

Combination of Options

$\downarrow$

$\downarrow$
Potential for Decisional Conflict, Confidence, Dissatisfaction with Decision, and Regret

Operational

Systems:

TINQ-BC \& Focus Group Findings

$\downarrow$

DCS, Confidence Scale, SWD, \& DRS, $\&$ Focus Group Findings 
Table 1

Possible Diagnostic Questions to Evaluate the Process of Effective Decision Making

1. Has the patient had time to thoroughly evaluate alternate plans of action?

2. Has the patient assessed the full range of options and implications of actions?

3. Has the patient weighed the benefit to risk ratio of alternate plans of action?

4. Has the patient thoroughly searched for new information concerning the alternative plans of action?

5. Has the patient correctly comprehended the new information even if it does not support her preferred plan of action?

6. Has the patient re-evaluated the positive and negative consequences of all plans of action before making a final decision?

7. Has the patient made preparations for implementing a new plan of action as well as formulate an alternative plan if new risks were to transpire?

Adapted from Janis and Mann (1977, p. 371).

\section{Definition of Terms}

The following section includes definitions that are essential in understanding the concepts under study for this particular study. Definitions are adapted from the Breast Cancer Dictionary (American Cancer Society, 2006) unless otherwise indicated.

Anti-hormonal therapy: A form of systemic therapy that often is used as an adjuvant therapy to help reduce the risk of cancer recurrence. It also is used to treat cancer that has returned after treatment or has spread. Tamoxifen and Aromatase inhibitors commonly are used as these anti-hormonal agents.

BRCA1: Breast cancer 1, is a mutated or damaged tumor suppressor gene that increases a woman's' risk for developing breast cancer. The presence of this gene results in a 50 percent increase in passing on the gene to offspring. 
BRCA2: Breast cancer 2, is a mutated or damaged tumor suppressor gene that results in a much higher risk for developing breast cancer.

Breast cancer: Cancer that originates in the breast tissue.

Breast cancer survivor: Patients who have been released from their medical oncologist. The medical oncologist has told these patients that they no longer need to be seen because they have completed treatment or do not need active monitoring. Survivors in the program are generally patients who are between two to five years post treatment. For the purpose of this study breast cancer survivors were defined as those women who were at least three months post completion of all treatment except long-term antihormonal therapy and less than five years post treatment completion.

Breast conservation surgery: Surgery involving removal of the breast cancer and a small amount of normal breast tissue without removing the entire breast. Lymph nodes may or may not be removed with this particular surgery. Radiation treatments are often administered with breast conservation surgery.

Breast reconstruction: Surgery performed to rebuild the breast after removal of one or both breasts. The patients own tissue may be used, a breast implant may be inserted, or a tissue expander might be used to expand the skin over a period of several months in preparation for permanent implant placement.

Confidence: The quality or state of being certain. This construct can be a function of training, education, and life experience (Estes \& Hosseini, 1988).

Cytotoxic: Poisonous to cells; cell killing. 
Decision making: The ability to use different strategies to choose or select from a variety of options involving different risks or expectations that are dependent upon the amount of gain or loss in the particular situation.

Decisional Regret: A negative, cognitively based emotion that may occur when perceiving that a situation would have a better outcome if a different action had been taken (Brehaut et al., 2003)

Ductal carcinoma in situ: A type of breast cancer that begins in the milk ducts but does not penetrate into the surrounding tissue. This type of cancer has a high cure rate and is usually treated with surgery and radiation.

Hormone replacement therapy (HRT): HRT is generally combined with estrogen and progestin and has been associated with an increased risk of developing breast cancer especially with long-term use. HRT differs from anti-hormonal therapy and is not being considered or evaluated in this study.

High-risk patient: Risk factors that are associated with the development of breast cancer include: family history, age, and age of menarche, menopausal status, hormone therapy, obesity, alcohol use, lack of physical activity, and dense or fibrocystic breasts.

Invasive ductal carcinoma: This cancer begins in the ducts and then invades the fatty tissue in the breast. The cancer has the ability to metastasize to other parts of the body. It is the most common type of breast cancer, responsible for about 80 percent of all breast carcinomas.

Invasive lobular carcinoma: This cancer starts in the milk producing glands or lobules and then breaks away and invades the fatty breast tissue. It can metastasize to 
other places in the body. Only ten percent of breast cancers are invasive lobular cancers. They are frequently hard to detect by a clinical breast examination or by mammography.

Lumpectomy: This surgical procedure removes the breast mass and a limited amount or surrounding tissue.

Mastectomy: The removal of all or a major portion of the breast tissue. Usually this includes taking away the areola and nipple complex.

Nipple reconstruction: Rebuilding of the nipple. Generally performed after the reconstructed breast has had time to heal. Tissue may be taken from another part of the body or from the new reconstructed breast tissue. Tattooing may also be performed to complete the procedure.

Satisfaction with decision: A choice made that is informed and consistent with the values of the decision maker (Holmes-Rovner et al., 1996).

\section{Summary}

As the number of breast cancer cases continues to increase in the United States it is necessary for nurses and other members of the treatment team to gain a better appreciation of the needs women have after receiving the diagnosis. Previous research indicates that women have high levels of educational, physical, and psychosocial needs after being diagnosed with breast cancer. Many times decisions concerning treatment options must be made in a short time frame and this may lead to later decisional regret and emotional distress. Therefore, it is important to assess how women make treatment decisions after being diagnosed with breast cancer. The aims of this proposed mixed methods study using five measures and two focus groups were: a) to assess information needs women have after receiving the diagnosis of breast cancer; b) to investigate how 
decisions about treatment options are made and; c) to assess the personal responses to the decisions made. 


\section{CHAPTER TWO}

\section{LITERATURE REVIEW}

The purpose of this chapter is to present an overview of breast cancer, to examine the literature related to how breast cancer patients make medical decisions concerning treatment choices, and to present the potential influences that affect and impact the quality and satisfaction of decision making. The chapter also includes a critical appraisal of issues related to decisional conflict, confidence in decision making, decision satisfaction, and decision regret. Additionally, the chapter discusses the need to educate patients as well as the treatment team in an effort to assist patients to make effective decisions regarding breast cancer treatment options. Research studies and what is known about the informational, physical, and psychosocial needs of breast cancer patients are described. The impact of technology for breast cancer education and support are reviewed. Recommendations for future research are discussed.

\section{Background}

Cancer of the breast is the most common occurring type of cancer diagnosed in women today. It also is the second most common cause of death from cancer in the female population. Although men can develop breast carcinoma it is very rare, accounting for less that one percent of breast cancer diagnoses. In 1960 about one in twenty women were diagnosed with the disease. Today approximately one in eight women have a lifetime risk of being diagnosed with breast cancer (American Cancer Society, 2009).

Cancer starts as a single abnormal cell and when the abnormal cell divides it eventually becomes a tumor. As a breast mass grows in size a blood supply develops that 
nurtures the tumor and aides in further growth (Cancer Guide, 2009). The Cancer Guide reports that $61 \%$ of breast cancers are discovered while the tumor is still contained in the breast, $31 \%$ are detected after the cancer has spread to the lymph nodes, and six percent are not diagnosed until the cancer has spread outside of the adjoining lymph nodes.

The number of women dying from breast cancer has been on the decline since 1990 . Presently, in the United States approximately two and a half million women have been diagnosed and treated for the disease. Early diagnosis of the disease has become possible through the use of expanded technology that includes early screening examinations such as mammography, ultrasound, magnetic resonance imaging, and genetic screening and testing procedures (U.S. Department of Health and Human Services, 2004).

Cancer of the breast is staged similar to other types of cancers. For the most part the prognosis of the cancer determined at the time of diagnosis dictates the various treatment options that are available to the patient. Surgery, radiation, chemotherapy, anti-hormonal therapy, or some combination approach may be recommended. After removal of the primary tumor the patient often has a choice of breast conservation surgery e.g. lumpectomy, or mastectomy alone, or mastectomy combined with reconstructive procedures (Cancer Guide, 2009).

After being diagnosed with breast cancer it is not uncommon that a woman is exposed to numerous doctors in a short time span to discuss the disease process, prognosis, and treatment options. Initially, the woman may receive the news of a breast cancer diagnosis from a radiologist or primary care provider. Second, the patient may be referred to a general breast surgeon for tumor or tumor and breast removal. Additionally, the patient may need appointments with a medical oncologist, radiation oncologist, or a plastic 
surgeon if reconstructive procedures are being contemplated. Naturally, all of the incoming information and assimilation of new knowledge can be overwhelming to the patient. As a woman attempts to deal with threats to physical and psychosocial well being, information processing is on overload (Spittler, 2008). The diagnosis of breast cancer can evoke concerns about death and dying as the patient is faced with possible alterations in relationships with others, financial concerns, and body image issues.

Losing any body part can be disturbing but when the part is associated with gender identification the results can be devastating. In our society breasts are linked to femininity and having one or both of the breasts removed can be traumatizing (Welch, 2008). Breasts are not merely a sign of gender but are associated with sexuality, motherhood, love, and nourishment (Lauersen \& Stukane, 1998). Other fears that might affect decision making about treatment options after the diagnosis of breast cancer include: concern of scarring, skin changes as a result of radiation therapy, hair loss from chemotherapy, and the possibility of significant weight loss or gain (Breastcancercare.org, 2008).

\section{Decision Making}

According to Horan (1977) a decision maker has to be able to canvass a wide path of alternatives for a particular course of action. The decision maker must be able to evaluate the values implicated by the decision and assess the benefits and risks associated with the choice. Furthermore, a decision maker needs to be capable of assimilating and judging the worth of the information and be able to discard information that is unsupportive of personal preferences. Finally, the process of decision making needs to include evaluation and reevaluation of positive and negative consequences. Alternate plans need to be formulated if new benefits or risks become apparent. 
Horan (1977) also explains the difference between what is referred to as "cold" and "hot" decisions. "Cold decisions" are made in a relaxed manner, or when a dispassionate state exists. These type of decisions are usually associated with low risks and generally do not evoke strong emotions. "Hot decisions" on the other hand occur in stressful situations when risks can be high and difficult to evaluate or involve ego issues. Horan gives an example for making a "hot decision" that could involve seeking a medical intervention for a serious illness; breast cancer certainly would fall into this category.

Decisions that are likely to trigger powerful emotions, motives, or confusion may contribute to making hasty or ill thought-out choices. It is essential that health care providers assist women in defining personal feelings and values and encourage patients to take time and explore options prior to making final treatment decisions (Reaby, 1998b). Patients who actively engage in decision-making processes fair better in the long run than those assuming passive roles (Reaby, 1998a). The Cancer Resource Guide (2009) recommends that before making medical decisions patients: (a) know their options, (b) find out as much as possible about each treatment option, (c) make sure resources are credible, (d) recognize what each decision means to them personally, and (e) make confident decisions after weighing the options. Other pertinent information patients may consider before making treatment decisions are to (a) understand what the goal is for their particular type of cancer, (b) understand the effectiveness of the treatment, and (c) find out if there are different options to achieve the same goal. Also, the patient needs to consider the potential risks, and learn how to prepare for treatment options, how long treatments last, and the effects on diet and activities of daily living. The patient also should be advised about time off work requirements, insurance coverage issues, 
opportunities for participation in clinical trials, and the possible need to obtain a second opinion.

Early research on decision making depicts the decision maker as absolutely rational in making treatment decisions after consideration of the benefits and consequences involved in each option. However, Hallenbeck (2002) noted that decision making is dependent upon much more than weighing facts, risks, and benefits. Hallenbeck described “explanatory narratives" using a qualitative approach to examine how women make medical decisions about hormone replacement therapy. The narratives discuss how patients primarily rely on past experiences, relationships with their physician and health care team, personal fears, and belief systems when making medical decisions. Hallenbeck describes that a "cultural divide" exists between practitioners and patients, and patients can experience intense personal conflict as they struggle with personal issues versus medical recommendations. Hallenbeck discusses the importance of being in sync with patients. Clinicians must recognize that the most difficult decisions in health care can be medically complex and "invested in the personhood" of the patient.

Sepucha, Belkora, Mutchnick, and Esserman (2002) discuss the importance of patient physician communication in helping patients making decisions about health care. According to Sepucha et al., past studies show that communication in medical consultations has been poor. Recent evidence reported by the American Society of Plastic Surgeons (2009) reveals many breast cancer patients are missing key conversations that should be occurring with their physicians. The society reports approximately $70 \%$ of women who are candidates for breast reconstructive surgery are not being informed of their options. 
As previously noted some women are not knowledgeable about asking the right questions and others are afraid of wasting the doctor's time with a plethora of questions. Findings from Sepucha et al. (2002) demonstrate $58 \%$ of women are unsure about what to ask, $53 \%$ did not choose the doctor but were referred, and $49 \%$ state they were on information overload at the time of consult. In an effort to reduce the aforementioned patient concerns, Sepucha and associates devised a consultation planning intervention to help prepare women diagnosed with breast cancer for a medical consultation. Preparing patients prior to arriving at a medical consultation may allow the patient to review information, formulate questions, and effectively communicate preferences with health care providers. Consequently, a consultation template was proposed by Sepucha, Belkora, Aviv, Mutchnick, and Esserman (2003). The template covers key points that need to be addressed during a medical consultation. The initial patient interview should include a discussion about process issues, diagnosis and prognosis, treatment options, treatment implications, patient values and preferences, and the next steps. Topic areas should address goals, timelines, tests, treatment options, hopes, fears, expectations, and how to make an informed decision. Examples of areas that facilitate the consultation are given to practitioners to provide them with the appropriate questions to ask as well as prompts to elicit valuable patient information that would promote a smooth, effective, and satisfied meeting with the health care professional.

Sepucha et al. (2003) also have developed consultation-recording templates. Use of the recording templates can provide both nurses and physicians with tools to document important information and findings during the consultation. The consultation-recording form can be shared with the patient so they do not feel pressured to remember everything 
that was discussed and in turn, they can share the form with family members, significant others, or other providers that the patient may consult with in the future. Documentation on the consultation form allows the patient to have a summary of the meeting and may help to avoid duplication of information being transmitted and received. Practitioners must be willing to listen to patient's needs and preferences and understand the patient's perspective when making certain decisions regarding the treatment choices. Until health care providers actively listen to patients concerns the possibility of misinterpretation, disconnection, mutual frustration, and poor health outcomes is likely to occur. However, review of the literature does not reveal any other studies that have used the consultationrecording planning or recording templates as described by the Sepucha research team.

Assessing Informational needs of Breast Cancer Patients

Graydon et al. (1997) were the first to use the Toronto Informational Needs Questionnaire-Breast Cancer (TINQ-BC) tool to assess information needs of women diagnosed with breast cancer. The study sample consisted of 70 women with breast cancer being treated with chemotherapy, radiation, surgery, or a combination of the therapies. Knowledge about the disease process, tests, and treatments were identified as the main area of informational needs. The women in the study named psychosocial concerns as the second area of concern. How to best meet the needs of women was not addressed in the study and Graydon et al. post this as a recommendation for future studies that include women diagnosed with breast cancer. Similarly, Harrison, Galloway, Graydon, Palmer-Wickham, and Rich-van der Bij (1999) used the TINQ-BC to evaluate informational needs in a sample of 125 women receiving radiation therapy as their treatment option after being diagnosed with breast cancer. The study revealed that 
women had high informational needs throughout therapy. Harrison et al. discussed the significance of giving accurate and relevant information to patients and highlight that presentation of information is a crucial part of the educational process and considered important to the patient. The researchers suggest that health care providers continually need to assess information needs of women throughout therapeutic treatments.

The TINQ-BC tool has also been used in other patient populations. Templeton and Coates (2001) adapted the TINQ-BC for subjects with prostate cancer. The purpose of the study was to test the $T I N Q-B C$ tool with a sample of 90 male subjects. The information needs for the men in the study was not reported. However, the researchers state that the preliminary data suggests an immense need for knowledge in all areas. Templeton and Coates propose an educational packet should be developed that is suitable to address the needs of patients and provide individual and holistic care.

\section{Decisional Conflict}

Stress and anxiety resulting from the diagnosis of breast cancer, and a patient's perceived urgency of the circumstances can lead some women to make decisions they later regret. As mentioned earlier, Janis and Mann (1977) state decisional conflict will inevitably result when a person has not had time to process information or there is a lack of available or preferred alternatives. Decisional conflict is defined as a state of uncertainty that occurs when making decisions involves unknown outcomes, are associated with a high degree of risks, when the ratio of benefits to loss is unclear and needs to be critically examined and assessed, or regret is a likely consequence of making decisions that involve tradeoffs. 
The nursing profession recognizes decisional conflict as a potential patient problem. Decisional conflict is an approved nursing diagnosis by NANDA (Kopala \& Burkhart, 2005). Kopala and Burkhart believe it is not uncommon that nurses consult with patients or "surrogate" decision makers such as family members. Frequently, the patient and significant others are struggling with issues related to making the best decision. Often patients ask what can be done to prevent, improve, or cure a medical problem. Likewise, patients may want advice on what should be done in their particular circumstances. Uncertainty can result from internal and external forces and influences. The patient or the designated decision maker is put in a position to obtain vital information and select the best treatment choice. Decision makers frequently need support, assistance, and reassurance from others and many times this is sought through members of the health care team (e.g., physicians, nurses, spiritual care providers, and social workers).

Waljee, Hu, Newman, and Alderman (2008) cite other important aspects in helping patients decrease dissatisfaction in the decision-making process after the diagnosis of breast cancer. Waljee et al. found women want to be included in the process of decision making, need to know their physician specializes in breast surgery, and have access to informational materials to make an informed decision.

LeBlanc, Kenny, O’Connor, and Legare (2009) note the process of decision making mostly has been studied at the individual level instead of at a dyad level. The researchers describe how interpersonal systems play an active role in making choices about treatment alternatives. Dyadic or shared decision relationships can be present between patients and their healthcare providers, their family members, or other individuals the patient identifies as influential in helping to make wise and satisfied decisions. LeBlanc et al. 
established the Actor-Partner Interdependence Model (APIM). The model helps to explain the interaction that occurs between two people and APIM has the potential to evaluate uncertain perspectives on either side of the dyad and aid in the understanding of the processes of decision making that can result from a clinical encounter. Either side of a dyad can undergo a feeling of lack of information, unclear values, inadequate support, or a sense of poor or ineffective decision making. The researchers aim is to shed light on the importance of shared decision making in health care matters. If only one side of the dyad is focused on the decision process then "collateral damage" is likely to occur with the other member in the dyad resulting in dissatisfaction in the relationship. Until there is an appreciation of the perspective of all parties at the table in any clinical meeting then dissatisfaction with decisions and poor health care outcomes likely are to occur. It is unclear if "dyadic" relationships are occurring in patients diagnosed with breast cancer. Although it would seem that shared decision making or a dyadic process is a reasonable approach, literature searches do not reveal studies to support this process with breast cancer patients.

Reaby (1998a) describes how the stress associated with the diagnosis of breast cancer and a perceived sense of urgency negatively can impact information seeking and produce decisional conflict. Women frequently leave the decision making to "experts" and this is thought to be influenced by emotions, subconscious issues, confusion, and a need for self-preservation. Reaby feels that women with breast cancer need to take time to thoroughly look at different options before making final decisions, and health care providers need to encourage this sort of behavior in patients. Reaby reports most women did not feel they had the time to explore alternatives before making decisions and too 
quickly they chose the first option thus, meeting only the minimum basic personal standards. Positive communication patterns and encouraging patients to seek additional information, or obtain a second opinion may be a possible solution to helping improve the overall long-term satisfaction with treatment decisions.

\section{Confidence and Decision Making}

A common definition of confidence is the state of being certain about one's own power or circumstances. Extremely low confidence levels related to decision making can be paralyzing and debilitating. Likewise, very high confidence levels may result in reckless behavior, excessive risk, or preventable loss (Estes \& Hosseini, 1988). According to Estes and Hosseini, confidence has been evaluated against the criterion of accuracy. Findings demonstrate that confidence is not always related to accuracy in decision making.

Estes and Hosseini (1988) developed the confidence rating scale for a study that they conducted on investment decision making. The researchers state that confidence is a construct that is impacted by the nature of the task, personal characteristics, knowledge of the domain, and information processing abilities of the individual. Findings of the study indicate women had significantly lower confidence levels in decision making. These findings may be significant when assessing confidence with decisions in women diagnosed with breast cancer. Literature searches revealed virtually no studies related to confidence in decision making about breast cancer treatment options as most studies focused on confidence in career planning and business decisions (Career Decisions, 2009). 


\section{Decision Satisfaction}

Past research on measures of patient satisfaction primarily has addressed satisfaction with the health care team, medical care, and outcomes but little is known about satisfaction with a health care decision (Holmes-Rovner et al., 1996). Today collaborative efforts between a patient and health care providers are expected and encouraged in the current medical arena. Often the patient and provider are involved in situations where there is no clear or perfect solution to a problem and more research is needed to account for the dynamics involved in making health care decisions. HolmesRover and associates developed the Satisfaction with Decision Scale to examine global satisfaction in decision-making. This particular tool was designed to differentiate personal satisfaction with a decision versus satisfaction with a health care provider or a desire to participate in the decision-making process. The researchers found the tool to be a valid and reliable instrument in measuring patient satisfaction related to medical decision making. Holmes-Rover encourage and support further research be directed at evaluating the process of patient decision making in order to enhance the delivery of health care and improve health care outcomes.

Wills and Holmes-Rovner (2003) also have used the Satisfaction with Decision Scale to measure satisfaction in primary care patients who were diagnosed with depression. Yet no other studies were found that had used the Satisfaction with Decision Scale. Limited information exists about how satisfaction has been measured with health care decisions made about breast cancer treatment options in women diagnosed with breast cancer. 


\section{Decision Regret}

Recent literature demonstrates as patients participate in making health care decisions a potential exists for the development of decision regret (Brehaut et al., 2003). Health care decisions that have a poor outcome often can lead to regret and regret can be a highly negative emotion. Brehaut and her team posit that little is known about the role that regret after decision making plays in subsequent behavior; this field of study is still in an infancy stage.

Brehaut et al. define decision regret as "remorse or distress over a decision" (p. 283). The researchers point out that there are certain types of health care decisions that have no clear or advantageous option. Many times individuals have to take into account their own personal "value-sensitive" or "preference-sensitive" choices when making decisions about medical treatment. The authors indicate regret can stem from two sources. The first is from the knowledge that a better outcome should have been selected. Second, a feeling of self-blame may ensue if a poor decision or outcome occurs.

Brehaut et al. (2003) list two possible implications of decision regret. One possibility is that future decision making may be affected by the experience of regret. The second possibility might occur if regret over medical decisions results in patient complaints or litigation. The researchers propose further study in this domain should take place to evaluate whether or not preparation for decision making with patients might decrease decision regret. Brehaut and associates have conducted most studies on decision regret in Canada. However, one study was completed in Ohio and Texas by the same researchers. The first study evaluated decision regret in a sample of women deciding whether or not to begin hormone replacement therapy. A second study examined breast cancer patients and 
their decisions about whether or not to proceed with some type of adjuvant therapy after surgical interventions. The third study assessed regret about surgical treatment options three years after a breast cancer diagnosis and the fourth study assessed decision regret in men considering options after the diagnosis of prostate cancer. Except for these aforementioned research studies there is a dearth of decision regret research in the literature on women diagnosed with breast cancer.

Only two recent studies were found that assessed decision regret in medical decision making. The first study evaluated decisional regret in women making a choice to proceed with prophylactic mastectomy. These women had been identified as positive for the BRCA1 or BRCA2 genetic markers but had not been diagnosed with breast cancer (van Dijk, van Roosmalen, Otten, \& Stalmeier, 2008). Furthermore, the study evaluated the use of decision aids and not the decision-making process in this sample of women. How treatment decisions were made was not studied in the women identified as carriers of the BRCA 1 and BRCA 2 mutated genes. The second study assessed decision regret in men diagnosed with metastatic prostate cancer (Clark, Wray, \& Ashton, 2001).

Needs of Patients with Breast Cancer

\section{Informational Needs}

Helping patients find and understand their medical team may be one of the first things to discuss with women recently diagnosed with breast cancer. Cancer Guide (2009) outlines a helpful list of the cancer specialists involved in the care of breast cancer patients. The role each specialist plays maybe beneficial in helping patients understand the multi-dimensional aspects involved in treating breast cancer. Graydon et al. (1997) studied informational needs of breast cancer patients and identified the highest area of 
needs revolved around the disease process, diagnostic tests, and treatments. Additionally, the need for information about the possibility of recurrence was extremely important to the women who participated in the study. Based on these results it is essential that nurses offer continued on-going educational support concerning the disease, how to prepare for investigative examinations, and what to anticipate before and after treatment procedures (Galloway, et al., 1997).

Physical Needs

Prior to treatment. Initially and prior to any decision, the patient's overall physical condition needs to be assessed. The patient's past medical history, family history, use of current medications, and social history needs to be reviewed to determine baseline information and aid in the patient's plan of care. Women need to know what medications and substances to avoid prior to surgical procedures. If surgical procedures are being considered thorough discussions about the risks, complications, and potential benefits need to occur with the patient and their significant others. An explanation of other treatment modalities (e.g. chemotherapy, radiation therapy, anti-hormonal therapy, or tissue expansion) needs to be described and explained to the patient and significant others when those types of procedures are being considered. Women also need to know how to prepare for procedures, what to expect after treatment procedures, and how to prevent, restore, and maintain body systems following a breast cancer diagnosis (Galloway et al., 1997).

After treatment. If surgery is the course of treatment patient education following surgery usually incorporates information on physical needs such as sleep, activity levels, pain control, and correct and compliant medication usage. Wound care, drain care, and 
correct documentation of drainage output need to be taught and demonstrated to the patient and caretaker. Post discharge instruction sheets are helpful for the patients and care takers to reference at home. If options such as chemotherapy, radiation, antihormonal therapy, or a combination of the two regimens are available patients need to know the potential risks, benefits, side effects, and frequency of administrations for the treatment protocols. Patients also need to know when to return to the clinic for post-op visits along with the signs and symptoms that are significant to report to members of the health care team.

\section{Psychosocial Needs}

The diagnosis of breast cancer and the possibility for removal of one or both breasts can have a traumatic affect on the psychosocial well being of a woman. Positive coping strategies have been associated with increased survival rates in breast cancer patients (Banning, 2007). Alteration in body image, pain, loss of work, and potential changes in social functioning are common fears in women after being diagnosed with breast cancer (Spittler, 2008). Women need to be aware of the feelings and social concerns that may arise as a result of the disease. Information on how to receive help or referral to support groups can be beneficial in assisting women to deal with feelings and concerns after a breast cancer diagnosis (Galloway et al., 1997). Positive and hopeful attitudes along with active coping styles have been linked to better psychological adaptation to breast cancer (Webb \& Koch, 1997).

However, an exploratory study conducted by Webb and Koch (1997) indicated that breast cancer patients did not recognize the role of the nurse in providing positive information and support. Without an understanding of the positive implications for the 
particular types of breast cancer diagnoses women can be left with a feeling of loss of hope surrounding the disease. Therefore, nurses and the treatment team need to design strategies to help clarify and interpret decision-making options and help diminish negative psychosocial consequences often associated with breast cancer.

Lindop and Cannon (2001) evaluated support needs of women with breast cancer and discovered categories of need included: (a) the effects of diagnosis, treatment, support, femininity, and body image and (b) relationships with family and friends. Women had a desire to share experiences with others in the same position, a need to maintain independence, expresses feelings, have a quiet refuge, and the need for reassurance. The acceptance of a changed appearance from a husband or partner also was viewed as vital in adjusting to the diagnosis. Additionally, having support from a partner, other family members, and friends was identified as helpful in alleviating some psychosocial problems. Age also may be a factor in how women cope with the diagnosis of breast cancer as younger women may face different concerns than older women. Concerns of younger women are raising children, loss of fertility due to premature menopause, loss of productivity, job security worries, concerns about sexuality, and an alteration in body image (Manuel, Burwell, Crawford, Lawrence, Farmer, Hege, Phillips, \& Avis, 2007).

Fitch, Gray, Godel, and Labrecque's (2008) work with breast cancer patients uncovered three themes present in young women after the diagnosis of breast cancer. The women under the age of 45 saw the diagnosis of cancer as something out of the anticipated order of life events (i.e., an older person's disease). The first theme women identified was a need to "act now"; this was seen as a need for self-preservation and survival. Second, women described a feeling that "everything is out of sync". Third, there 
was the sense that cancer had invaded their entire life; all their life roles such as being a mother, daughter, sibling, partner, or employee had been impacted. This further emphasizes the importance of health care workers examining all the unique role alterations women face following the diagnosis of breast cancer and underscores the essential need to provide holistic care to these patients.

\section{Spiritual Needs}

Spirituality issues in breast cancer patients needs to be assessed. Meraviglia (2006) explains that healthcare providers frequently overlook spirituality issues and described the significance of spirituality. Exploring the meaning and purpose of life, and if appropriate for the patient, the use of prayer could reduce the impact of a breast cancer diagnosis. Following the diagnosis of breast cancer patients may have concerns about death and dying; feelings of hopelessness or a loss of faith may occur (Spittler, 2008). Nurses and the treatment team may need to intervene when deficits in the spiritual dimension of the patient are discovered. Exploration of spiritual concerns by healthcare providers may be necessary prior to assisting patients with their spirituality needs. Some examples of helpful interventions could include encouraging the patient to contact their own clergy members, or possible referral of the patient to a hospital chaplain, faith-based therapist, or support groups familiar with addressing spiritual needs (National Cancer Institute, 2009).

\section{Impact of Technology}

Not long ago patients routinely assumed a passive role in health care practices. However, today patients are expressing a need to be involved and participate in making decisions about their health care. With advancements in technology that includes 
computers, patients now have the advantage of being able to retrieve information quickly, at their own pace, and in their own personal environment (Pellise \& Sell, 2009). Pellise and Sell claim obtaining medical information and advice on the Internet should not be a concern but healthcare providers need to be aware of and evaluate credible and valid websites that can assist the patient in getting additional information. A potential exists for seriously ill and vulnerable patients to be given false hopes and expectations by Web sites that might mislead or present unreliable and inaccurate claims. Even though ethical groups exist to monitor and evaluate web sites for being reputable and credible, the ability of patients to access this information is limited.

Shon and Musen (1999) established metadata criteria. The purpose of the criteria is to help patients locate quality links to credible web sites. The four criteria included authorship, references, disclosures, and currency. The researchers evaluated 97 breast cancer sites; unfortunately only one web page met all four criteria.

A recent survey found that over 60 million people in the United States search for health information online and the gap between age, income, race, and education is narrowing in regards to computer access and usage (Berland, Elliott, Morales, Algazy, Kravitz, Broder, Munoz, Puyol, Lara, Watkins, Yang, \& McGlynn, 2001). Berland et al. state that more than $70 \%$ of patients report that the health information they find online influences their decisions about treatment options. The researchers allege key information is poor and inconsistent in both English-and Spanish-based web sites. Berland and her colleagues also discovered that high reading levels are needed to understand health information published on many of the web sites. The researchers outline five recommendations to improve the dissemination of health information on Internet sites: 
(a) search efficiency methods need to be improved; (b) web site developers should provide more complete information; (c) health information needs to be accurate, up to date, and free from conflict; (d) a rating system should be developed and performed to confirm the credibility of the information; and (e) the information needs to be "readable" to accommodate those people with lower reading levels.

A further concern about Internet information is the rapid growth of information availability. It is estimated that the amount of information doubles every five months. The number of patients living with chronic illness, an increase in life expectancy, and patients requiring knowledge in learning how to perform at home self-care activities has had an enormous impact on the need for accessible, reliable, and accurate web sites. These facts underscore the need for regulation and frequent monitoring of Internet sites to ensure patients can easily perform online searches and acquire valid information in a timely manner (Cowan \& Hoskins, 2007).

Dolinsky, Wei, Hampshire, and Metz (2006) reveal breast cancer patients are frequent and active users of Internet services and use the web to gain health-related information about their illness. It is estimated that $43 \%$ of women diagnosed with breast cancer use the Internet to obtain information about the disease. However, the researchers state minority groups were less likely to have used or use the Internet to obtain cancer-related information.

Services need to be in place to teach patients and family members basic computer skills and guide them to reputable sites that provide access to needed information required to assist in making decisions on healthcare and treatment alternatives. Satterlund, McCaul, and Sandgren (2003) discuss the importance of the Internet in 
supplementing patients by providing knowledge and support after being diagnosed with breast cancer. The researchers state that it is incumbent upon providers of health care to be proficient with the use of the Internet and to be able to explore, teach, and facilitate an uncomplicated path for accessing quality information and resources.

Although most cancer patients report that they value their physician's opinion as the best source of obtaining information, many patients use the Internet to supplement knowledge about their disease and treatment options. Therefore, health care providers must be aware of the role that the Internet plays in patient education. It has been suggested that hospitals develop and endorse patient education web sites to supply people with credible information about disease processes and treatment options (van de PollFranse \& van Eenbergen, 2008).

Interactive Internet tools have been created to help cancer patient's monitor and report disease management. A website known as WebChoice was designed by Ruland, Jeneson, Andersen, Andersen, Slaughter, Osmo, and Moore (2007). The purpose of the site is to assist patients in monitoring their disease and reporting symptoms when necessary. The site also provides evidence-based practices for a variety of patient needs. WebChoice offers patients the ability to contact a clinical nurse specialist about health care advice. Additionally, a chat room is available and patients can share experiences with other cancer patients as well as offer support to one another. A specific module exists for breast cancer patients through WebChoice. Patients can use the module for assessment, self-management, information, communication, and personal journaling. WebChoice aims to empower patients in assuming an active role by gaining needed health information and encouraging shared decision making with healthcare providers. 
Previous studies have indicated psychosocial support has a positive impact on quality of life after a diagnosis of cancer. Owen, Klapow, Roth, Nabell, and Tucker (2004) designed a web-based psychosocial intervention to provide psychosocial support for women diagnosed with breast cancer. The researchers found Internet-based psychosocial support was equally or more apt to produce improvements in mental health opposed to traditional face-to-face encounters. Yi, Kim, Noh, Lee, Yoo, Hwang, and Chang (2008) discovered women diagnosed with breast cancer often feel neglected by the health care team after treatments were finished and the person transitions from cancer patient to cancer survivor. Yi et al. posit Internet sources such as blogs, online chat rooms and clubs, and community sponsored resources have been shown to decrease feelings of abandonment in breast cancer survivors. However, women in their 30s and 40s with higher education and income levels tend to be more likely to perceive these type of support services as beneficial in the survivorship stage of the disease.

Review of literature indicates women with breast cancer have elevated needs for a variety of information. Unfortunately, little confirmation can be found to exhibit if certain personality traits or characteristics are a factor in the way in which information is actively sought and obtained (Cowan \& Hoskins, 2007). Virtually nothing is known about how women are made aware of the psychosocial services that are available to them after the diagnosis of breast cancer (Owen, Klapow, Roth, Nabell, \& Tucker, 2004). Patients without emotional support have exhibited lower rates of survival compared to women reporting adequate levels of emotional support. Hospital surveys received from breast cancer patient's experiences frequently cite deficits in the ability of healthcare providers 
to provide and meet psychosocial needs post diagnosis (Personal communication, Cathy Glennon July 22, 2009).

There have been few research studies conducted with minority women or those from different ethnic and cultural groups examining how they acquire knowledge (Karliner, Napoles-Springer, Kerlikowske, Haas, Gregorich, \& Kaplan, 2006). A patient's geographical location may also be a factor in how information is gathered. Bettencourt, Schlegel, Talley, and Molix (2007) state little information is present on how women residing in rural areas with a diagnosis of breast cancer obtain sufficient information and support. Evaluation of web sites geared to supporting and enhancing racial, ethnic, cultural, or geographic diversity has the potential to improve overall well being in patients. It is necessary for nurses to be aware and knowledgeable about sites and resources that are relevant in providing support to minority groups (Fogel, Albert, Schnabel, Ditkoff, \& Neugut, 2003). Fogel et al. report racial differences may play a role in the long-term survival rates of breast cancer patients.

Using technologies such as interactive health communication tools to access and transmit health information have been shown to help meet psychosocial needs of cancer patients (Loiselle, \& Dubois, 2009). These services have the capability of offering patients and family members quick and complementary information, and support. The need for efficient and cost-effective health care support is critical in our current health care system. Loiselle and Dubois postulate as more patients are diagnosed with cancer the need for cancer-related information and support are expected to escalate. Studies have revealed that when psychosocial needs are not met, poor health outcomes, a decrease in quality of life, and increased health care costs are incurred. 


\section{Research Gaps Identified}

\section{Understanding Decision Making}

Many studies have been conducted with women that examine physical and psychosocial adaptation after the diagnosis of breast cancer (Bettencourt, Schlegel, Talley, \& Molix, 2007) and much research has been done to assess coping styles and quality of life issues in breast cancer survivors (Webb \& Koch, 1997). However, there is an inadequate understanding about how women make decisions about treatment options after being diagnosed with breast cancer (O’Brien, et al., 2008). O’Brien and her colleagues report emotional distress can inhibit women from being able to engage in effective treatment decision-making processes with healthcare providers, and women rely heavily on surgeons to make treatment decisions for them.

According to Balneaves and Long (1999) quantitative measures assessing treatment decision making are severely lacking in the literature and it is unclear if social implications impact how women with breast cancer balance physical, psychosocial, and social issues when making medical treatment decisions. Additional research using prospective studies needs to be performed to assess the quality of information given to breast cancer patients about treatment options, how the information is assimilated, and analyze the effectiveness of interventions healthcare providers use to help women in decision making (Reaby, 1998). Bravata, Rastegar, and Horwitz, (2002) describe the study of decision analysis and previous research in eliciting patient preferences; although this has contributed to what decisions are made it has not provided knowledge about how decisions are made. Webb and Koch (1997) posit information giving is surprisingly 
deficient to breast cancer patients and most women do not understand the positive implications of a diagnosis of non-invasive forms of breast cancer.

Further gaps identified in the literature address the potential for decisional conflict after making medical decisions. O'Connor, (1995) claims many health decisions are "value-laden" and can not be deemed right or wrong; measures are needed to assess uncertainty and confusion so that interventions can be developed to help people make effective decisions. With the exception of the Holmes-Rovner research group (1996) no studies were located that discussed decision regret in patients. Confidence levels by and large have been measured in terms of career choices, business, and investment decisions (Estes \& Hosseini, 1988). Holmes-Rovner et al. have pioneered work in the assessment of patient satisfaction in making medical decisions. However, they state more research needs to be conducted to explain the dynamics of health care decisions made by patients. Finally, Brehaut et al. (2003) holds the opinion that the measurement of regret has not been consistently measured in health care and the concept is often left undefined or only measured by a single question. The Brehaut team encourages the need for more studies on decisional regret to be performed with patients about medical decision making.

\section{Demographic Differences}

Limited information exists that captures how ethnicity and socioeconomic factors might affect patient satisfaction with decisions following breast-conserving surgery (Waljee, Hu, Newman, \& Alderman, 2008). Throckmorton and Esserman (2009) recommend the study of decision-making research across different ethnic and racial groups. Decisional aids, knowledge and value surveys should be assessed and decisional conflict needs to be measured. Women residing in rural areas are another population of 
breast cancer patients needing further study. Bettencourt and her associates (2007) discuss the need to assess women in rural settings. The breast cancer experience may be different for women in rural areas as opposed those residing in urban locations. Bettencourt et al. reference this statement about cancer patients living in rural areas: "Cancer is for rural people, a very lonely experience and as prevalent as the disease is, not many people can understand the emotional toll it takes (p. 875)." Collins, Moore, Clay, Kearing, O'Connor, Llewellyn-Thomas, Barth, and Sepucha (2009) suggest further research needs to be conducted with women in different locations of the country to assess if informed decisions are being made about choosing mastectomy in breast cancer patients.

Fitch, Gray, Godel, and Labrecque (2008) state only scant research exists that describes younger women's supportive care needs. The researchers advocate the need for studies to assess decision making about treatment options in younger women diagnosed with breast cancer. Fitch et al. claim healthcare providers frequently do not address specific informational needs that younger women have about sexuality, reproduction, and reconstruction issues after receiving a breast cancer diagnosis.

\section{Internet Use}

It is well recognized that the Internet has become an important source to acquire health information. However, more research is required to assess how patients use on-line information and to determine if this knowledge complements or complicates communication between patients and healthcare professionals (Berland, et al., 2001).

Fogel et al. (2002) state that no studies conducted then examined racial or ethnic differences and the role they play in how medical information is sought on the Internet. 
The researchers believe a clinical trial to evaluate Internet use would assist in better understanding how patients obtain and use medical information on breast health issues. Furthermore, studies to evaluate communication and outcomes using Internet support groups would be valuable to determine how this type of technology could improve services (e.g. psychosocial, individual counseling, and informational support) that assist patients to assume a more active role in their health care needs (Owen et al., 2004). Yi and associates (2008) recommend more research on whether women who use the Internet feel more satisfied and informed long term about decisions they have made. The authors foresee improvements could be made on websites by customizing breast information content by specific age group categories. Although Internet tools such as "Adjuvant" exist to help patients make effective decisions after the diagnosis of breast cancer it is in the best interest of healthcare providers and patients to search for even more effective tools to aid in treatment decision making (Ravdin, Siminoff, Davis, Mercer, Hewlett, Gerson, \& Parker, 2001). Finally, it is imperative that the treatment team explores websites to ensure patients are able to obtain quality information on the Internet (Satterlund, McCaul, \& Sandgren, 2003).

Exploration and further study needs to be undertaken in how breast cancer patients make treatment decisions. An example of recommended websites related to breast cancer is available through the University of Kansas Cancer Center library (Appendix A). The present study limited its focus to: a) assessing information needs women have after receiving the diagnosis of breast cancer; b) investigating how decisions about treatment options are made and, c) assessing the personal response to the decisions made. 


\section{CHAPTER THREE}

\section{METHODS}

In an effort to increase the understanding of women's needs after the diagnosis of breast cancer this study used a mixed methods approach to focus on the following research questions.

1. What information about breast cancer, diagnostic tests, treatment options, physical and psychosocial needs do breast cancer survivors report as being important in making informed decisions as measured by the Toronto Informational Needs Questionnaire-Breast Cancer (TINQ-BC) (Graydon et al., 1997)?

2. How confident are women about the decisions they made about breast cancer treatment as measured by the Confidence in Decision Scale (Estes \& Hosseini, 1988)?

3. How satisfied are women with the decisions they made about breast cancer treatment as measured by the Satisfaction with Decision Scale (Holmes-Rovner, Kroll, Schmitt, Rovner, Breer, Rothert, Padonu, \& Talarczyk, 1996)?

4. What is the degree of decision conflict and regret if any that women diagnosed with cancer have in making decisions about breast cancer treatment choices after being diagnosed with breast cancer as measured by the Decisional Conflict Scale (O'Connor, 1993) and the Decisional Regret Scale (DRS) (Brehaut, O'Connor, Wood, Hack, Siminoff, Gordon, Feldman-Stewart, 2003)?

5. What is the relationship of the demographic characteristics (marital status, educational level, and treatment choices), confidence in decisions, satisfaction with the decision, regret about the decision, and degree of decisional conflict to 
informational needs of 109 breast cancer survivors in making decisions about treatment options?

6. What considerations went into making decisions about treatment options after receiving a breast cancer diagnosis as shared in two focus groups?

The current chapter includes an overview of the research design, focus group methods, sample, sample size, setting, thorough review of the measures and measurement of variables, data collection procedures, data analysis plan, and ethical considerations.

\section{Research Design}

This study used a mixed methods design to collect, analyze, and merge quantitative and qualitative data. A concurrent, mixed methods, two-phased embedded design using quantitative and qualitative methods was conducted (Creswell \& Clark, 2007). First, quantitative data was obtained from five on-line surveys. Based on the quantitative survey scores a high regret and low regret sample was created. Second, eight women were selected from the high regret sample and eight were selected from the low regret sample. This approach was used to enhance the quantitative portion of the study with a supplemental source of data using qualitative findings from two focus groups.

Combining the quantitative and qualitative research methods has the potential to increase study validity by collaborating both types of findings, along with drawing on strengths and offsetting the weakness of either method. A mixed methods study can provide a more comprehensive accumulation of information and different questions can be posed to answer different study dimensions. Mixing the research methods has the capability of increasing the explanation of findings and unexpected findings may come forth or be brought to light using the combined approach (Connelly, 2009). The use of a 
mixed methods approach may yield new insights and better comprehension about the needs of women after being diagnosed with breast cancer (Driessnack, Sousa, \& Mendes, 2007).

The description of qualitative "explanatory narratives" (Hallenbeck, 2002) was used as a method to assess how women made medical decisions about treatment options. Additionally, the study examined if and how past experiences, relationships with the health care team, personal fears, body image concerns, sexuality, values, and beliefs impacted the medical decisions made.

\section{Setting and Sample}

\section{Phase One}

The sample for phase one of the study was comprised of women breast cancer survivors. A power analysis was conducted prior to data collection to determine appropriate sample size for the study. Greens' formula (1991) was used to perform the calculations: $\left(L=6.4+1.65 m-.05 m^{2}\right) . L=8.0+1.5+1.4+1.3+1.2+1.1+1.0+.09=$ 16.4. $L=6.4+1.65(8)-.05\left(8^{2}\right)=16.4$. Accordingly, a sample size of 109 participants was needed to perform multiple regression analysis procedures with the level of significance (alpha) set at .05, power at .80, a medium effect size, and eight predictor variables.

Participants were initially recruited from a Midwestern academic medical center breast cancer survivorship clinic. The Breast Cancer Survivorship Center is comprised of women breast cancer patients. Survivors in the program are generally patients who are between two to five years post treatment. 
However, due to low recruitment five additional sites were added after obtaining approval. The other sites to recruit participants from included a Midwestern Plastic surgery center, Komen Foundation, Young Survivors Coalition, Cancer Action, and MyPinkPlanner.com. The Plastic surgery center is a private practice setting located in the Midwest. The practice specializes in breast surgery and provides surgical options to women seeking breast reconstruction following the diagnosis of breast cancer. The Komen Foundation is dedicated to find a cure for breast cancer. Other goals of the foundation are to empower women and ensure quality of care to women dealing with a breast cancer diagnosis. Young Survivors Coalition is an organization dedicated to addressing issues related to young women diagnosed with breast cancer. The organization works with medical, research, and legislative bodies to improve the quality and quantity of life for young breast cancer survivors. Cancer Action is a community-based agency that provides cancer patients with hope, support, education, and empowerment. The organization addresses physical, emotional, social, spiritual, and financial needs of patients diagnosed with cancer. A local Kansas City woman diagnosed and treated with breast cancer created MyPinkPlanner.com. The purpose of the website is to help with planning needs and support to women diagnosed with breast cancer. On-line discussions include living with cancer and lists available resources and research opportunities. Ultimately, only participants from the Midwestern academic medical center and the Midwestern plastic surgery center were recruited for this study. A total of 111 participants were recruited from these two sites.

Criteria for inclusion into the study were women over the age of 18. Participants had to be breast cancer survivors. The participants had to be able to read, write, and speak 
English, be able to give informed consent, have access to a computer, and be able to perform simple computer functions to complete five questionnaires. Participants were excluded if they had not completed all forms of treatment for at least three months and less than five years except long-term anti-hormonal therapy. These treatments included surgery, chemotherapy, radiation, any type of cytotoxic therapy, and reconstructive procedures. Additionally, phase one participants were asked if they were willing to participate into a focus group session if they were selected for phase two of qualitative data collection.

Data were first examined to look for missing data and outliers. Two cases were eliminated because the response of "currently being treated for cancer" was answered as "yes" and these cases were not eligible for study participation. Seven other cases were deleted due to an extreme amount of missing data. The final sample for the study was 102.

The intended sample participants were expected to be reflective of the local population demographics in this Midwestern metropolitan area. There are eight counties that make-up this Midwestern region. The median household income is $\$ 46,000,35 \%$ of the individuals have an educational level of an associates degree or higher. Caucasians make up the majority (75\%) of the population with $13 \%$ of the population being African America, seven percent Hispanic, and two percent Asian (Metro Outlook Live, 2009).

Participants in this study were recruited from the local eight Midwestern counties that make-up this region. The women were mainly Caucasian (97\%) and three per cent of the participants in the study were African-American. No other ethnic groups made up this 
study. Approximately, 52\% of the sample had an education level of an Associates degree or higher. Income levels were not obtained from the participants in this study.

\section{Phase Two}

Two focus group sessions were conducted to obtain data for phase two of the study. Guidelines outlined by Patton (2002) were used to prepare for and conduct the focus group meetings. Advantages for using focus group interviews include: a) the collection of data is usually cost-effective; b) information can be gathered in a short span of time from more than one person at a time; c) participants can perform a system of checks and balances among each other during the interaction period, which can weed out extreme views; and d) shared and diverse views can be quickly identified (Patton, 2002). Furthermore, focus groups have the potential to elicit participants' attitudes, feelings, experiences, and reactions in a manner that may not be achievable in other methods such as individual interviews or questionnaire type surveys. A multitude of views and emotional processes may be more easily recognized in the social context setting (Gibbs, 1997). The goal of the focus groups is to encourage self-disclosure among the participants. Focus groups often take on a life of their own as participants add to each others comments and thoughts, thus it may produce a richness to the discussion that may have not been realized in a one-to- one interview (Rennekamp \& Nall, 2009).

For phase two of the study the focus group participants were purposively sampled from the sample that was used to collect quantitative data in phase one of the study. Eight participants were selected from the upper one-third of responders indicating they had experienced high degrees of decisional conflict, dissatisfaction with decision and decision regret. Likewise, eight responders were selected from the lower one-third of participants 
that indicated they had experienced low levels of decisional conflict, dissatisfaction with the decision made and regret over the decision made. Potential focus group participants were notified by phone or e-mail for the request to attend one of the two focus group sessions. A balance of individuals reporting high and low levels of regret participated in each of the two separate sessions.

\section{Measures}

The Theory of Decisional Conflict (Janis \& Mann, 1977) was used as the theoretical framework to guide the selection of variables of interest in exploring how women make treatment decisions after receiving a breast cancer diagnosis. The measures in the study were used to assess the baseline knowledge of informational needs, the degree of conflict experienced in making decisions about treatment choices, the confidence about the decisions made, the degree of satisfaction with the decision, and the possibility of decision regret that these women potentially experienced in making treatment decisions.

\section{Toronto Information Needs Questionnaire-Breast Cancer}

The Toronto Information Needs Questionnaire-Breast Cancer (TINQ-BC) (Appendix B) was used to evaluate the informational needs of patients newly diagnosed with breast cancer (Galloway et al., 1977). Galloway et al. developed the tool to assess the specific needs of women with breast cancer. The researchers discovered that a lack of evidence exists about recently diagnosed breast cancer patients' needs, and women are often unsure what questions to ask thus many issues go unanswered. The $T I N Q-B C$ is a selfadministered questionnaire constructed to obtain women's perceptions of informational needs linked with the breast cancer experiences. Galloway et al. state the tool takes approximately twenty minutes to complete. The $T I N Q-B C$ is composed of five subscales: 
disease, investigative tests, treatment options, physical, and psychosocial needs. Table 2 displays the operational definitions of the subscales.

Each item on the questionnaire begins with the stem: "To help me with my illness it is important for me to know." Participants were asked to rate the importance of each item on a Likert-type scale with one = "not important", two, = "slightly important", three = "moderately important", four = "very important", and five = "extremely important". The total scale score ranges from 51-255. Higher scores represent greater informational needs. Individual subscale values also can be calculated. The 52 items of the $T I N Q-B C$ have item-total correlations of zero to .25 or higher. Intercorrelations of the five subscales are reported to range from $r=0.38-0.73$. Internal consistency reliability using Cronbach's alpha test for all of the subscales had values greater than .80 and the Cronbach's alpha for the total score was .96 . Content validity has been established with 11 oncology nurse experts and 34 women with and without a diagnosis of breast cancer. Evidence of construct validity was reported based on compatibility with the theoretical model and the scale.

Table 2 Operational Definitions of the TINQ-BC Subscales

\begin{tabular}{|l|l|}
\hline Subscale & Definition \\
\hline Disease & $\begin{array}{l}\text { Knowledge of the disease process of breast cancer } \\
\text { prognosis }\end{array}$ \\
\hline Investigative Tests & $\begin{array}{l}\text { Procedures used to assess the type and extent of } \\
\text { disease process, how and why tests are performed } \\
\text { and side effects that may be experienced }\end{array}$ \\
\hline Treatment Options & $\begin{array}{l}\text { Breast Conservation Surgery, Mastectomy, } \\
\text { Mastectomy with Reconstruction, Chemotherapy, } \\
\text { Radiation therapy, Anti-Hormone Therapy or a } \\
\text { combination of therapies }\end{array}$ \\
\hline
\end{tabular}




\begin{tabular}{|l|l|}
\hline Subscale & Definition \\
\hline Physical Needs & $\begin{array}{l}\text { Knowledge needed to prevent physical problems, } \\
\text { restore body systems, and maintain body care and } \\
\text { functioning. }\end{array}$ \\
\hline Psychosocial Needs & $\begin{array}{l}\text { Body image concerns, relationships with others, } \\
\text { emotional concerns, spirituality issues, financial } \\
\text { worries, and fears of death and dying. }\end{array}$ \\
\hline
\end{tabular}

\section{Decisional Conflict Scale}

O'Connor (1993) created the Decisional Conflict Scale (DCS) (Appendix C). The scale is based upon the theory of decisional conflict developed by Janis and Mann (1977). The objective of the decisional conflict scale is to measure the degree of decisional conflict people experience when faced with different options. Decisional conflict is operationally defined as a state of uncertainty in which lack of information or knowledge, unclear personal values, and lack of support may lead to ineffective or dissatisfied decision making resulting in potential emotional distress and possible negative health outcomes. O'Connor postulates that decisional conflict can be reduced if people are knowledgeable about the options, risks, benefits, and side effects. Furthermore, O'Connor feels it is crucial to review value clarity with patients before decisions are made. Value clarity assessments must be analyzed (e.g., how important does the patient view the physical, social, and emotional ramifications of the decision). O'Connor also emphasizes the importance of shared decision making to decrease decisional conflict about treatment options. Shared and effective decision making is more likely to result in long-term patient satisfaction (Redman, 2003). 
The Decisional Conflict Scale takes five to ten minutes to administer. Sixteen items are included in the total scale with five subscales. The five subscales are: informed, value clarity, support, uncertainty, and effective decision making. Participants were asked to rate items on the Likert scale from zero (strongly agree) to four (strongly disagree): five negatively implied statements are reversed scored. Higher scores are indicative of higher degrees of decisional conflict. A total score was calculated by summing all the items, dividing by sixteen, and multiplying by twenty-five. Scores can range from zero to one hundred. A low score represents no decisional conflict whereas a score of one hundred demonstrates a high degree of decisional conflict. O'Connor explains that scores lower than 25 are associated with the ability to make and implement decisions whereas scores above 37.5 are linked to delayed decision making and uncertainty about making effective decisions.

Subscales (i.e., informed, value clarity, support, and uncertainty) are scored by summing the items, dividing by three and multiplying by twenty-five. The scores for the previous subscales range from zero to hundred. However, the effective decision making subscale is calculated in different fashion. This subscale is summed, divided by four, and multiplied by twenty-five. Scores for the effective decision making subscale also range from zero to one hundred.

Cronbach's alpha coefficients are reported as 0.78 or greater for all subscales and the total score. Test-retest values were $r=.81$. Construct validity has been conducted and the subscales and total score were correlated to constructs related to knowledge, regret, and discontinuance. Known group differences also were used to establish construct validity and the tool discriminates between people who make and people who delay decision 
making. Effect size range between 0.4 and 0.8 . O'Connor presents additional information on the tools responsiveness to change before and after studies on decision-making interventions. She reports values between 0.4 to 1.2 for the entire scale and reports the informed subscale consistently discriminates with effect sizes that range from 0.3 to 0.4 . Moreover, O'Connor describes data related to predictive validity of the tool and states "that for every unit increase in the scale a patient was 59 times more likely to change their mind, 23 times more likely to delay their decision, five times more likely to experience regret, and three times more likely to fail a knowledge test on options" (p. 6). O'Connor recommends researchers base sample sizes on detecting effect sizes between 0.30 and 0.40 .

\section{Confidence in Decision Scale}

The Confidence in Decision Scale (Appendix D) was developed by Estes and Hosseini (1988). The scale consists of one item and takes less than one minute to complete. Participants were asked to rate their confidence in the decision they have made. The response ranges from one to ten with one indicating "no confidence at all" to ten representing "complete confidence". No information is available on the psychometric properties of the one-item scale (Holmes-Rovner et al., 1996). However, psychometric properties of single-item indicators have been reported in the literature to be valid and reliable measures (Youngblut and Casper 1993).

\section{Satisfaction with Decision Instrument}

The Satisfaction with Decision (SWD) Instrument (Appendix E) is designed to measure satisfaction with a health care decision and is not dependent on the health care outcome or prognosis (Holmes-Rovner, 1996). The Likert scale is made up of six items 
with response options that range from one (strongly disagree) to five (strongly agree). It can be completed in less than one minute. Holmes-Rover and her colleagues report the scale is short, easy to use, and is based on an eighth-grade reading level. The scale was used in a study of 252 women considering decisions about menopause and hormone replacement therapy. Cronbach's alpha was reported as 0.86 . The Satisfaction with Decision scale is moderately correlated with the Decisional Conflict Scale $(r=-0.54)$, and positively correlated with the Confidence in Decision Scale $(r=0.64)$.

The Satisfaction with Decision (SWD) scale was used in an independent study conducted by O'Connor (1994). The study assessed decisions elderly patients made about influenza vaccinations. Reliability of the $S W D$ scale in the O'Connor study revealed an alpha coefficient of 0.85 , and the scale was found to discriminate between patients who were sure about what they would do as opposed to those who were less sure about what to do.

\section{Decision Regret Scale}

The Decision Regret Scale (Appendix F) is a measure to assess distress or remorse after making a health care decision (Brehaut, et al., 2003). The Likert scale ranges from one (strongly agree) to five (strongly disagree). Two items are reverse scored.

O'Connor (2003) recommends that the scores from the scale be converted so that others more familiar with scales ranging from zero to 100 can more easily can interpret the findings. Subtracting one from each item and then multiplying by 25 transforms the scores. The items are summed and averaged. Psychometric properties resulted in Cronbach's alpha coefficient ranging from 0.81 to 0.92 . She reported that the total scale is correlated with Satisfaction with Decision Scale, Decisional Conflict Scale, and with 
ratings of overall quality of life. She reports group differences $\left(F_{(2,190)}=31.1 ; p<.001\right)$ on feelings about the decision made and noted the groups also differed on rated regret. Additionally, O’Connor posits regret was statistically higher $\left(T_{(175)}=16.11, p<.001\right)$ among people who changed their decision versus those who did not. The Decision Regret Scale has been used with cancer patients, menopausal women contemplating hormone replacement therapy, and women considering osteoporosis therapy.

Twenty-two demographic variables were collected. See (Appendix H) for an explanation of the demographic variables that were analyzed.

\section{Data Collection Procedures}

For phase one, data collection began by establishing contact with breast cancer patients involved in the survivorship program through the director of the program at the Midwestern academic medical center Breast Center. A flyer was provided in person to eligible breast cancer survivors by healthcare providers in the Cancer Center's breast oncology and surgery clinics and the Breast Cancer Survivorship Center, inviting them to participate in the study (Appendix G). Potential participants from a Midwestern Plastic surgery center were presented a flyer in person during clinic hours, by mail, or e-mail by primary researcher in this study.

Breast cancer survivors willing to participate were directed to the investigator's e-mail address. Once it was determined that the participant met the inclusion criteria they were assigned an identification number and were directed to a link where they accessed all the necessary forms, directions, and tools needed to complete the quantitative phase of the study. This link was set up through the academic medical center's "Vovici" system. 
Vovici is a widely used source of web-based research surveys. The data were secured on a password-protected server where the data were backed up daily. The researcher had entree through one person at the Midwestern academic medical center that had access to the surveys and the data. The information was confidential and not shared with anyone other than the researcher (Personal communication, Helen Schaag, November 19, 2009).

For the purpose of determining study eligibility, forced entry fields were used to obtain necessary information from participants. This information included name, e-mail address, or phone number(s), and time since diagnosis; the purpose of the information was to determine study eligibility and later to contact potential participants for participation in the focus group meetings. As part of the consenting process, study volunteers were informed and indicated if they agreed to take part in a focus group session after the quantitative data had been collected and analyzed. Identification numbers were stored in a locked drawer, accessible only to the primary investigator and were destroyed after the study was complete.

\section{Phase one data collection}

First, quantitative data was collected from study participants. The participants were asked to fill out a Participant Information Form (Appendix H) and an instruction sheet was provided for directions on completing the surveys (Appendix I). The participants were requested to complete the Toronto Informational Needs Questionnaire-Breast Cancer, Decisional Conflict Scale, Confidence with Decision Scale, Satisfaction with Decision, and Decision Regret survey tools using the Vovici web-based survey tool. 
Phase two data collection

For phase two, two separate focus group meetings were conducted. Focus group participants $(n=16)$ were purposively selected from the 102 subjects who participated in phase one of the study. Participants for Phase two of the study were selected based on scores from the Satisfaction with Decision Scale, Decisional Conflict Scale, and the Decision Regret Scale. Scale scores from the upper one-third and the lower one-third of the instruments measuring dissatisfaction with decision, degree of decisional conflict and decision regret instruments were analyzed. The low regret individuals were composed of those participants who scored greater than 4.8 on the Satisfaction with Decision Scale, less than ten on the Decisional Conflict Scale, and less than six on the Decision Regret Scale. The high regret individuals were made up of those participants who score less than four on the Satisfaction with Decision Scale, greater than 26 on the Decisional Conflict Scale, and greater than nine on the Decision Regret Scale. A semi-structured interview guide was used to guide the discussion (Appendix J).

The qualitative focus groups lasted approximately 90 minutes. The focus group meetings were held at a Midwestern Plastic surgery center. Participants were informed by email the location of the focus group. Both focus groups were taped recorded and transcribed. Focus groups started with introductions, an overview of the purpose of the session, and review of HIPPA privacy regulations. Participants were instructed not to share any information they felt uncomfortable talking about. The women in this study were eager to participate and tell their story.

The primary researcher led the group meeting beginning with a Grand Tour Question: "Tell me about the first things or questions that came to your mind after the diagnosis of 
breast cancer and the treatment options presented to you." Further questions and probes were used to elicit responses from participants about how they made treatment decisions and what influences impacted the decisions made. Open-ended questions were used to draw out responses and provide a mechanism for rich, thick descriptions of the phenomenon under study. With Human Subjects Approval, a follow-up e-mail was sent to the focus group participants to gain further data, expand on the data, and information about the specifics about treatment considerations (Appendix K).

Data Analysis Procedures

Phase one data analysis

Analysis of data proceeded in several phases. Initially, descriptive statistics were computed to assess sample demographics. The presence of missing data and outliers were examined, and it was determined that multiple imputation procedures were not required to replace missing data. Multiple regression procedures were used to determine what or if any of the demographic variables predicted the degree of decisional conflict, confidence, satisfaction, or regret experienced after receiving a breast cancer diagnosis. The quantitative statistics were generated using SPSS 16.0 for Windows (SPSS, 2007).

\section{Research Questions 1 through 4}

The first four research questions were to evaluate the informational needs of breast cancer patients, assess the degree of decisional conflict that the patient may be experienced, examine confidence in the decision made, satisfaction with decision made, and the possibility of decision regret. Descriptive statistics were used to analyze the first four research questions. 


\section{Research Question 5}

For the fifth research question multiple regression procedures were used to analyze the relationship of the demographic characteristics, confidence, satisfaction, and regret about decisions, and degree of decisional conflict to informational needs in making decisions about treatment options in 102 breast cancer survivors.

\section{Phase two data analysis}

Focus group procedures were used to collect information that addressed the sixth research question, "What considerations went into making decisions about treatment options after receiving a breast cancer diagnosis as shared by women in two focus groups? Qualitative content analysis was used to answer this question. A qualitative descriptive methodology is a suitable approach when exploring the meaning of concepts from people actually experiencing the phenomenon. Descriptive methodology allows for events, feelings, or ideas to be described in everyday terms and can be employed when straightforward accounts of a phenomenon are desired (Sandelowski, 2000). A qualitative descriptive approach is less interpretative than other methods of qualitative research and is a way to accurately depict events that most individuals would agree upon if experiencing the same situation. The six steps outlined by Elo and Kyngas (2008) were used for the content data analysis. The procedures started with data preparation, followed by open coding, development of a coding sheet, grouping, forming of categories, and ended with an abstraction process for both the focus group transcripts and the follow-up e-mails. Manifest and latent content, unit analysis, meaning unit, condensation, abstraction, content area, coding, and the creation of categories and themes are all possible dimensions for analysis (Lincoln \& Guba, 1985). The descriptive approach was 
felt to be a relevant fit in answering the sixth research question by exploring the descriptions of how women considered treatment options after being diagnosed with breast cancer. The categories and themes discovered from phase two of the study were used to examine and compare with the quantitative data findings. The qualitative data findings also, were used to support and interpret the data collected in phase one of the study.

\section{Follow-up Analysis}

Additional analyses were conducted to examine and compare the findings from Phase one and Phase two of the study. Descriptive statistics were used to evaluate the instrument scale scores, education level, tumor stage, time since diagnosis, employment status, and support between women who are currently widowed and the rest of the sample. Descriptive statistics also were conducted to examine instrument scales scores between the high and low regret individuals and the high and low satisfaction individuals. Last, descriptive statistics were analyzed between the focus group participants and the total sample on the disease subscale and concerns about dying item, support subscale and help with feelings item, and the support from health care providers items.

\section{Ethical Considerations}

Approval for the study was obtained from the Protocol Review and Monitoring Committee and human subjects approval for the study was obtained from the University of Kansas Medical Center Human Subjects Committee. Potential risks for this study included emotional distress associated with remembering the initial breast cancer diagnosis experience or re-evaluating the possible negative consequences of medical decisions made in the past. The women were informed that referral to the Director of the 
Breast Cancer Survivorship Program would be initiated if this type of situation became apparent or was encountered. However, this situation did not occur.

Confidentiality of the data was preserved by removal of any type of identifying factors such as name, addresses, or birthdates. Qualitative data such as notes and audiotapes were maintained and securely stored by the primary investigator of the study. Tapes were destroyed at the end of the study. 


\section{CHAPTER FOUR}

\section{RESULTS}

The purpose of this mixed methods study was to explore how women made treatment decisions after being diagnosed with breast cancer. Chapter four presents the results of the study. The chapter is organized by presentation of the sample demographics, the findings for each research question for Phase I of the study, the presentation of Phase II findings that includes a discussion on the coding, creation of categories, the development of study themes, and further exploration of topics revealed of findings from Phases I and II of the study. All findings are summarized at the end of the chapter.

\section{Phase I Results}

The following research questions were explored for the quantitative study: a) what information about breast cancer, diagnostic tests, treatment options, physical, and psychosocial needs do breast cancer survivors report as being important in making informed decisions; b) how confident are women about the decisions that have been made about breast cancer treatment choices; c) how satisfied are women with the decisions they made about breast cancer treatment options; d) what is the degree of decisional conflict and regret if any do women diagnosed with breast cancer have in making decisions about breast cancer treatment choices?

\section{Sample Characteristics}

The final sample size for this study was 102. Sample demographics are provided in Table 3. The participants in the study were primarily Caucasian females (97\%), most were married at the time of being given a breast cancer diagnosis, and the majority of the women (75\%) still currently were married at the time of survey completion. About seven 
percent of the women reported they currently were widowed as compared to being married at the time of diagnosis. Having a bachelor's degree was the most frequently cited (28\%) level of education. Over half of the women indicated they were employed full-time. A large portion (77\%) of the women indicated that they live in a suburban area while less than ten percent live in a rural setting.

At the time of diagnosis women in this sample reported being predominately premenopausal (64\%) whereas at the time of the study most $(84 \%)$ reported being postmenopausal. This is not surprising since many of the treatments induce menopause.

Because of a computer input error the variable of age was not measured in this study. A proxy variable for age was created to estimate age by menstrual status at time of diagnosis. Of those reporting, $64 \%$ of the total sample $(n=65)$ was pre-menopausal and $36 \%(n=36)$ were post-menopausal at the time of diagnosis indicating the women in the total sample were more likely diagnosed at a younger age. More than half the women (53\%) were given a tumor stage of I or II at the time of diagnosis. Thirteen women were unsure of their tumor stage when their breast cancer was diagnosed.

Table 3

Total Sample Demographics

\begin{tabular}{lcr}
\hline & Frequency & Percent \\
\hline Race & 99 & \\
$\quad$ Caucasian & $\frac{3}{102}$ & 97.1 \\
African-American & & 2.9 \\
& & \\
Marital Status at Diagnosis & 5 & \\
Single & 82 & 4.9 \\
Married & 4 & 80.4 \\
Widowed & $\underline{10}$ & 3.9 \\
Divorced & $101^{*}$ & 9.8
\end{tabular}


Table 3 (Continued)

Total Sample Demographics

\begin{tabular}{|c|c|c|}
\hline & Frequency & Percent \\
\hline \multicolumn{3}{|l|}{ Current Marital Status } \\
\hline Single & 6 & 6.1 \\
\hline Married & 74 & 74.7 \\
\hline Widowed & 7 & 7.1 \\
\hline \multirow[t]{2}{*}{ Divorced } & 12 & 12.1 \\
\hline & $99 *$ & \\
\hline \multicolumn{3}{|l|}{ Education } \\
\hline High School & 15 & 14.7 \\
\hline Associates & 10 & 9.8 \\
\hline Some College & 25 & 24.5 \\
\hline Bachelors & 28 & 27.5 \\
\hline Some Graduate & 9 & 8.8 \\
\hline Masters & 12 & 11.8 \\
\hline \multirow[t]{2}{*}{ Higher than Masters } & 3 & 2.9 \\
\hline & 102 & \\
\hline \multicolumn{3}{|l|}{ Employment } \\
\hline Unemployed & 10 & 9.8 \\
\hline Part-Time & 25 & 24.5 \\
\hline Full-Time & 54 & 52.9 \\
\hline \multirow[t]{2}{*}{ Retired } & $\underline{11}$ & 10.8 \\
\hline & $100 *$ & \\
\hline \multicolumn{3}{|l|}{ Living Location } \\
\hline Urban & 12 & 11.8 \\
\hline Suburban & 78 & 76.5 \\
\hline \multirow[t]{2}{*}{ Rural } & 10 & 9.8 \\
\hline & $100^{*}$ & \\
\hline \multicolumn{3}{|c|}{ Menstrual Status At Diagnosis } \\
\hline Pre-Menopausal & 65 & 63.7 \\
\hline \multirow[t]{2}{*}{ Post-Menopausal } & $\underline{36}$ & 35.3 \\
\hline & $101 *$ & \\
\hline \multicolumn{3}{|l|}{ Current Menstrual Status } \\
\hline Pre-Menopausal & 15 & 14.7 \\
\hline \multirow[t]{2}{*}{ Post-Menopausal } & $\underline{86}$ & 84.3 \\
\hline & $\overline{101} *$ & \\
\hline
\end{tabular}


Table 3 (Continued)

Total Sample Demographics

\begin{tabular}{|c|c|c|}
\hline & Frequency & Percent \\
\hline \multicolumn{3}{|c|}{ First Degree Relative with Cancer } \\
\hline Yes & 30 & 29.4 \\
\hline \multirow[t]{2}{*}{ No } & 71 & 69.6 \\
\hline & $101 *$ & \\
\hline \multicolumn{3}{|c|}{ Tumor Stage at Diagnosis } \\
\hline 0 & 20 & 19.6 \\
\hline I & 28 & 27.5 \\
\hline II & 26 & 25.5 \\
\hline III & 14 & 13.7 \\
\hline IV & 1 & 1.0 \\
\hline \multirow[t]{2}{*}{ Unknown } & $\underline{13}$ & 12.7 \\
\hline & $1 \overline{02}$ & \\
\hline \multicolumn{3}{|c|}{ Time Since Diagnosis } \\
\hline 6-12 months & 4 & 3.9 \\
\hline $1-2$ years & 35 & 34.3 \\
\hline $3-5$ years & 40 & 39.2 \\
\hline \multirow[t]{2}{*}{ Over 5 years } & $\underline{23}$ & 22.5 \\
\hline & 102 & \\
\hline \multicolumn{3}{|l|}{ Widowed Now } \\
\hline All others & 92 & 91.0 \\
\hline \multirow[t]{2}{*}{ Widowed } & $\underline{7}$ & 6.9 \\
\hline & $99 *$ & \\
\hline
\end{tabular}

*Numbers do not total to 102 due to missing data

The majority of the sample had a mastectomy (86\%) after being diagnosed with breast cancer and most women chose some type of reconstructive surgery (75\%). Forty-two percent of the women had received radiation treatments, $62 \%$ had been given chemotherapy and $41 \%$ of the women had been placed on some form of anti-hormonal therapy. See Table 4 for the reported treatment choices. 
Table 4

Description of Sample by Treatment Choices

\begin{tabular}{lcc}
\hline & Frequency & Percent \\
\hline Reconstruction & 76 & 74.5 \\
$\quad$ Tissue Expanders & 54 & 52.9 \\
$\quad$ TRAM Flap & 3 & 2.9 \\
$\quad$ Latissimus Dorsi & 1 & 1.0 \\
Lumpectomy & 33 & 32.4 \\
Mastectomy & 88 & 86.3 \\
Preventative Mastectomy & 25 & 24.5 \\
Radiation & 43 & 42.2 \\
Chemotherapy & 63 & 61.8 \\
Anti-Hormonal Therapy & 42 & 41.2 \\
\hline
\end{tabular}

Of the 76 women who chose reconstruction $71 \%$ used the process of tissue expansion. Nineteen of the 33 women (58\%) that initially had a lumpectomy later had a mastectomy. Of the total sample $79 \%$ of the participants reported having a combination of chemotherapy and radiation treatments, $56 \%$ reported receiving both radiation and antihormonal therapy, and $41 \%$ had a combination of chemotherapy and anti-hormonal therapy.

In examining tumor stage at time of diagnosis with treatment options (reconstruction, lumpectomy, mastectomy, radiation, and anti-hormonal therapy), there were no significant $(p>.05)$ Chi-square differences. However, a higher proportion of the sample that reported a Stage II or III tumor stage at the time of diagnosis received chemotherapy more often than would be expected by chance $\left(\chi^{2}=46.82 ; p<.001\right)$. 
Sample Descriptives

Data were collected from five questionnaires: the Toronto Information Needs Questionnaire for Breast Cancer Patients (TINQ), Confidence in Decision Scale (CDS), Satisfaction with Decision (SWD), Decisional Conflict Scale (DCS), and the Decision Regret Scale (DRS). Descriptive statistics for each of the scales are shown in Table 5 along with the coefficient alphas for each of the scales.

Table 5

Descriptive Statistics for the Toronto Information Needs Questionnaire, Confidence in Decision Scale, Satisfaction with Decision Scale, Decisional Conflict Scale, and Decision Regret Scales.

\begin{tabular}{|c|c|c|c|c|c|}
\hline Scales & Mean & $S D$ & Range & $N$ & Cronbach's $\alpha$ \\
\hline Total TINQ ${ }^{\mathrm{a}}$ & 207.7 & 33.44 & $90-260$ & 102 & 0.97 \\
\hline $\mathrm{CDS}^{\mathrm{b}}$ & 9.0 & 1.30 & 4-10 & 101 & NA \\
\hline Total SWD ${ }^{\mathrm{c}}$ & 4.2 & 1.12 & $1-5$ & 102 & 0.98 \\
\hline Total DCS ${ }^{\mathrm{d}}$ & 20.1 & 16.11 & $0-75$ & 102 & 0.932 \\
\hline Total DRS ${ }^{\mathrm{e}}$ & 7.8 & 3.69 & $5-25$ & 100 & 0.884 \\
\hline
\end{tabular}

Key: ${ }^{a}$ TINQ-Toronto Information Needs Questionnaire ${ }^{b}$ CDS-Confidence in Decision Scale ${ }^{\mathrm{c}}$ SWD-Satisfaction with Decision Scale ${ }^{\mathrm{d}}$ DCS-Decisional Conflict Scale ${ }^{\mathrm{e}}$ DRSDecision Regret Scale

Research Question One

The first research question was what information about breast cancer, diagnostic tests, treatment options, physical, and psychosocial needs do breast cancer survivors report as being important in making informed decisions? From the descriptive statistics results 
indicate the women state information about breast cancer, disease process, prognosis, and treatment options are "very important" in making informed decisions (on average they scored 208 on a scale that ranged from 90-260).

Additionally, there were five subscales that were scored from the Toronto Information Needs Questionnaire. The descriptive statistics along with the reliabilities generated from the five TINQ subscales are shown in Table 6.

Table 6

Reliability Statistics of the TINQ Subscales

\begin{tabular}{lcccc}
\hline Subscales & Mean & Range & Number of Items & Cronbach's $\alpha$ \\
\hline Disease $^{\mathrm{a}}$ & 38.33 & $16-45$ & 9 & 0.835 \\
Tests $^{\mathrm{b}}$ & 29.65 & $12-40$ & 8 & 0.82 \\
Treatments $^{\mathrm{c}}$ & 67.95 & $35-80$ & 16 & 0.921 \\
Physical $^{\mathrm{d}}$ & 41.31 & $15-55$ & 11 & 0.888 \\
Psychosocial $^{\mathrm{e}}$ & 26.73 & $11-35$ & 8 & 0.832 \\
\hline Key: $^{\mathrm{a} D i s e a s e-I n f}$
\end{tabular}

Key: ${ }^{a}$ Disease-Information needed to know about the disease process ${ }^{b}$ Tests-Information needed to know about Investigative Tests ${ }^{\mathrm{c}}$ Treatments-Information needed to know about how to prepare for exams, and expected side-effects ${ }^{\mathrm{d}}$ Physical-Information needed to know about restoring health, body care, and function ${ }^{\mathrm{e}}$ Psychosocial-Information needed to know about body image, emotional, financial, and mortality concerns

Findings from the Toronto Information Needs Questionnaire revealed the women in this study felt that obtaining information about a breast cancer diagnosis in regards to the disease process, tests, treatments, physical, and psychosocial needs were key factors in considering options and making treatment decisions. 
The need to know about the disease and its process was rated as "very important" $(M=38$ on a scale of $16-45)$ in making an informed decision. The women rated knowledge that they needed to know about investigative tests (i.e., types of procedures, how and why treatments are performed) were "moderately to very important" $(M=30$ on a scale from 12 to 40) in making decisions. Knowing about treatment procedures (i.e., knowing why procedures are performed, potential side effects, and complications) was rated as "very important" ( $M=68$ on a scale from 35 to 80$)$. Likewise, knowing how to prevent physical problems (i.e., restoring health, maintaining body care, and function) was "very important" ( $M=42$ on a scale from 15 to 55). Psychosocial needs such as body image concerns, emotional issues, financial worries, and fear of dying were listed as "moderately important" ( $M=27$ on a scale of 11 to 35$)$ in making an informed decision after being diagnosed with breast cancer (See Table 5).

\section{Research Question Two}

Research question two was to determine how confident the women were about the treatment choices they had made. The mean confidence level rated by the participants in the study was nine on a range from one to ten indicating that the women in this sample had a high degree of confidence in the decisions they had made. The histogram (Figure 2) depicts the distribution of scores. 
Figure 2. Histogram of Confidence in Decision Scale (CDS)

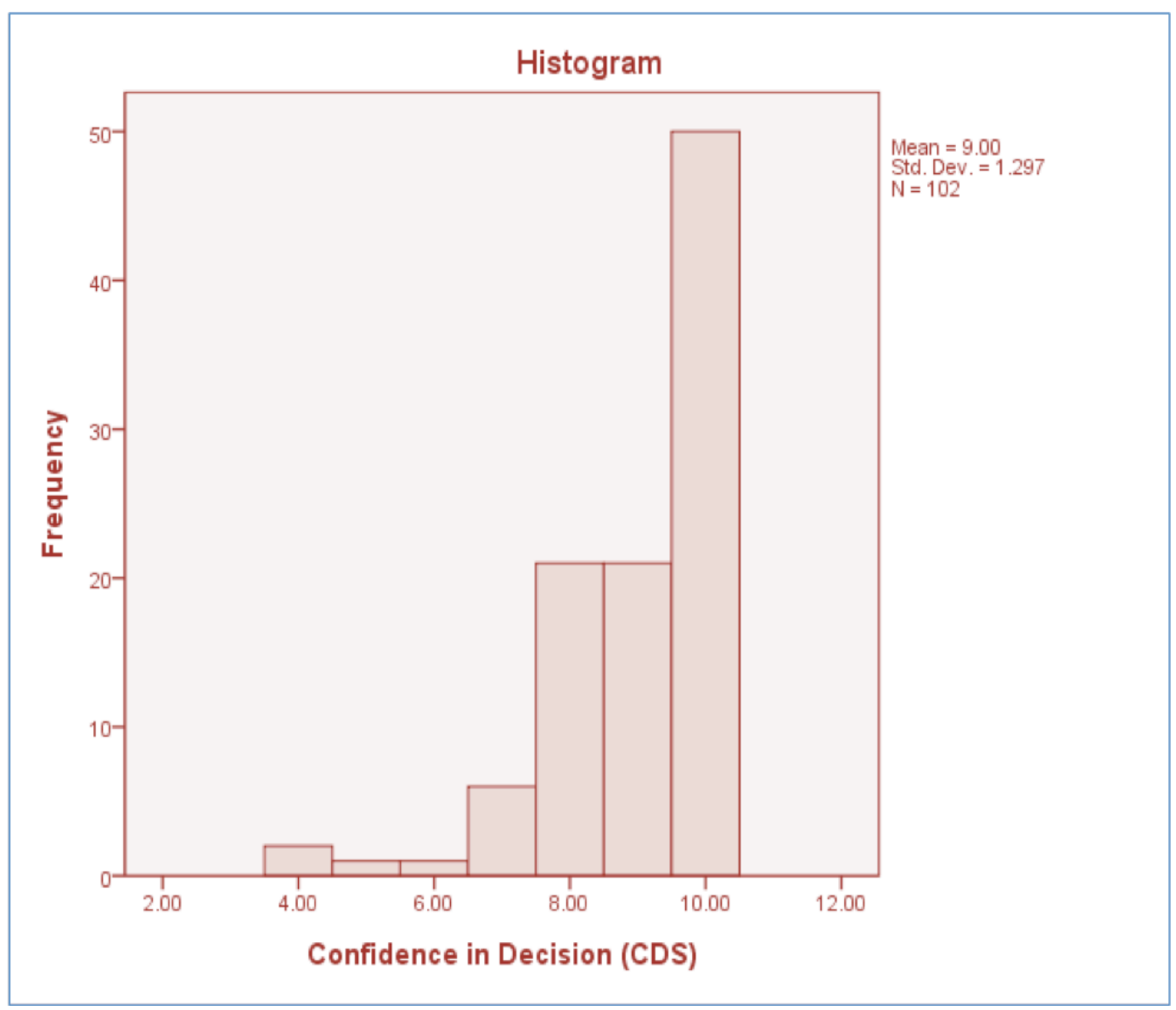

Research Question Three

Research question three was to assess how satisfied the women were with the decisions they made about breast cancer treatment choices. The Satisfaction with Decision scale was used to assess the degree of satisfaction about the decisions that had been made by the study participants. Participants agreed that they were satisfied with the decisions they made ( $M=4.2$ on a scale of 1 to 5$)$. Additionally, $31 \%$ of the women were "totally satisfied" with the health care decisions they had made while only $7.8 \%$ were "totally dissatisfied" with their decisions. 


\section{Research Question Four}

Research question four was to measure the degree of decisional conflict and decision regret if any that women diagnosed with cancer had in making decisions about breast cancer treatment options. The degree of decisional conflict that was reported by women in this study was low ( $M=20$ on a scale of 0 to 75 ; a high score represented high decision conflict). Only one percent of the study sample reported high decision conflict, and 16\% reported no decisional conflict. Likewise, the degree of decision regret that was reported was very low ( $M=7.8$ on a scale of 5 to 25 ; a high score represented high decision regret). The majority of the women reported low decision regret (79\%) and of these $44 \%$ had no decision regret.

Additionally, there were five subscales that were scored from the Decisional Conflict Scale. The descriptive statistics along with the reliability statistics generated from the five Decisional Conflict subscales are shown in Table 7.

The majority of the women agreed that being informed (88\%), having support (78\%), and being clear about personal values (82\%) contributed to decreasing decisional conflict. Forty-six percent of the women rated their feelings as uncertain about the decisions they made ( $M=3.95$ on a scale of 0 to 12 with a high score representing higher decisional conflict). Most women (65\%) agreed that they had made an effective decision $(M=1.86$ on a scale of 0 to 9 ). 
Table 7

Reliability Statistics for the Decisional Conflict Subscales.

\begin{tabular}{|c|c|c|c|c|}
\hline Subscales & Mean & Range & Number of Items & Cronbach's $\alpha$ \\
\hline Informed $^{\mathrm{a}}$ & 2.39 & $0-11$ & 3 & 0.925 \\
\hline Values $^{\mathrm{b}}$ & 2.5 & $0-9$ & 3 & 0.886 \\
\hline Support $^{\mathrm{c}}$ & 2.12 & $0-9$ & 3 & 0.796 \\
\hline Uncertainty $^{\mathrm{d}}$ & 3.95 & $0-12$ & 3 & 0.844 \\
\hline Effective $^{\mathrm{e}}$ & 1.86 & $0-9$ & 4 & 0.890 \\
\hline
\end{tabular}

Key: ${ }^{a}$ Informed-Feeling that all options have been presented and explained ${ }^{b}$ ValuesBeing clear about what options are important to individual preferences and beliefs ${ }^{\mathrm{c}}$ Support-Having adequate support from family, friends, and significant others ${ }^{\mathrm{d}}$ Uncertainty-Feeling unsure about decisions that have been made ${ }^{\mathrm{e}}$ Effective-Feeling certain that an effective decision had been made based on individual preferences

\section{Research Question Five}

The fifth research question was to examine the relationship of the demographic characteristics (marital status, educational level, and treatment choices), confidence in decisions, satisfaction with the decision, degree of decisional conflict, and regret about the decision to informational needs of the study participants in making decisions about treatment options. Multiple regression procedures were used to answer this question.

Prior to the generation of the multiple regression analysis, one-way analysis of variance (ANOVA) and t-test statistics were conducted with the demographic variables race, marital status, education, employment, menstrual status at the time of diagnosis, living location, months since breast cancer diagnosis, first degree relative with breast cancer, and tumor stage at time of diagnosis to eliminate categorical variables from the regression procedures that did not show any significant relationships with the dependent 
variable, informational needs (TINQ). There were no significant differences $(p>.05)$ on informational needs among the categories of race, marital status at time of diagnosis, months since diagnosis, tumor stage at time of diagnosis, and first-degree relative with breast cancer. Consequently, these variables were eliminated as independent variables in the multiple regression procedures.

ANOVA procedures revealed the following differences for the variables of current marital status. For current marital status, the widowed group $(M=170 ; n=7)$ was significantly different $\left(F_{(3,95)}=3.28, p=.02\right)$ from the other groups ( $\operatorname{single} M=207 ; n=6$; married; $M=211 ; n=74$; and divorced; $M=208 ; n=12$ ). A dichotomous variable was created that was defined as widowed now (1) and all other marital status categories (0) that was used in the multiple regression procedures.

Tests for the assumptions for multiple regression analysis interpretation normality, linearity, independence, non-multicollinerarity, and homoscdedasticity of the data were conducted through SPSS. Results of the analysis indicated that the assumptions for multiple regression had been met.

Table 8 shows the Pearson correlations for the variables Satisfaction with Decision, and Decision Regret Scales, Decisional Conflict, Confidence in the Decision, and Widowed now with the Toronto Information Needs Questionnaire total score. Confidence level was positively correlated $(r=.19)$ with making a satisfied decision and negatively correlated with decision regret and decisional conflict ( $r=.41$ and $r=-.59$ respectively). Decisional regret was positively correlated $(r=.50)$ with decisional conflict. 
Table 8

Correlation Matrix

\begin{tabular}{|c|c|c|c|c|c|}
\hline & Total TINQ & Total SWD & Total DRS & Total DCS & $C D S$ \\
\hline Total TINQ $^{\mathrm{a}}$ & -- & & & & \\
\hline Total SWD ${ }^{\mathrm{b}}$ & -0.21 & -- & & & \\
\hline Total DRS & 0.12 & -0.15 & -- & & \\
\hline Total DCS ${ }^{\mathrm{d}}$ & 0.15 & -0.12 & 0.50 & -- & \\
\hline $\mathrm{CDS}^{\mathrm{e}}$ & -0.03 & 0.19 & -0.41 & -0.59 & -- \\
\hline Widowed & -0.30 & 0.14 & -0.03 & -0.13 & -0.06 \\
\hline $\begin{array}{l}\text { Key: }{ }^{\text {a}} \text { Total T } \\
\text { Satisfaction } \\
\text { Total Decisio } \\
\text { widowed }\end{array}$ & $\begin{array}{l}\text {-Total Torc } \\
\text { Decision Sc } \\
\text { Conflict Sca }\end{array}$ & $\begin{array}{l}\text { Information } \\
\text { cTotal DRS- } \\
\text { CDS-Confic }\end{array}$ & $\begin{array}{l}\text { Is Question } \\
\text { Decision I } \\
\text { in Decisio }\end{array}$ & $\begin{array}{l}\text { re, }{ }^{b} \text { Total SV } \\
\text { et Scale }{ }^{d} \mathrm{Tc} \\
\text { cale }{ }^{\mathrm{f}} \text { Widowe }\end{array}$ & $\begin{array}{l}\text {-Total } \\
\text { I DCS- } \\
\text { currently }\end{array}$ \\
\hline
\end{tabular}

Regression analysis procedures were completed with the five independent variables entered in a block. With all the variables in the model (Widowed now, and the scale scores of Confidence in Decision, Satisfaction with Decision, Decisional Conflict, and Decisional Regret), they accounted for approximately $14 \%$ of the variance in the informational needs (TINQ) of the participants. These findings were significant,

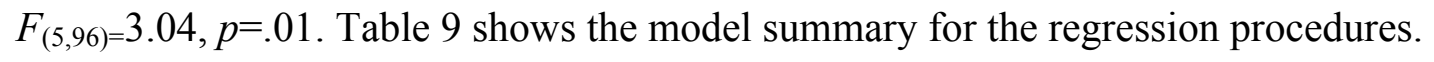

Table 9

Model summary statistics for the regression analysis

\begin{tabular}{lcccc}
\hline & $R$ & R square & $F$ & Sig. F Change \\
\hline Model 1 & 0.37 & 0.137 & 3.04 & 0.014 \\
\hline
\end{tabular}


The findings from the coefficients (See Table 10) showed only one variable to be significant. Widowed Now $(t=-2.60, p=.011 ; \beta=-.256)$. Satisfaction with decision (SWD) had the next highest coefficient $(\beta=-.169)$ with the dependent variable, but was a nonsignificant predictor $(t=-1.72 ; p=.09)$.

Table 10

Regression Coefficients

\begin{tabular}{lcccc}
\hline & $b$ & Beta & $t$ & Sig. \\
\hline Widowed $^{\mathrm{a}}$ & -33.70 & -0.256 & -2.61 & 0.01 \\
Confidence $^{\mathrm{b}}$ & 2.22 & 0.086 & 0.71 & 0.48 \\
Total SWD $^{\mathrm{c}}$ & -5.02 & -0.169 & -1.71 & 0.09 \\
Total DCS $^{\mathrm{d}}$ & 0.23 & 0.113 & 0.64 & 0.38 \\
Total DRS $^{\mathrm{e}}$ & 0.65 & 0.071 & 0.64 & 0.52 \\
\hline
\end{tabular}

Key: ${ }^{a}$ Widowed-currently widowed ${ }^{b}$ CDS-Conflict in Decision Scale ${ }^{\mathrm{c}}$ Total SWD-Total Satisfaction with Decision Score ${ }^{\mathrm{d}}$ Total DCS-Total Decisional Conflict Scale ${ }^{\mathrm{e}}$ Total DRS-Total Decision Regret Scale

Zero-order, partial, and part correlations were also examined between Widowed Now, Confidence Scale, Satisfaction with Decision, Decisional Conflict Scale, and Decision Regret Scale. Due to the sign change among the correlations (See Table 11) suppression appears to be present with the Confidence with Decision Scale and the Satisfaction with Decision Scale. The moderate correlations and shared variance between the Confidence with Decision Scale with the Decisional Conflict Scale $(r=-.59)$ and the Decisional Regret Scale $(r=-.41)$ and the correlations among Satisfaction with Decision and widowed now ( $r=-.30)$ may be accounting for this (Table 8). 
Table 11

Zero-order, Partial, and Part Correlations among Widowed, Confidence Scale, Total SWD, Total DCS, and Total DRS.

\begin{tabular}{lccc}
\hline & Zero-order & Partial & Part \\
\hline Widowed $^{\mathrm{a}}$ & -.30 & -.257 & -.247 \\
CDS $^{\mathrm{b}}$ & -.03 & .072 & .067 \\
Total SWD $^{\mathrm{c}}$ & -.212 & -.173 & .163 \\
Total DCS $^{\mathrm{d}}$ & .15 & .090 & .084 \\
Total DRS $^{\mathrm{e}}$ & .13 & .065 & .061
\end{tabular}

Key: ${ }^{a}$ Widowed-currently widowed ${ }^{b}$ CDS-Conflict in Decision Scale ${ }^{\mathrm{c}}$ Total SWD-Total Satisfaction with Decision Score ${ }^{\mathrm{d}}$ Total DCS- Total Decisional Conflict Scale ${ }^{\mathrm{e}}$ Total DRS-Total Decision Regret Scale

Separate regression analyses were done using each of the five subscales of the TINQ as the dependent variables to determine if specific information about disease, investigative tests, treatments, physical needs, and psychosocial needs produced different results. For disease, investigative tests, treatment, and psychosocial needs, the analyses produced very similar results with Widowed Now being the only significant $(p<.05)$ determinant of the specific types of information needs. However, results from the analysis of physical needs subscale revealed that satisfaction with decision $(\beta=-.217$; $p=.03)$ and Widowed Now $(\beta=-.21 ; p=.04)$ were important to the informational needs of the participants.

\section{Summary}

The women reported that they had obtained adequate knowledge about breast cancer, the disease process, investigate tests, treatments, physical and psychosocial needs, and 
this information was very important in their decision-making activities. Overall, the participants were highly confident about the decisions they had made and the majority of them were very satisfied with the treatment decisions they had chosen. Additionally, they reported low decisional conflict and low decision regret about their treatment decisions they had made. From the regression model along with "widowed now" demographic characteristics, the scores from the Confidence with Decision, Satisfaction with Decision, Decisional Conflict Scale, and Decision Regret Scale accounted for $14 \%$ of the variance in the informational needs of the women in this study. The significant predictor of information needs were those reported being currently widowed versus the other participants.

\section{Phase II Results}

\section{Research Question Six}

The following research question was explored for phase II of the study: what considerations went into making treatment decisions after being diagnosed with breast cancer as shared by the focus group participants? Two separate focus group meetings were held at a Midwestern plastic surgical office.

\section{Sample}

A total of 15 women participated in the focus group sessions from a sample of 21 that met the selection criteria. Sixteen women were randomly selected for participation by using SPSS version 16.0. Eight women were chosen from the lower one-third reporting low decisional regret and conflict and high satisfaction with their decision and eight participants randomly were selected from the upper one-third of women experiencing 
high regret and conflict and low satisfaction with their decision. One woman was unable to attend due to a scheduling conflict. The low regret individuals $(n=8)$ were selected from those participants who had a Satisfaction with Decision Scale score greater than 4.8, a Decisional Conflict score less than ten, and Decisional Regret Scale score less than six. Similarly, the high regret individuals $(n=8)$ were chosen based on participants scores using the same scales. Participants scoring less than four on the Satisfaction with Decision scale, greater than 26 on the Decisional Conflict scale, and greater than nine on the Decisional Regret scale were selected as the high regret individuals.

All of the participants $(n=15)$ in the focus group meetings were Caucasian. The majority of the women were married (74\%) and most had some college degree (47\%). Nine of the women $(60 \%)$ were employed full-time, three $(20 \%)$ listed themselves as unemployed, and three (20\%) reported being retired. Thirteen of the participants were post-menopausal $(86 \%)$ at the time of the focus group session. The proxy variable created for age was estimated by menstrual status at the time of diagnosis for the focus group participants. Twenty-nine percent of the focus group members were pre-menopausal and $71 \%$ were post-menopausal at the time of diagnosis indicating these women were most likely diagnosed at an older age. Most of the women lived in a suburban area (86\%), one resided in an urban setting, and the other participant lived in a rural environment. Forty percent of the women had a first-degree relative diagnosed with breast cancer. None of the women in the focus group sessions had been given a stage IV diagnosis. Five women had been given a Stage 0 or "DCIS" diagnosis (33\%), four were staged at one (27\%), three Stage II (20\%), and three women said they had been given a Stage III breast cancer diagnosis (20\%). Table 12 displays the demographics of the focus group participants. 
Crosstabs and Chi-square analysis were conducted on the demographic variables between the focus group participants and the total sample. The only significant Chisquare difference between the focus group and the total sample was with employment status $\left(\chi^{2}=3.84 ; p=.05\right)$. A variable was created $0=$ unemployed (not working or retired) and $1=$ employed (part-time or full-time). Eighty-two percent of the total sample was employed versus $60 \%$ of the focus group participants.

Table 12

Demographic Characteristics of the Focus Group Participants.

\begin{tabular}{|c|c|c|}
\hline & Frequency & Percent \\
\hline \multicolumn{3}{|l|}{ Race } \\
\hline Caucasian & 15 & 100.0 \\
\hline \multicolumn{3}{|c|}{ Marital Status at Diagnosis* } \\
\hline Single & 1 & 7.0 \\
\hline Married & 11 & 74.0 \\
\hline Widowed & 1 & 7.0 \\
\hline Divorced & 2 & 13.0 \\
\hline \multicolumn{3}{|l|}{ Current Marital Status* } \\
\hline Single & 0 & 0.0 \\
\hline Married & 11 & 74.0 \\
\hline Widowed & 2 & 13.0 \\
\hline Divorced & 2 & 13.0 \\
\hline \multicolumn{3}{|l|}{ Education* } \\
\hline High School & 3 & 20.0 \\
\hline Associates & 1 & 6.0 \\
\hline Some College & 4 & 27.0 \\
\hline Bachelors & 4 & 27.0 \\
\hline Some Graduate & 0 & 0.0 \\
\hline Masters & 3 & 20.0 \\
\hline Higher than Masters & 0 & 0.0 \\
\hline \multicolumn{3}{|l|}{ Employment } \\
\hline Unemployed & 3 & 20.0 \\
\hline Part-Time & 0 & 0.0 \\
\hline Full-Time & 9 & 60.0 \\
\hline Retired & 3 & 20.0 \\
\hline
\end{tabular}


Table 12 (Continued)

Demographic Characteristics of the Focus Group Participants.

\begin{tabular}{|c|c|c|}
\hline & Frequency & Percent \\
\hline \multicolumn{3}{|l|}{ Living Location* } \\
\hline Urban & 13 & 86.0 \\
\hline Suburban & 1 & 7.0 \\
\hline Rural & 1 & 7.0 \\
\hline \multicolumn{3}{|c|}{ Menstrual Status At Diagnosis* } \\
\hline Pre-Menopausal & 12 & 80.0 \\
\hline Post-Menopausal & 3 & 20.0 \\
\hline \multicolumn{3}{|c|}{ Current Menstrual Status* } \\
\hline Pre-Menopausal & 2 & 13.0 \\
\hline Post-Menopausal & 13 & 86.0 \\
\hline \multicolumn{3}{|c|}{ First Degree Relative with Cancer* } \\
\hline Yes & 6 & 40.0 \\
\hline No & 8 & 53.0 \\
\hline Unsure & 1 & 7.0 \\
\hline \multicolumn{3}{|c|}{ Tumor Stage at Diagnosis* } \\
\hline 0 & 5 & 33.0 \\
\hline I & 4 & 27.0 \\
\hline II & 3 & 20.0 \\
\hline III & 3 & 20.0 \\
\hline IV & 0 & 0.0 \\
\hline \multicolumn{3}{|l|}{ Widowed Now* } \\
\hline All others & 13 & 87.0 \\
\hline Widowed & 2 & 13.0 \\
\hline
\end{tabular}

* No significant Chi-square differences between focus group and the total sample demographics

The focus group sessions were audio taped and transcribed verbatim. Data were prepared and checked for accuracy. Both focus group transcriptions were read multiple times and the researcher listened to the audio version of the focus group sessions on several separate occasions to begin the open coding process. An iterative process was 
used to extract, condense, and organize codes from the data. A coding sheet was developed and the grouping of common codes formed categories and subcategories (Appendix L). Two researchers were involved in the process of peer debriefing during the data collection, analysis, and interpretation of the findings for Phase II of the study.

Two themes were developed from the subcategories and categories through the data abstraction process. The first theme identified from the data extraction was feelings, thoughts, and essential factors that impact treatment considerations. The second theme was tips for enhancing treatment consideration options (See Table 13).

Table 13

Qualitative Findings: Themes, and Categories:

Theme I: Feelings, thoughts, and essential factors that impact treatment considerations

\section{A. Category- Treatment considerations-Personal thoughts and feelings}

a. Initial personal reactions

b. First Impressions of the treatment team

c. Thoughts

d. Feelings

B. Category-Treatment considerations-Decision aids

a. Personal resources and strategies

b. Treatment team strengths

C. Category-Treatment considerations-Deterrents

Theme II: Tips for enhancing treatment consideration options

D. Category-Treatment considerations-Recommendations

a. Recommendations for future breast cancer patients

b. Recommendations for Health Care Providers 
Within the first theme there were three categories identified: (a) treatment consideration-personal thoughts and feelings, (b) treatment considerations-decision aids, and (c) treatment considerations-deterrents. Within the second theme, there was one category, treatment considerations-recommendations. Additionally, several of the categories contained subcategories. The category "treatment considerations-personal thoughts and feelings" was made up of subcategories. Those subcategories were initial personal reactions, first impressions of the treatment team, thoughts, and feelings. The category "decision aids" also contained subcategories related to personal resources and strengths and treatment team strengths. The category "treatment considerationsdeterrents" had no subcategories. The category "treatment considerationsrecommendations" was subcategorized into recommendations for future breast cancer patients and recommendations directed to health care providers.

Theme I: Feelings, thoughts, and essential factors that impact treatment considerations

The first theme that emerged from the data was: "Feelings, thoughts, and essential factors that impact treatment considerations". The first theme captures the participants' initial reactions to being diagnosed with breast cancer and their beginning thoughts to the decision-making process by evaluating available treatment options. This theme also contains the components that were viewed by the participants as essential in the consideration of treatment choices.

Treatment considerations-Personal Thoughts and Feelings. The focus group sessions began by asking the participants to describe the first feelings and responses that they experienced after being diagnosed with breast cancer. The "initial personal reactions" women generally gave as responses after being diagnosed with breast cancer were: 
“shock", "shell-shocked", "overwhelmed", "taken off guard”, "wow”, "felt in a fog”, "felt naïve", "felt I'm dying", "felt rushed", and "just one more thing to happen to me". One participant said, "When I heard the words breast cancer, it was just like wow". Another women stated, "You know I just couldn't believe you know, just the shock. The shock".

The women in the focus group sessions described their "first impressions of the medical team" after being diagnosed with breast cancer. Some women described the initial experience after being diagnosed with breast cancer as positive while others related a negative experience. The majority of the women were alone when they received the diagnosis of breast cancer and many insisted that the physician give them the news over the phone rather than meeting in person. Following the diagnosis for the most part the breast surgeon was the medical team member to present treatment options to the participants. Treatment options given to the women were dependent upon the tumor stage at the time of diagnosis. Women with a "Stage 0" breast cancer had more choices for example lumpectomy and radiation versus mastectomy and possibly no further treatment required. Whereas, higher graded tumors often necessitated more aggressive therapy, likely to include total breast removal, chemotherapy, and radiation treatments.

Most women stated they were given adequate time by the treatment team to make decisions but others reported feeling rushed. Some of the women expressed that they did not feel good about the physician, setting, or recommended treatment options. Similarly, some of the participants did not want a clinical or impersonal feel from the physician. They wanted a doctor that listened, had a good bedside manner, and understood personal 
preferences. As one woman reported, "Sometimes the first initial contact it can really screw up the whole process or be a good starting point."

Approximately two-thirds of the women in the focus groups felt they had received either a "conflicting opinion" or were "not satisfied" with the treatment options presented". Four of the women switched physicians due to opinions that were not consistent with their own preferences or beliefs. Several women requested to consult with another physician when encountering conflicting opinions. A woman conveyed, "If you're not happy with somebody, cause you're going to be with them for a long time, you know, then go get that second opinion.” Most then remained with the doctor who was most aligned with their own personal preferences about treatment choices. Another participant felt, "I think most of us probably grab on to the conflicting opinion that is closest to what we are in favor of doing." Four of the women reported no conflicting opinions between physicians.

For the subcategory "thoughts" the main consideration for the participants was that they wanted "it" [meaning the cancer] out quickly. Many stated they did not want to wait any longer. They wanted to rid their body of the cancer cells as soon as possible. The women described their thoughts after receiving a breast cancer diagnosis, they gave statements such as, "Like most of us we wanted it out yesterday, you know, when they find it" or "I did not want to wait any longer." One participant explicitly stated "The mastectomy was scheduled as soon as a slot was available. I felt the sooner the better!" Thoughts about body image, sexuality, and reproductive concerns also were voiced but were not the primary focus in what treatments were considered by the participants. A few of the women talked about the sadness of losing one or both breasts, but again 
survival outweighed these self-image issues. "They (my breasts) were my favorite part of my body and it was a very difficult decision to make but like other things or activities I have had or done, I wasn't not going to let what I liked best kill me.” One woman explained, "Body image, sexuality, reconstruction, reproductive issues were not a consideration for me." Only one woman stated that sexuality issues were a day-to-day battle.

The women that chose breast reconstruction frequently said they thought reconstruction helped to restore body image and self-confidence after a disfiguring surgery. "I chose reconstruction because I felt it would give me more self-confidence and a better self-image if I were to date again." Although the loss of one or both breasts was described as significant it did not seem to be affecting sexual relationships with most spouses or significant others within this group. A participant said, "My husband was supportive in that he would love me and think I am beautiful or sexy no matter what." By and large the women in these focus groups were not concerned with body image, sexuality, or reproductive concerns or problems.

In the subcategory identified as "feelings" the main concern cited by the breast cancer survivors in the focus group sessions was survival. The threat of dying was the driving force behind why some women chose certain treatment options. One participant told us "I thought I'm dying, I'm going to be dead next week." Another woman stated, "My feeling came from my sister who died of breast cancer. So I had something to go by and the fact that I was 67 when it was diagnosed and that was last year and everybody in my family has died in their 60 s. So you add up, okay everybody dying in their 60 s, my sister died of breast cancer, well, you know, to me it was logical, I was next." Lastly, a 
participant summed up her feelings about dying, "What I wanted most was to have as much removed as possible to avoid death at an early age."

Other "Feelings" expressed by the participants were the fear of a cancer reoccurrence and fear of the unknown. Some of the responses the participants gave about fear of a reoccurrence were "All my treatment decisions were based on one question: Will this give me my best chance at living another 40 years?" Another participant voiced "My breasts didn't define me but I realized I wasn't giving up my breasts willingly...my ultimate goal was to do everything possible to reduce my risk of reoccurrence." Also, some of the women stated they just "had a gut feeling" about what choices they wanted based upon individual opinions and preferences. "In spite of all the information that's out there, how important it is to be knowledgeable, sometimes it just comes down to your gut."

Treatment consideration-Decision aids. The category of "treatment considerationsdecision aids" was comprised of the subcategories of personal resources and strategies along with treatment team strengths. Within the subcategory of personal resources and strategies women in the study felt it was important to find the right doctor, make a game plan, be prepared for consultations by doing preliminary research, take notes during consultations, and build and create their own treatment team.

Having medical friends and taking a family member or friend with them to the consultation was also described as being helpful. Only three of the focus group participants had some type of medical background. The women that did have a medical background did not report it as necessarily important in considering treatments and making decisions. Those that had family or friends in the medical field stated that the 
medically-oriented family or friends did not make treatment decisions for them but rather supported the decisions the women already had made.

The participants were somewhat split in how family and friends experiences with cancer affected their treatment decisions. A vast majority of the women had been exposed to a friend or family member that had some past experience with cancer, although not necessarily breast cancer. Women who had been exposed to a parent that had a bad reaction to chemotherapy or radiation tended not to chose that as a treatment option if possible. Having a mother with long-term breast health issues also was a reason why some women chose more drastic surgical options. The women's relationships with family members who have experienced regret, positive or negative results with treatments chosen and the long term outcomes they witnessed impacted their treatment considerations. Supporting information from participants were:

"Family experience definitely affected how I chose treatments since I had a sister die of breast cancer and had two cousins die of it in their 30's." "My mother had the same type of cancer as I did, but chose not to have both breasts removed. She regretted that decision soon after her mastectomy and worries she will have issues with the remaining breast." "My mom went through it when she was 70. I didn't want to wait and go through that later on. Like what if I have the one done and then like when I'm 60 or 70 now I've got to have the other one off."

Women that had personal experiences with breast health concerns and those that had family members who were previously diagnosed with cancer also reported that this was beneficial in considering treatment options. Several of the women stated they knew what they were going to do and made choices based on long-standing personal breast health 
issue experiences. One participant stated that "when I was diagnosed I knew exactly what I was going to do. After 20 years of breast issues my decision was bilateral mastectomies, hands down."

The women complained of being tired of frequent follow-up exams, and other diagnostic tests "I had been in the high risk study group for several years prior to diagnosis and had plenty of time to imagine the what ifs. I was tired of being poked and prodded and all the regimen of the mammograms and sonograms." Some of the women who had cancer that was diagnosed early chose to have bilateral mastectomy to avoid radiation or future breast surgery. In contrast, a few of the women held the view that if the cancer had been caught in an early stages (e.g., ductal carcinoma in situ) there was no need for drastic measures and felt it beneficial to keep the unaffected breast for body image and sexuality purposes.

Spirituality also was mentioned as an aid to why certain decisions were made. The power of prayer was given as an important consideration in determining why one made certain choices. One participant stated "Prayer helped. I prayed and asked God for guidance, other people prayed with me and for me. The spiritual aspect was definitely a key factor in making decisions."

Support from family, friends, and talking with previous survivors were named as helpful decision aids. As a follow-up, the focus group participants were questioned about who was involved in helping makes treatment decisions after being diagnosed with breast cancer. The majority of the women reported that they had made their decision alone or "individually". However, most had consulted with family, friends, or doctors prior to the decision and felt supported by these people about the decisions they ultimately had made. 
One woman in particular felt the need to talk to a breast cancer survivor who was a "complete stranger" to get advice and opinions about treatment options. Additionally, listening to your "gut feeling" and trusting in your doctor and health care team was paramount when considering treatment options in making an informed and satisfied decision.

The majority of the women stated they had enough time to make treatment decisions and consider options. Knowing they were able to consider options on their own and make individual decisions also comforted women. The need to gather information on their own from a variety of sources such as breast cancer books, pamphlets, and the Internet was named as being important to this study sample. Several of the women were able to cite specific resources (e.g. comprehensive book received from an oncology program and specific pamphlets from the American Cancer Society) that were most helpful to them. Resources that they conveyed were not helpful were websites that were not branded or familiar like trusted sources such as the American Cancer Society or Susan Komen foundation.

Most of the women in the focus group sessions had prepared for the initial consultation with their physician. Those that prepared felt this helped to decrease the amount of time needed to consider treatment choices and also aided in communicating their preferences to their health care providers. "I had done so much research beforehand, I was ready for the surgery sooner, if the doctor had been available." One woman stated, "I love to read and read a lot of current books on breast cancer." This helped in considering choices and making treatment decisions. 
The study group participants cited factors that were seen under the subcategory, "treatment team strengths". Being informed that the diagnosis was not a death sentence was important in instilling hope for the future. Feeling trust in the doctor, specialists, and medical team were crucial in considering the available treatment options. Having an advocate or navigator, and collaboration with and between health care team members helped to decrease time spent on considerations and stress on the women. Other helpful factors recounted were: feeling informed by being given the entire range of options, having access to up-to date and reliable information provided by the health care team, getting time-lines, and having ample time to make decisions about treatment considerations. One participant stated, "The surgeon went over the results with me, discussing the full range of options." A comfort voiced by one survivor was, "Having a dedicated team so that the surgeon, the oncologist, the radiation oncologist, the nurse, the pathologists are all having their meeting together assessing your case."

Treatment considerations-Deterrents. The category of "deterrents to treatment considerations" encompassed aspects of care that were viewed as negative or a draw back to treatment considerations. First, women who had been diagnosed at a higher stage of breast cancer were somewhat limited as to what choices were available. A few women named sexuality concerns and loss of a breast(s) as being hard to take. As one participant stated, “I struggle daily on my sexuality...I haven't had an intimate relationship since my double mastectomy." Mixed information and conflicting information posted on the Internet from both reliable and unreliable sources was seen as a deterrent while they were considering treatment options. Other deterrents that were identified were lack of followup by trusted support groups and not being informed about the possibility for future 
"touch-up" surgeries. One woman said: "I had no idea that they might have to go back in (additional surgery)." Finding out about potential available resources and available support groups "after the fact" also was cited as a detriment as one participant expounded, "So it (support groups) wasn't nearly as easy as I had imagined...they weren't there when I need them. They really weren't."

\section{Theme II: Tips for enhancing treatment consideration options}

The second theme abstracted from the data was: "Tips for enhancing treatment consideration options". This theme encompasses helpful treatment consideration hints to future patients newly diagnosed with breast cancer. Another aspect of this theme is directed to health care providers. Guidelines to aid health care workers providing care to breast cancer patients are incorporated in this theme to assist women with treatment considerations and help them in making a satisfied and informed decision.

Treatment considerations-Recommendations. The category "recommendations for treatment considerations" was subcategorized into "recommendations for future breast cancer patients" and "recommendations to health care providers". As "recommendations for future breast cancer patients" the study group participants felt it was important to convey the following things to women newly diagnosed with breast cancer: be proactive, take charge, educate yourself, have the doctor recommend reputable books and websites, and take time to absorb the information. A recommendation given by a participant was "Okay this is my body, I'm going to control it, what is going on here, they need to follow my...I think you just have to be so proactive." Other helpful hints included: finding a breast cancer specialist, writing down and asking questions, and taking a tape recorder to consultation appointments. A participant gave this suggestion "One valuable piece of 
advice that I got from a public meeting with medical professionals on breast cancer several years ago was to get the best possible doctor for you before the biopsy. I used that information and felt very confident in the breast cancer specialist I had." The women also felt it was necessary to take someone with you to appointments and find an advocate or support group. Lastly, many of the women stated "go with your gut feeling" and don't let anyone change your mind. A woman in the focus group meeting said "In spite of all the information that's out there, how important it is to be knowledgeable, sometimes it just comes down to your gut." Another woman explained, "You've got to trust in that doctor then when they say something then you kind of follow, or at least look at it seriously what they're saying."

"Recommendations to health care providers" voiced by the focus group participants for members of the health care team include: (a) tell women the diagnosis is not a death sentence, (b) give women time to make decisions as well as give permission to postpone or delay some treatment decisions, (c) provide simple guidebooks, and comprehensive resource books, and (d) tell women about the potential for future surgeries or the development of lymphedema. One participant stated, “Once we're diagnosed somebody has got to give us these pamphlets and say there are advocates, you have to have someone go with you to be an advocate to every appointment." Similarly, a participant said "I think what needs to be stressed it that they do have time to take a breath...they need to know they have time to absorb it, to just kind of go through a little bit of a fog, cry a little bit... and then they need to be given simple things to education them." The women also thought health care providers need to talk to women about the potential for the development of lymphedema, unexpected surgeries, or possible complications. 


\section{Summary}

As described previously, the women selected for the focus group meetings were split based on those experiencing high regret and those with low decision regret. The fear of dying, need for hope, and a good working relationship with the treatment team were cited as crucial aspects in adjusting and dealing with their cancer diagnosis and making treatment decisions. Women in the focus group meetings expressed a need for hope and often chose treatments that would most likely enhance their life expectancy. The women also felt it important to give an account of recommendations to future breast cancer patients and to members of the treatment team to help women needing to consider options and make treatment decisions.

\section{Follow-up Analyses}

Follow-up analyses were conducted to explore relevant findings from Phase I of the study. Additional analyses also were done to determine if there was further support for the findings from the focus group sessions using data obtained from Phase I.

Widowed participants. Although a small sample, women who were widowed had lower informational needs than the other participants (See Table 14). The currently widowed group reported similar Confidence scores, Satisfaction with Decision scores, and Decision Regret levels. Stark differences were seen between the currently widowed group and all others in relationship to the Decisional Conflict scores and the Support subscale. The widowed group reported lower decisional conflict $(M=12.2 ; S D=17.6)$ but also cited lower levels of support $(M=1.1 ; S D=2.3)$ when compared to "all others" that reported a decisional conflict score $(M=20.6 ; S D=16)$ and the degree of support $(M=2.2$; 
$S D=2.4$ ). The widowed women were similar to the rest of the sample in relationship to time elapsed since diagnosis and employment status but differed in their education levels and tumor stage at time of diagnosis. The widowed women mostly had a high school education (71\%) as compared to the rest of the sample that had some type of college experience or degree $(81 \%)$.

Table 14

Descriptive Statistics for the Toronto Information Needs Questionnaire, Confidence in Decision Scale, Satisfaction with Decision Scale, Decisional Conflict Scale, and Decision Regret Scale, Education, Tumor Stage, Time Since Diagnosis, Employment, Support with Widowed Now and All Others.

\begin{tabular}{|c|c|c|}
\hline Scales & $\begin{array}{c}\text { Widowed Now } \\
\quad(n=7) \\
M(S D)\end{array}$ & $\begin{array}{c}\text { All others } \\
\quad(n=95) \\
M(S D)\end{array}$ \\
\hline TINQ $^{\mathrm{a}}$ & $171(60.3)$ & $210(29.3)$ \\
\hline $\mathrm{CDS}^{\mathrm{b}}$ & $8.7(1.8)$ & $9.0(1.3)$ \\
\hline $\mathrm{SWD}^{\mathrm{c}}$ & $4.7(.55)$ & $4.1(1.1)$ \\
\hline $\mathrm{DCS}^{\mathrm{d}}$ & $12.2(17.6)$ & $20.6(16)$ \\
\hline Support subscale ${ }^{\mathrm{d} 1}$ & $1.1(2.3)$ & $2.2(2.4)$ \\
\hline $\mathrm{DRS}^{\mathrm{e}}$ & $7.4(4.2)$ & $7.9(3.6)$ \\
\hline
\end{tabular}


Table 14 (Continued)

Descriptive Statistics

\begin{tabular}{ccc}
\hline & Widowed Now & All others \\
& $(n=7)$ & $(n=95)$ \\
Scales & $\%$ & $\%$
\end{tabular}

Education $^{\mathrm{f}}$

Employment $^{\mathrm{g}}$

Tumor Stage

Time Since $\mathrm{Dx}^{\mathrm{i}}$
71 (high school)

86 (employed)

29 (Stage 0)

86 (1-5years post $\mathrm{dx})$
81 (college experience/degree)

77 (employed)

19 (stage 0)

$73(1-5$ years post $d x)$

Key: ${ }^{\mathrm{a}}$ TINQ-Toronto Information Needs Questionnaire ${ }^{\mathrm{b}}$ CDS-Confidence in Decision Scale ${ }^{\mathrm{c}}$ SWD-Satisfaction with Decision Scale ${ }^{\mathrm{d}}$ DCS-Decisional Conflict Scale Support subcale ${ }^{\mathrm{d} 1}{ }^{\mathrm{e}}$ DRS-Decision Regret Scale, ${ }^{\mathrm{f}}$ Education level, ${ }^{\mathrm{g}}$ Employment status, ${ }^{\mathrm{h}}$ Tumor stage at time of diagnosis, and ${ }^{\mathrm{i}}$ Months since receiving a diagnosis of breast cancer

High versus low regret individuals. Descriptive statistics were generated and reviewed between the high and low regret individuals chosen for the focus groups on the following variables; (a) the five survey scales, (b) Support subscale from the Decisional Conflict scale, (c) "Widowed Now", (d) education, (e) tumor stage, (f) time since diagnosis, and (g) employment status The results between the high and low regret individuals revealed that the low regret individuals actually had higher informational needs than the high regret individuals (See Table 15). As one would expect, the low regret individuals were more confident and satisfied with their decisions. There was a large discrepancy between the Decisional Conflict and Decision Regret scores between the high and low regret individuals. The participants with high regret reported higher decisional conflict $(M=46.7 ; S D=15.9)$ and higher decisional regret $(M=12.7 ; S D=2.7)$ than the low regret individuals $(M=3.5 ; n S D=4.0),(M=5.0 ; S D=.06)$, respectively. 
Table 15

Descriptive Statistics for the Toronto Information Needs Questionnaire, Confidence in Decision Scale, Satisfaction with Decision Scale, Decisional Conflict Scale, and Decision Regret Scales for the High Regret and Low Regret Individuals.

\begin{tabular}{|c|c|c|}
\hline Scales & $\begin{array}{c}\text { High Regret } \\
\quad(n=7) \\
M(S D)\end{array}$ & $\begin{array}{c}\text { Low Regret } \\
\quad(n=8) \\
M(S D)\end{array}$ \\
\hline $\mathrm{TINQ}^{\mathrm{a}}$ & $211.2(33.3)$ & $223.3(16.5)$ \\
\hline $\mathrm{CDS}^{\mathrm{b}}$ & $7.9(1.9)$ & $9.7(.70)$ \\
\hline $\mathrm{SWD}^{\mathrm{c}}$ & $3.6(.31)$ & $5.0(.06)$ \\
\hline $\mathrm{DCS}^{\mathrm{d}}$ & 46.7 (15.9) & $3.5(4.0)$ \\
\hline $\mathrm{DRS}^{\mathrm{e}}$ & $12.7(2.7)$ & $5.0(.00)$ \\
\hline
\end{tabular}

Satisfaction with decision. The participants who reported low satisfaction with their decision had higher informational needs as would be expected (See Table 16). The low satisfaction individuals reported higher confidence in their decision, lower decisional conflict, and lower decisional regret. 
Table 16

Descriptive Statistics for the Toronto Information Needs Questionnaire, Confidence in Decision Scale, Decisional Conflict Scale, and the Decision Regret Scale for the High and Low Satisfaction Individuals.

\begin{tabular}{lcc}
\hline Scales & $\begin{array}{c}\text { High Satisfaction } \\
(n=93) \\
M(S D)\end{array}$ & $\begin{array}{c}\text { Low Satisfaction } \\
(n=9) \\
\end{array}$ \\
\hline TINQ $^{\mathrm{a}}$ & $206(33.1)$ & $226(33.6)$ \\
$\mathrm{CDS}^{\mathrm{b}}$ & $8.9(1.3)$ & $9.7(1.0)$ \\
$\mathrm{DCS}^{\mathrm{c}}$ & $21.2(16.0)$ & $8.0(13.6)$ \\
$\mathrm{DRS}^{\mathrm{d}}$ & $8.0(3.8)$ & $6.3(1.7)$ \\
\hline
\end{tabular}

Key: ${ }^{\mathrm{a}}$ TINQ-Toronto Information Needs Questionnaire ${ }^{\mathrm{b}}$ CDS-Confidence in Decision Scale ${ }^{c}$ DCS-Decisional Conflict Scale ${ }^{\mathrm{d}}$ DRS-Decision Regret Scale

A follow-up ANOVA was performed with months since diagnosis and the informational needs of the total sample. Results of the ANOVA indicated that women between six to twelve months post diagnosis had lower informational needs than the other groups. Women who were one to two years post diagnosis reported the highest need to know about the disease process, prognosis, treatment options, investigate tests, physical and psychosocial needs $(M=212)$. It is possible that women in this time period had time to come out the "shock" phase and were now able to consider what needs would have been important to them at the time of making treatment decisions. These same assumptions may also be applicable to the women three to five years and greater than five years post diagnosis (See Table 17). 
Table 17

Time Since Diagnosis in Relationship to Informational Needs $\left(T_{I N}{ }^{a}\right)$

\begin{tabular}{lcccc}
\hline Time & Mean & SD & Minimum & Maximum \\
\hline 6-12 months & 187.0 & 22.0 & 171 & 218 \\
1-2 years & 212.4 & 32.0 & 115 & 260 \\
3-5 years & 206.0 & 39.1 & 90 & 260 \\
Over 5 years & 207.2 & 25.4 & 161 & 256 \\
\hline
\end{tabular}

Key: ${ }^{\mathrm{a}}$ Toronto Informational Needs Questionnaire

Key themes from Phase II. One of the key findings from the focus group was the participants' reaction to their diagnosis was their fear of dying. Further examination of items from the Disease subscale of the Toronto Information Needs Questionnaire revealed items on this subscale addressed this topic. One example of these items was "If the cancer will come back". Additionally, there was another item "Concerns About Dying" from the Toronto Information Needs Questionnaire. Both the participants of the focus groups and the total sample reported the need to know about the disease process as "very important" $(M=40 ; S D=3.9$, and $M=38 ; S D=5.4$ respectively, on a scale of $16-45)$. Again both samples reported high "Concerns About Dying" ( $M=3.7 ; S D=1.2$ on a scale of 1-5), (See Table 18). 
Table 18

Descriptive Statistics for the Disease subscale and Concerns About Dying Item

\begin{tabular}{lccc}
\hline & $\begin{array}{c}\text { Focus Group } \\
(n=15)\end{array}$ & $\begin{array}{c}\text { Total Sample } \\
(N=102)\end{array}$ & Range \\
& $M(S D)$ & $M(S D)$ & $16-45$ \\
TINQ-Disease Subscale $^{\mathrm{a}}$ & $40.3(3.9)$ & $38.3(5.4)$ & $1-5$ \\
Concerns about Dying $^{\mathrm{b}}$ & $3.7(1.3)$ & $3.7(1.2)$ & \\
$\begin{array}{l}\text { Key: } \\
\text { Dying Item }\end{array}$ & & \\
\end{tabular}

Another concern expressed by the focus group participants was finding the necessary support they needed to deal with their feelings and get advice about their treatment decisions. The Decision Conflict scale contained a Support subscale that included the following items: (a) having enough support from others to make a choice, (b) making a choice without pressure from others, and (c) having enough advice to make a choice. The sample means revealed that both the focus group participants and the total sample agreed that they had adequate support $(M=3.0$; and 2.1, respectively, where a lower score indicates higher support). Focus group participants reported a slightly higher need for support than the total sample. Both the focus group sample and the total sample reported similar findings in their desire to know where to get help dealing with their feelings, and their need to gather advice from members of the health care team. The results are listed in Table 19. 
Table 19

Descriptives of Support Subscale, Support Groups and Help with Feelings item for the Focus Group Sample and the Entire Sample.

\begin{tabular}{lccc}
\hline & $\begin{array}{l}\text { Focus Group } \\
(n=15) \\
M(S D)\end{array}$ & $\begin{array}{c}\text { Total Sample } \\
(N=102) \\
M(S D)\end{array}$ & Range \\
\hline & & $2.1(2.4)^{*}$ & $0-12$ \\
DCS-Support Subscale $^{\mathrm{a}}$ & $3.0(3.1)^{*}$ & $3.0(1.3)^{* *}$ & $1-5$ \\
TINQ-Needs $^{\mathrm{b}}$ & $3.4(1.5)^{* *}$ & $4.7(.68)^{* *}$ & $1-5$ \\
TINQ-Feelings $^{\mathrm{c}}$ & $4.9(.26)^{* *}$ & & \\
\hline
\end{tabular}

Key: ${ }^{\mathrm{a} D C S}$-Decisional Conflict Scale ${ }^{\mathrm{b}}$ TINQ-Toronto Information Needs QuestionnaireSupport Needs item ${ }^{\mathrm{c}}$ TINQ-Toronto Information Needs Questionnaire-Feelings Item * Lower scores indicate higher support, **higher scores indicate higher needs and feelings

Another key finding from the participants in the focus groups was having a good working relationship with the treatment team. In Phase I, participants rated the following items from the TINQ: (a) the need to know about who to call about questions related to care and treatment, (b) who to call about questions after treatment has ended, and (c) who to talk to about specific treatments. These items were rated as highly important by the women in this study $(M \geq 4$; range $1-5)$, confirming that support from health care providers was crucial to them (See Table 20). 
Table 20

Descriptive Statistics for Health Care Provider Support items from the TINQ ${ }^{\mathrm{a}}$; Who to Call with Questions, Who to Call After Treatment is Over, Who to Talk to About Specific Treatments with the Focus Group Sample versus the Entire Sample.

\begin{tabular}{lccc}
\hline & $\begin{array}{c}\text { Focus Group } \\
(n=15) \\
M(S D)\end{array}$ & $\begin{array}{c}\text { Entire Sample } \\
(N=102) \\
M(S D)\end{array}$ & Range \\
\hline Who to Call with Questions & $4.7(.72)^{*}$ & $4.4(.84)^{*}$ & $1-5$ \\
Who to Call After Treatment & $4.5(.83)^{*}$ & $4.4(.90)^{*}$ & $1-5$ \\
Who to Talk with About Specifics & $4.1(1.1)^{*}$ & $3.9(1.1)^{*}$ & $1-5$ \\
& & & \\
\hline $\begin{array}{l}\text { Key: } \\
\text { degree of }\end{array}$ & & &
\end{tabular}

\section{Summary of Results}

The important findings from this study were the high confidence and satisfaction levels reported by the breast cancer survivors that made up this sample. This particular group of women also reported very low conflict with the decisions that they had made as well as having low levels of regret. These women felt knowledgeable about the information they had received after being diagnosed with breast cancer and all the aspects that are encompassed in the treatment of the disease and therapeutic modalities. On the whole, the sample of women in this study were clear about their values, had adequate support, were certain about the decisions they had made, and felt they had made effective decisions based on their own preferences. Personal experiences with friends or family members who had undergone treatment for cancer, tumor stage given at the time of 
diagnosis, availability of resources, and access to specialty treatment teams and centers played a role in what treatment options were considered.

The follow-up analysis using SPSS aided in merging and validating the results found in Phase I and Phase II of this study. The main concerns voiced by the focus group participants were the fear of death and dying, need for personal support, and the need for support from the treatment team. These findings were confirmed by the additional analyses. Although the need to provide hope was named as important by the focus group participants this variable was not measured in the survey data collected for this study. Measuring the degree of hope may have yielded additional findings to further validate study findings. 


\section{CHAPTER FIVE}

\section{DISCUSSION, IMPLICATIONS, AND CONCLUSIONS}

This chapter presents a discussion of the findings of exploring how women made treatment decisions after being diagnosed with breast cancer. Theoretical relevance and clinical implications are discussed. The strengths and limitations of the study are reviewed and recommendations for future research are presented.

\section{Summary of Study Findings}

Prior to the initiation of this study, the researcher made certain assumptions about how women made treatment decisions. The researcher had over eight years of clinical experience in caring for women diagnosed with breast cancer. The researcher has been employed by a plastic surgeon that specializes in breast reconstruction following mastectomy and frequently assesses newly diagnosed breast cancer patients that are considering what type of treatment options are available after receiving the diagnosis.

The investigator assumed that the women in the study largely would have felt rushed about making treatment decisions and would not have been given enough time to make an informed decision. However, the findings revealed that the study participants did not

feel rushed in making treatment decisions and for the most part participants felt they had adequate information to make informed decisions. The investigator assumed that informational needs would be high after receiving a breast cancer diagnosis, and the study participants supported this assumption in reporting that their informational needs were very important in the decision-making process. The researcher did not anticipate that the satisfaction and confidence levels would be as high as what was reported nor would the degree of decisional conflict and regret be as low as what was reported. 
Body image, sexuality, reproductive issues, and self-esteem also were presumed to be key factors in considering treatment options. Although body image, sexuality, and reproduction were altered from surgery or treatment procedures by many of the participants, most did not report it as being a major reason for choosing certain treatment options and this was an unexpected finding. This differed from Banning's (2007) findings that reported body image, self-esteem, sexuality, and reproduction to be major concerns of women diagnosed with breast cancer. While the women cited loss of a breast(s) as significant it was not reported to have caused serious psychological or emotional distress. Likewise, participants did not report that treatment responses such as skin changes from radiation, effects from chemotherapy, or weight changes were important in considering treatments (Brestcancercare.org, 2008).

The most compelling reason focus group participants chose certain types of treatment was based on their fear of dying or their fear of a cancer recurrence and for the most part all other factors took second place. This need for self-preservation and to "act now" was also reported by Reaby (1998a) and Fitch et al. (2008). The following statement was echoed by several of the participants, "My very first reaction to the news that I had breast cancer was that I did not have long to live". The overriding concern about the fear of death and dying after being diagnosed with breast cancer by the focus group participants was confirmed with results from surveys reported by the total sample. Both of the groups were extremely similar in their concern about dying and disease needs related to dying. This underscores the importance of the need for the treatment team to communicate to women that the diagnosis in most cases is not a death sentence and that optimism for long-term survival needs to be emphasized. The women looked to the treatment team for 
hope, good communication styles, and preferred a shared decision-making process. The bottom line was that the women felt it was imperative to go with their "gut feelings" when making treatment decisions.

Participants in this study were for the most part well educated, married, Caucasian women living in urban areas, and working full-time. Also, the majority of the women were married at the time of diagnosis as well as being married at the time of participation in the study. Most of the women in the study had been given a tumor stage of DCIS (Stage 0) or Stage I and more than two-thirds of the women did not have a first-degree relative that had been diagnosed with breast cancer. Overall, the participants in this study were a homogenous group of women.

\section{DISCUSSION}

There has been limited research and information about how satisfied women are after making breast cancer treatment decisions. This study added to the body of nursing knowledge about the assessment of patients' personal satisfaction with their health care decision versus their satisfaction with their health care providers. Furthermore, this study supplemented research on decision regret. Until this study, no research had been reported about women's decision regret related to their treatment decisions after receiving a breast cancer diagnosis.

The participants revealed that gaining information about the disease process as well as why tests and treatments were performed were main areas of concern. Surprisingly, information about psychosocial needs was the least important dimension reported as a need by the women in this study. Being married and having adequate support from 
significant others, along with having a highly educated group of women may be factors contributing to why psychosocial needs were rated as the lowest need in this study.

Graydon et al. (1997) found knowledge about breast cancer, tests, and treatments were the major concerns of 70 women diagnosed with breast cancer. The possibility of cancer reoccurrence also was cited as extremely important in the Graydon study. Participants in this study reported the same fears. Comparable findings also were reported as psychosocial needs being a second area of concern by the Graydon research team.

Low confidence levels in decision making by women were not seen in this study. These findings are in stark contrast to the Estes and Hosseini (1998) study. However, the Estes and Hosseini team studied confidence levels in women related to investment decision making not breast cancer treatment decisions. It is possible that the differences in confidence levels between this study and the Estes and Hosseini research is due to the context of the subject matter being measured. Holmes-Rover (1996) adapted the Estes and Hosseini confidence scale to use in conjunction with studying personal satisfaction with making a health care decision. Prior to this study the confidence scale had not been used with women making treatment decisions after being diagnosed with breast cancer.

The women surveyed in this study were very confident about the decisions they had made. Approximately one-fourth of the participants came from a breast cancer survivorship clinic at a Midwestern academic medical center. These participants had been exposed to frequent exams and follow-up care and may have had time to consider risks and benefits associated with different treatment options. The remainder were recruited from a plastic surgery center and consequently they had all chosen some type of breast reconstruction (i.e., either unilateral or bilateral tissue expansion using tissue expanders). 
These women may have had adequate time to review and weigh treatment considerations, since there is usually a time delay from initial diagnosis to specialty surgical consultation appointments. Having adequate time to absorb and process the information may have contributed to the high confidence levels reported.

Generally, the participants reported a high level of satisfaction with the decisions they had made. Less than eight percent were totally dissatisfied. Exposure to breast cancer specialists and multi-disciplinary environments also may have influenced the high degree of satisfaction levels reported by the participants. The women who received treatment from specialty centers stated the breast center treatment team helped guide and move them through the system. Others reported wanting the "tried and true" (physicians that specialize in breast cancer) and breast specialists and specialty clinics may have aided women in making a satisfied treatment decision. Being prepared and able to make individual decisions may have contributed to this finding as well.

The follow-up analysis conducted with SPSS version 16.0 revealed that the high satisfaction group had lower information needs than the low satisfaction group. Oddly, the high satisfaction group had lower confidence levels, higher decisional conflict, and higher decision regret than the low satisfaction group. It is puzzling why these findings were reported and this needs further evaluation in future studies.

The degree of decisional conflict reported from this particular sample was low. Only one percent of the participants said they had high decision conflict. These findings indicate that the women felt informed, were clear about their personal values, had support from significant others, and did not experience a high degree of uncertainty about the treatment decisions they made. Many of the focus group participants reiterated the vital 
importance of being given ample time to research and weigh all of their options before making treatment decisions.

The majority of the women reported having no regret, remorse, or anguish about the health care decisions that were made. Being under the care of a specialty team, talking to previous breast cancer survivors, and "making a game plan" was cited as helpful to organizing thoughts and considering available treatment options. These factors certainly contribute to low decisional conflict and low decision regret.

Using a mixed methods approach validated some of the focus group findings with information obtained from the surveys. As one would expect, the low regret individuals had higher confidence and satisfaction with decisions and reported remarkably lower decisional conflict and decision regret. One unusual finding in this sample is that the low regret individuals reported higher informational needs than the high regret individuals. The focus group participants stated that they were eager to read and research their disease and treatment options. It is presumed that even though they reported higher informational needs they gathered adequate information so they could make a more confident and satisfied decision. Perhaps the personal enjoyment of reading and researching on their own may have contributed to experiencing less decisional conflict, decisional regret, and a sense of satisfaction with the decisions that they had made as a result of the knowledge they had gained.

Examining the correlations among the other variables indicated that as confidence levels about decision making increased so did satisfaction in decision making. As one would expect, higher confidence levels also were associated with lower decisional conflict and regret. 
Several demographic variables were analyzed in relationship to the informational needs of women diagnosed with breast cancer. There was only one significant demographic characteristic, participants who currently were widowed, in relationship to the informational needs of the participants. Possibly the stress of losing a spouse and lack of other support may account for these results. Loss of a spouse also may contribute to a deficit in having physical needs met and dissatisfaction with decisions that had been made due to absence of a source of support. Lindop and Cannon (2001) found that acceptance of a changed appearance from a husband or partner was viewed as crucial to adjusting after a breast cancer diagnosis and support from a significant other is beneficial in decreasing psychosocial concerns especially when it is related to skin changes or loss of a body part. Furthermore, death of a spouse may be similar to the cancer experience described by rural patients in the Bettencourt (2007) study. Bettencourt reports that the diagnosis of cancer can be a very lonely experience. The lack of a spouse or significant other may elicit these same lonely or isolated feelings.

The women who were currently "widowed now" reported a greater need to know more about how to restore and maintain health as compared to "all others". Physical needs such as: a) how to care for wounds and incisions; b) when personal hygienic care can begin; c) when usual diet, hobbies, social activities, and exercises can resume; and d) if help will be needed for personal care were ranked as being higher in importance than "all others". Perhaps, women who did not have a day-to-day significant support person felt this type of information was more important to know for self-care purposes than the "all others" group. The currently widowed women also reported items on the physical subscale as important to know and that they contributed to making a satisfied decision. 
Widowed women did cite lower levels of support than the entire sample and this is to be anticipated if a significant support person has been lost.

Unexpected results were found with the women who were currently widowed. This group of women reported lower informational needs, confidence, and educational levels. With these findings it was surprising that the widowed women reported being more satisfied with the decisions they had made and had less decisional conflict. Further research needs to be conducted to explain why or if this would recur in future studies.

Overall, the women in the focus group sessions reported feelings of shock after being diagnosed with breast cancer. Although some of the women had anticipated being given this news sometime in the future it still caught them off guard once they received the actual diagnosis. One participant developed breast health concerns in her early thirties but was not diagnosed with breast cancer until she was in her early fifties. She commented, "For me it wasn't a matter of if, it was a matter of when".

Frequently, initial reactions to the medical consultations played a role in the perception of whether or not the experience was positive or negative. When conflicting or negative experiences were encountered, the women in this study tended to seek out second opinions or other advice by contacting trusted physicians, family members, or friends for advice. Many of the women felt comfortable seeking referrals from their personal obstetrician/gynecologist for direction and advice. In addition to seeking advice this group of women reported being avid readers and spent time reading and seeking information especially when it came to acquiring health care information.

Understanding what is important to women based on their personal feelings and values as well as their past experiences is one of the major reasons why certain treatments 
options (e.g., choosing lumpectomy and radiation versus mastectomy or opting out of chemotherapy regimens if possible) were preferred over others. A major feeling voiced by several of the participants was the need to go with their "gut feelings" when making final treatment decisions. If women had fewer treatment options it often was due to having a more advanced tumor stage that resulted in fewer treatments options to consider. Some examples were:

“My cancer was more advanced. I didn't get to consider other approaches. I thought about refusing chemotherapy because I did not want to miss work, stop working out, or lose my hair but ultimately I did what my oncologist told me to do". Another women said, "My breast cancer was of an aggressive nature and I was told I would need chemo. I was hoping the surgeon was wrong but the oncologist said I needed chemo. I felt I had no choice".

The narratives described by Hallenbeck (2002) also rang true with these women. The participants did rely on past experiences, personal fears, and beliefs when considering a medical decisions. Witnessing positive and negative outcomes of family members' cancer experiences accounted for why some treatments were chosen or rejected. This also coincides with Brehaut et al. (2003) findings that treatment decisions must account for "value-sensitive" or "preference-sensitive" choices and health care providers must be in tune with these feelings. Reaby (1998b) reported similar findings in that the women in her study felt it was critical that the treatment team helped women to define personal feelings and values, to evaluate different options, and to take adequate time before making a healthcare decision. 
The importance of physician-patient communication was emphasized and some participants indicated that communication patterns were poor. Women wanted health care providers actively listen to patient's preferences and appreciate individual perspectives about decision priorities. This finding was similar to the Sepucha et al, (2003) study. The researchers stated that it is crucial that information is not being presented in a hurried fashion.

Support needed from health care providers was reinforced through focus group comments and survey findings. Knowing who to call and follow-up with about general and specific treatment questions during and after the treatments were completed are important aspect in the treatment process. Additional studies need to assess the degree and significance of support from health care providers that is necessary to assist women in making informed and satisfied treatment decisions after being diagnosed with breast cancer.

Data from the surveys also supported the findings from the focus group participants in regards to feeling they had adequate support and advice, and not feeling they were not forced to make any treatment decisions. Furthermore, the need to know who to turn to if help was needed help with feelings, or assistance from support groups was equally important.

Additionally, it was discovered that collaboration with support group providers was somewhat disjointed. Some local support groups known to represent various organizations dedicated to breast cancer patients in assisting and supporting newly diagnosed breast cancer patients were described as unreliable. One participant said, "I had to really seek them (support organizations) out and it was difficult...I called a center 
because I was familiar with them through my work, they never returned my call...I also called another program several times and it took not only me calling but also the advocate to get someone to come and see me".

Several of the women felt isolated after finishing the cancer treatments. One participant stated "Ending the chemotherapy and radiation treatments was frightening because I did not feel that I was doing anything more". Another women said, "I did not want the port taken out. I felt a sense of security while it was in. I liked it." Finishing treatments made some women feel that they were not fighting the cancer any more and this increased the fear of death or recurrence. Yi et al, (2008) reported that women often feel neglected or abandoned after treatments are completed. The researchers found that chat rooms, blogs, and involvement with support groups helped to decrease these feelings of abandonment.

In summary, findings from the focus group meetings led to the emergence of two themes: (a) feelings, thoughts, and essential factors that impact treatment considerations and (b) tips for enhancing treatment consideration options. Taking action, considering options, and making a game plan are included in the first theme. Helpful decision aids and pitfalls to treatment considerations and decision making also are woven into this theme.

The second theme contained tips that were directed to future patients and advice was also given to aid the treatment team to help guide future breast cancer patients in making effective decisions. The main recommendations given to women diagnosed with breast cancer in the second theme were to prepare for consultations, take control of your own care, voice concerns, and most importantly go with your "gut feeling". This group of 
women held similar beliefs to the women in the Waljee et al. (2008) study. Participants felt it was important to find a breast cancer specialist to aid in informed decision making.

The fear or threat of dying highly resonated among the participants and primarily women wanted to be told the diagnosis was not a death sentence. They wanted to be equipped with information via pamphlets, books, and recommended websites to be prepared before consultation appointments. Ultimately, women need to be given permission to take the time to make an informed decision.

\section{Theoretical Relevance}

Theoretical constructs and concepts (Figure 2, p. 12) were used to design the study for obtaining the data. Data collected in Phase I of the study came from several survey tools including the Toronto Informational Needs Questionnaire, the Confidence in Decision Scale, the Satisfaction with Decision Scale, the Decisional Conflict Scale, and the Decision Regret Scale. Phase II reported the findings from the focus group. The Possible Diagnostic Questions to Evaluate the Process of Effective Decision Making provided a helpful guide in examining how the women in this study considered treatment decisions (Table 1, p. 13).

The theory of decisional conflict provided an appropriate framework for examining how women made treatment decisions after being diagnosed with breast cancer. Receiving a diagnosis of breast cancer invokes feelings of stress and can bring about a state of uncertainty in decision making. The treatment options the women considered in many cases involved unknown outcomes, were associated with risks, and the possibility of experiencing guilt, remorse, or feelings of regret (Janis \& Mann, 1977). The study participants voiced these concerns especially when they described their initial reactions 
and impressions to the treatment team. One finding from this study is in the area of the concept of hope that evolved as an important part of the treatment process and should be considered as another concept in the model.

The descriptions of antecedent conditions, mediating processes, and consequences by Janis and Mann (1977) were applicable to the women in this study. Many women in this study referenced how they had a lot going on in their own lives at the time of being given a diagnosis of breast cancer. The diagnosis further complicated their normal routine in dealing with normal activities associated with active and somewhat stressful life situations. Janis and Mann list communication as an extremely important antecedent condition to effective decision making. These women reported good communication with and between health care providers as vital. The personality types, personal preferences, and life experiences also were crucial in impacting how they made treatment decisions. The women in this study appeared to go through mediating processes outlined by Janis and Mann while assessing treatment options and basing some decisions on knowledge, risks, options, hope for a favorable outcome, and having ample time to consider choices. Many participants had experience with the mediating processes by accruing knowledge through personal long-standing breast health concerns or family and friends' experiences with a cancer diagnosis. Lastly, the women in this study largely experienced vigilance as a consequence. Generally, the women were motivated to take action and had the cognitive ability to acquire information and knowledge to make an effective decision. Many described how important it was to gather information on their own to aid in making an individualized treatment decision. The Theory of Decisional Conflict model was supported by the data obtained from this study. 


\section{Clinical Implications}

Important recommendations given by the participants were directed to members of the health care team. A disconnect was reported by women when the manner in which health care information was presented to them after being diagnosed with breast cancer did not include consideration for their personal preferences. Health care providers primarily presented all the information and the full range of treatment options and then asked "any questions?" Many of the women felt the treatment team did not listen to their thoughts, preferences, personal feelings, and past experiences and incorporate these concepts into the presentation of information, scope of options, and recommended treatments and plan of care.

The role of nursing as a member of the treatment team can enhance the experience of the patient. The role nursing plays as a key member of the treatment team is essential to providing holistic care in this patient population. Treatment team members including nurses need to actively listen and consider the patient's fears, concerns, past experiences, and preferences before presenting an overabundance of information. Determining what the patient's feelings, desires, and needs is an important aspect of providing care and information. It is imperative that consultation time with the patient is not rushed. LeBlanc et al. (2009) discuss the importance of establishing an effective dyadic relationship (good working relationship between two people) with a patient to foster shared decision making. When a good working relationship is developed between the health care team and the patient, both sides of the dyad are more likely to have a positive and mutually satisfying experience. Also, assisting patients to find a specialty treatment team is extremely important to women newly diagnosed with breast cancer (Cancer 
Guide, 2009). The participants in this study echoed these recommendations. Referring patients to specialty centers may result in a more cohesive and coordinated approach to patient care and treatment.

Health care providers also need to tell women the diagnosis of breast cancer is not necessarily a death sentence. Fears of the possibility of breast cancer reoccurrence need to be addressed with patients. Hope for a favorable outcome needs to be emphasized by members of the treatment team. The need to foster hope in women diagnosed with breast cancer was also cited by Sepucha et al. (2003) as important in dealing with the disease process. Women diagnosed with breast cancer need to be provided with up-to-date comprehensive resource books, pamphlets, or directed to reputable Internet sites recommended by members of the treatment team depending on the woman's preferred learning style to seek information on their particular type and stage of cancer. Chat rooms or respected "blog" sites should be developed by health care providers in an effort to provide support for and among breast cancer survivors. These sites also may provide a beneficial connection for women who have completed breast cancer treatments and are feeling isolated or neglected. Finally, women need to be given permission to take the time they need to assimilate the information and consider available treatment options, so they can make the best individual treatment decisions.

\section{Education Implications}

It is essential that undergraduate nursing programs include didactic materials to educate nursing students about the informational needs, need for hope, fear of dying, and the fear of cancer recurrence of women diagnosed with breast cancer and assist women to make informed and satisfied decisions. Additionally, this type of information needs to be 
conveyed in graduate nursing programs specifically to those specializing in oncology nursing. The need for referral to specialty centers and assigning an advocate to meet the patient's needs should be emphasized to nursing students regardless of level of program.

\section{Strengths and Limitations}

Using a mixed methods approach for this study was extremely valuable in merging data and gaining insights into how women made treatment decisions after being diagnosed with breast cancer. Merging the two research methods helped to substantiate and expound upon the Phase I survey results. The data collected from the focus group sessions and follow-up e-mails contained relevant information about the "specifics" on treatment considerations and decision making. Findings from the focus groups conveyed a clearer picture about how treatment decisions were made. This has study contributed to evidence based practice in nursing by providing nurses with research-based findings and has emphasized the importance of taking into account the patients preferences in making clinical decisions when providing caring and patient education to women diagnosed with breast cancer.

Retrospectively, data collection for this study was expedient and efficient. Data collection began in May 2010 and was completed in October 2010. Use of the internet for obtaining information from subjects dramatically reduced data collection time and having data that is readily available for analysis with few entry errors (Duffy, 2002). However, the trade-off is having a convenience sample that is not necessarily from a diverse population, as lower socioeconomic groups who may not have access or skills necessary to participate in computer-based surveys. 
A strength and limitation to this study was the homogeneity of the participants. The homogenous sample of women in this study gave insight into how treatment decisions were made, informational needs, confidence levels, satisfaction with decisions, and decision regret in this particular sample. Only participants from two sites were recruited with one site being a Midwestern plastic surgery center where these women already had made the decision to seek breast reconstruction. Likewise, the women from the breast cancer survivorship clinic also had primarily chosen reconstruction as a treatment option. Many of the participants recruited from the survivorship clinic stated they had been given ample time to consider the "what ifs" if diagnosed with cancer since most had been involved in frequent follow-up and exams because of personal or family history of breast cancer. Additionally, the sample participants were predominantly Caucasian women who were well educated and lived in a suburban area. On the whole the women in the focus group meetings appeared to be proactive about their medical care, and most stated they loved to read books and search the Internet. The participants in this study were reflective of the population. Breast cancer has a higher prevalence in Caucasian women that are more educated and have a higher socioeconomic status (Personal communication, Dr. Jennifer Klemp April 13, 2011).

Women in this study were between more than three months post treatment and less than five years post treatment. These inclusion parameters might have excluded women experiencing confidence level issues, dissatisfaction with decisions, decisional conflict, or regret because of progression of the disease, cancer recurrence, medical problems, or surgical complications experienced after treatment decisions had been made. 
Problems or complications encountered during the treatment process might be viewed as choosing the wrong treatment or making an erroneous decision.

Another limitation of this study was the potential for participant bias. It is possible that the participants in this study viewed their decisions more confidently with higher satisfaction and lower levels of conflict and regret since they are still alive and have not had a cancer recurrence. Knowing their outcome and having it be positive could contribute to satisfied feelings with the decisions that had been made. An additional question that was not asked in this study was whether or not the participants had always received care at the same clinical setting. Switching providers or treatment settings may have implied some degree of dissatisfaction and this factor was not measured in the current study.

\section{Recommendations for Future Research}

Future research needs to be conducted to explore how women make treatment decisions after being diagnosed with breast cancer. This study needs replication in a variety of settings to include a greater diversity of ethnic groups, educational levels, and geographical locations. It would be of interest to include those women still undergoing treatment to evaluate how they made treatment decisions. Including these potential participants may capture women that have been given a higher tumor stage and provide a better comprehensive understanding about the treatment options they considered. Additionally, an understanding about women experiencing treatment complications as a result of the decisions they had made would be beneficial in examining considerations that went into the decision-making process. Feelings related to decision making and the fear of death, need for hope, trust in your "gut feelings", communication patterns and 
partnerships with health care providers also needs further study in women diagnosed with breast cancer. Studying the treatment team and the impact they have on decision making in women diagnosed with breast cancer would be of value.

The use of a national website or on-line survey site e.g. the Avon/Love Army of Women dedicated to breast cancer survivors would be advantageous in collecting quantitative data from a large sample quickly and efficiently. This is especially true when utilizing multiple surveys in a study to obtain information about the decision making process. Also, conducting another study using solely a qualitative method such as a phenomenological approach would give more in-depth perceptions or possibly elicit new or different findings about how women considered treatment options when making health care decisions. Lastly, including scales that assess the fear of dying and need for hope may be helpful in evaluating the importance of this dimension in women after being diagnosed with breast cancer.

\section{Conclusions}

There has been limited research conducted on how women have made treatment decisions after being diagnosed with breast cancer. This study has aided in the acquisition of nursing knowledge by determining what areas are important in assisting women to make satisfied and informed treatment decisions. This study has contributed to research in the area of satisfaction with decisions, decision regret, and confidence levels reported by women in making health care treatment decisions after a breast cancer diagnosis. The focus group findings have supplied nursing and health care team members with valuable information about the specific needs and components necessary to assist women in treatment considerations and decision making by learning about the impact of the fear of 
death, need for hope, importance of gut feelings, and good communication between and with health care providers. The mixed methods research design complemented and confirmed the findings for each method in exploring how women have made treatment decisions after being diagnosed with breast cancer. 


\section{REFERENCES}

American Cancer Society. (2006). Breast Cancer Dictionary. [Brochure]. Author. American Cancer Society. (2009). Breast Cancer Facts \& Figures 2009-2010.

American Society of Plastic Surgeons. (2009). Are breast cancer patients being kept in the dark? Retrieved on July 7, 2009 from http://www.plasticsurgery.org/x8357.xml

Balneaves, L.G. \& Long, B. (1999). An embedded decisional model of stress and coping: Implications for exploring treatment decision making by women with breast cancer. Journal of Advanced Nursing, 30(6), 1321-1331.

Banning, M. (2007). Advanced breast cancer: aetiology, treatment and psychosocial features. British Journal of Nursing. 16, 86-90. [Brochure]. Author.

Berland, G.K., Elliott, M.N., Morales, L.S., Algazy, J.I., Kravitz, R.L., Broder, M.S., Kanouse, D.E., Munoz, J.A., Puyol, J.A., Lara, M., Watkins, K.E., Yang, H., \& McGlynn, E.A. (2001). Health information on the internet accessibility, quality, and readability in english and spanish. Journal of the American Medical Association, 285 (20), 2612-2621.

Bettencourt, B.A., Schlegel, R.J., Talley, A.E., \& Molix, L.A. (2007). The breast cancer experience of rural women: A literature review. Psycho-Oncology. 16, 875-877.

Bravata, D.M., Rastegar, A.R., \& Horwitz, R.I. (2002). How do women make decisions about hormone replacement therapy? The American Journal of Medicine. 113, 22-29.

Breastcancer.org. (2008). Retrieved on June 7, 2008 from http://www.breastcancercare.org.uk/content.php?page id=1021

Brehaut, J.C., O’Connor, A.M., Wood, T.J., Hack, T.F., Siminoff, L., Gordon, E., \& Feldman-Stewart, D. (2003). Validation of a decision regret scale. Medical Decision 
Making. 23, 281-292.

Cancer Guide. (2009). A treatment and facilities guide for patients and their families. Patient Resource Publishing. 62-68.

Career Decisions. (2009). Career Center, University of California. Retrieved on October, 16, 2009 from https://career.berkely.edu/Plan?MakeDecision.stm.

Clark, J.A., Wray, N.P., \& Ashton, C.M. (2001). Living with treatment decisions: Regrets And quality of life among men treated for metastatic prostate cancer. Journal of Clinical Oncology, 19(1), 72-80.

Collins, E.D., Moore, C.P., Clay, K.F., Kearing, S.A., O’Connor, A.M., LlewellynThomas, H.A., Barth, R.J., \& Sepucha, K.R. (2009). Can women with early-stage breast cancer make an informed decision for mastectomy? Journal of Clinical Oncology. 27(4), 519-525.

Connelly, L. (2009). Planning a Mixed Methods Study PowerPoint Presentation. University of Kans, School of Nursing. Presented on April, 28, 2009.

Cowan, C., \& Hoskins, R. (2007). Information preferences of women receiving chemotherapy for breast cancer. European Journal of Cancer Care. 16, 543-550.

Creswell, J.W. \& Clark, V.L. (2007). Designing and conducting mixed methods research. Thousand Oaks, CA: Sage.

Dolinsky, C.M., Wei, S.J., Hampshire, M.K., \& Metz J.M. (2006). Breast cancer patients' attitudes toward clinical trials in the radiation oncology clinic versus those searching for trial information on the internet. The Breast Journal. 12(4), 324-330.

Driessnack, M., Sousa, V.D., \& Costa Mendes I.A. (2007). Overview of research designs relevant to nursing: Part 3: mixed and multiple methods. Revista latino-americana de 
enfermagem. 15(5), 1046-1049.

Duffy, M.E. (2002). Methodological issues in web-based research. Journal of Nursing Scholarship, 34, 83-88.

Elo, S., \& Kyngas, H. (2008). The qualitative content analysis process. Advanced Nursing, 62(1), 107-115.

Estes, R. \& Hosseini, J. (1988). The gender gap on wall street: An empirical analysis of Confidence in investment decision making. The Journal of Psychology, 122(6), 577-590.

Fitch, M.I., Gray, R.E., Godel, R., \& Labrecque, M. (2008). Young women's experiences with breast cancer: An imperative for tailored information and support. Canadian Oncology Nursing Journal, 74-86.

Fogel, J., Albert, S.M., Schnabel, F., Ditkoff, B., \& Neugut, A.I. (2002). PsychoOncology. 12, 107-113.

Galloway, S., Graydon, J., Harrison, D., Boyden-Evans, B., Palmer-Wickham, S., Burlein-Hall, S., Rich-van der Bij, R. West, P., \& Blair, A. (1997). Informational needs of women with a recent diagnosis of breast cancer: development and initial testing of a tool. Journal of Advanced Nursing. 25, 1175-1183.

Gibbs, A. (1997). Focus groups. Social Research Update, University of Surrey, United Kingdom, 19.

Graydon, J., Galloway, S., Wickham-Palmer, S., Harrison, D., van der Bij, West, P., Hall-Burlein, S., \& Boyden-Evans, B. (1997). Information needs of women during early treatment for breast cancer. Journal of Advanced Nursing. 26, 59-64.

Green, S.B. (1991). How many subjects does it take to do a regression analysis? 
Multivariate Behavioral Research, 26(3), 499-510.

Hallenbeck, J.L. (2002). What's the story-How patients make medical decisions. American Journal of Medicine, 13(1), 73-74.

Harrison, D.E., Galloway, S., Graydon, J.E., Palmer-Wickham, S., \& Rich-van der Bij, L. (1999). Information needs and preference for information of women with breast cancer over a first course of radiation therapy. Patient Education and Counseling, 38, 217-225.

Harrow, A., Wells, M., Humphris, G., Taylor, C., \& Williams, B. (2008). Seeing is believing and believing is seeing: An exploration of the meaning and impact of women's mental images of their breast cancer and their potential origins. Patient Education and Counseling. 73, 339-346.

Healthy People 2010. 11 Communication. Retrieved on June 6, 2009 from www.healthypeople.gov/document/HTML/Volume1/11HealthCom.htm. Holmes-Rovner, M., Kroll, J., Schmitt, N., Rovner, D.R., Breer, M.L., Rothert, M., Padonu, G., \& Talarczyk, G. (1996). Patient satisfaction with health care decisions: The satisfaction with decision scale. Medical Decision Making, 16(1), 58-64.

Holtzmann, J.S., \& Timm, H. (2005). The experiences of and the nursing care for breast cancer patients undergoing immediate reconstruction. European Journal of Cancer Care. 14, 310-318.

Horan, J.J. (1977). Current topics in decision making. Counseling for Effective Decision Making. Retrieved from horan.asu.edu/cfedm/chapter5.php on June 16, 2009.

Janis, I.L., \& Mann, L. (1977). Decision making a psychological analysis of conflict, choice, and commitment. New York: Macmillian Publishing Co. 
Jones, N.I., Aslett, I.A., Richardson, A., Tookman, A., Mason, C., \& King, M. (2007). Perceived concepts of continuity of care in people with colorectal and breast cancer: A qualitative case study analysis. European Journal of Cancer Care. 17, 569-577.

Karliner, L.S., Springer-Napoles, A., Kerlikowske, K., Haas, J.S., Gregorich, S.E., \& Kaplan, C.P. (2006). Misses opportunities: Family history and behavioral risk factors in breast cancer risk assessment among a multiethnic group of women. Journal of General Internal Medicine. 308-314.

Kopala, B. \& Burkhart, L. (2005). Ethical dilemma and moral distress: Proposed new nanda diagnoses. International Journal of Nursing Terminologies and Classifications. $16(1), 3-13$.

Lauersen, N.H. \& Stukane, E. (1998). The complete book of breast care. New York: Fawcett Columbine.

LeBlanc, A., Kenny, D.A., O’Connor, A.M., \& Legate, F. (2009). Decisional conflict in patients and their physicians: A dyadic approach to share decision-making. Medical Decision Making. Retrieved on May 31, 2009 from http://mdm.sagepub.com.

Lincoln, Y.S., \& Guba, E. G. (1985). Naturalistic inquiry. Beverly Hills, CA: Sage.

Lindop, E.L. \& Cannon, S. (2001). Evaluating the self-assessed support needs of women with breast cancer. Journal of Advanced Nursing, 34(6), 760-771.

Loiselle, C.G., \& Dubois, S. (2009). The impact of a multimedia informational intervention on healthcare service use among women and men newly diagnosed with cancer. Cancer Nursing, 32(1), 37-44.

Mangerich, B. \& Stichler, J.F. (2008). Breast and ovarian cancer. A new model for education women. Nursing for Women's Health. 490-499. 
Manuel, J.C., Burwell, S.R., Crawford, S.L., Lawrence, R.H., Farmer, D.F., Hege, A., Phillips, K., Avis, N.E. (2007). Younger women's perceptions of coping with breast cancer. Cancer Nursing, 30(2), 85-94.

Meraviglia, M. (2006). Effects of spirituality in breast cancer survivors. Oncology Nursing Forum, 33(1), E1-7.

Metro Outlook Live. (2009). The Kansas City Area's Demographics. The Mid-America Regional Council. Retrieved from www.metrooutlook.org/ on June 13, 2009.

National Cancer Institute. U.S. National Institutes of Health (2006). Cancer survivor research, Office of cancer survivorship. Retrieved on October 30, 2009 from www.cancer.org.

National Cancer Institute (2009). Spirituality in cancer care health professional version. Retrieved on September 6, 2009 from www.nci.nih.gov/cancertopics/pdq/.../spirituality/.../page6/print

O’Brien, M., Whelan, T.J., Charles, C., Ellis, P.M., Gafni, A., Lovrics, P., Hasler, A., \& Dimitry, S. (2008). Women's perceptions of their treatment decision-making about breast cancer treatment. Patient education and Counseling. 73, 431-436.

O’Connor, A. (1993). User-manual decisional conflict scale. Retrieved on June 4, 2009 from www.ohri.ca/decisionaid.

Owen, J.E., Klapow, J.C., Roth, D.L., Nabell, L., \& Tucker, D.C. (2004). Improving the effectiveness of adjuvant psychological treatment for women with breast cancer: The feasibility of providing online support. Psycho-Oncology, 13, 281-292.

Patton, M.Q. (2002). Qualitative Research \& Evaluation Methods $3^{\text {rd }}$ ed. Sage Publications. Thousand Oaks: CA. 
Pellise, F. \& Sell, P. (2009). Patient information and education with modern media: The spine society of Europe patient line. European Spine Journal. 119-129.

Ravdin, P.M., Siminoff, L.A., Davis, G.J., Mercer, M., Hewlett, J., Gerson, N., \& Parker H.L. (2001). Computer program to assist in making decisions about adjuvant therapy for women with early breast cancer. Journal of Clinical Oncology, 19(4), 980-991

Reaby, L. (1998, a). Breast restoration decision making: Enhancing the process. Cancer Nursing. 21(3), 196-204.

Reaby, L. (1998, b). The quality and coping patterns of women's decision-making regarding breast cancer surgery. Psycho-Oncology. 7, 252-262.

Redman, B. (2003). Measurement Tools in Patient Education. $2^{\text {nd }}$ ed. New York: Springer Publishing Co.

Rennekamp, R. A., \& Nall, M.A. (2009). Using focus groups in program development and evaluation. University of Kentucky College of Agriculture. Retrieved on October 19, 2009 from www.ca.uky.edu/AgPSD/Focus.pdf.

Ruland, C.M., Jeneson, A., Andersen, T., Andersen, R., Slaughter, L., Osmo, B.S., \& Moore, S.M. (2007). Designing tailored internet support to assist cancer patients in illness management. American Medical Informatics Association. 635-639.

SPSS, (2007). Graduate Pack 16.0 for Windows. Chicago: Il.

Sandelowski, M. (2000). Whatever happened to qualitative description? Research in Nursing \& Health, 23, 334-340.

Satterlund, M.J., McCaul, K.D., \& Sandgren, A.K. (2003). Information gathering over time by breast cancer patients. Journal of Medical Internet Research, 5(3), 1-8.

Sepucha, K.R., Belkora, J.K., Mutchnick, S., \& Esserman, L.J. (2002). Consultation 
Planning to help breast cancer patients prepare for medical consultations: Effect on communication and satisfaction for patients and physicians. Journal of Clinical Oncology. 20(11), 2695-2700.

Sepucha, K.R., Belkora, J.K., Aviv, C., Mutchnick, S., \& Esserman, L.J. (2003). Improving the quality of decision making in breast cancer: Consultation planning template and consultation recording template. Oncology Nursing Forum. 30(1), 99106.

Shon, J., \& Musen, M.A. (1999). The low availability of metadata elements for Evaluating the quality of medical information on the world wide web. American Medical Informatics Association. 945-949.

Spittler, C. (2008). Breast reconstruction using tissue expanders: Assessing patient needs utilizing a holistic approach. Plastic Surgical Nursing. 28(1), 27-32.

Templeton, H. R.M., \& Coates, V.E. (2001). Adaption of an instrument to measure the Informational needs of men with prostate cancer. Journal of Advanced Nursing, 35(3), $357-364$.

Throckmorton, A.D. (2008). When informed all women do not prefer breast conservation. Journal of Clinical Oncology. 27(4), 484-486.

University of Kansas Cancer Center. Breast Cancer Survivorship Center. Retrieved from www.kumc.edu/bcsc/.

U.S. Department of Health and Human Services. (2004). Surgery Choices For Women with Early-Stage Breast Cancer.

van de Poll-Franse, L. \& van Eenbergen, M. (2008). Internet use by cancer survivors: current use and future wishes. Support Care Cancer. 16, 1189-1195. 
van Dijk, van Roosmalen, M.S., Otten, W., Stalmeier, P.F. (2008). Decision making regarding prophylactic mastectomy: Stability of preferences and the impact of anticipated feelings of regret. Journal of Clinical Oncology, 26(4), 2358-2363.

Waljee, J.F., Hu, E.S., Newman, L.A., Alderman, A.K. (2008). Correlates of patient satisfaction and provider trust after breast-conserving surgery. Cancer, 112(8), 16791687.

Webb, C. \& Koch, T. (1997). Women's experiences of non-invasive breast cancer: literature review and study report. Journal of Advanced Nursing, 25, 514-525.

Welch, M. (2008). Breast reconstruction: Restoring self-esteem and femininity. The University of Toledo Medical Center. Retrieved on September 6, 2009 from www.utmatters.com/archive uhm.php?article $=77$

Wills, C.E., \& Holmes-Rovner, M. (2003). Preliminary validation of the satisfaction scale with depressed primary care patients. Health Expectations, 6, 149-159.

Wujcik, D.M. (2008). Oncology nurses are key to ensuring that patients' decision making is truly informed. Oncology Nursing Science. (9), 5.

Yi, M., Kim, J., Noh, D., Lee, J., Yoo, K., Hwang, K., \& Chung, H. (2008). Evaluation of the satisfaction and usefulness of a web-based educational program for breast cancer patients. The Open Medical Informatics Journal. 2, 129-137.

Youngblut, J.M., \& Casper, G.R. (1993). Single-item indicators in nursing research. Research in Nursing \& Health, 16 (6), 459-465.

Zuckerman, D. (2009). Mastectomy v. lumpectomy: Who decides? National Research Center for Women \& Families. Retrieved on June 16, 2009 from www.center4research.org/sitemap.htm. 
APPENDICES 


\title{
Appendix A
}

\section{BREAST CANCER WEBSITES}

\author{
http://www/stopbreastcancer.org. (National Breast Cancer Coalition) \\ http://www.cancer.org. (American Cancer Society) \\ http://www.wcn.org. (Women's Cancer Network) \\ http://www.webmd.com (Web MD) \\ http://www.cancernet.nci.nih.gov (National Cancer Institute) \\ http://www.acor.org (Association of Cancer Online Resources) \\ http://www.rxlist.com (The Internet Drug Index) \\ http://www.oncolink.upenn.edu (OncoLink) \\ http://www.komen.org (Susan G. Komen Breast Cancer Foundation) \\ http://www.blochcancer.org (Bloch Cancer Center) \\ http://www.mayo.edu (Mayo Clinic) \\ http://clinicaltrials.gov (Clinical Trials Information) \\ http://www.cancercare.org/types/breast/index.asp (Cancercare-Breast) \\ http://www.cancerweb.ncl.ac.uk.omd (Online Medical Dictionary) \\ http://www.sistersnetworkinc.org (African-American Breast Cancer Survivor Group) \\ http://www.y-me.org (Y-Me National Breast Cancer Organization) \\ http://www/sgo.org (Society of Gynecologic Oncologists) \\ http://www.butterflydreams.com/ (Butterfly Dreams- Clothing, Beauty, Support)
}


(TINQ-BC)

\section{Breast Cancer Assessment Survey}

\section{Decision Scale 1}

1. I am interested in learning about the types of information women with breast cancer need. Please read each of the following sentences and check the circle that best describes how important it was for you to have this information.

It was important for me to know:

\begin{tabular}{|c|c|c|c|c|c|}
\hline & $\begin{array}{c}\text { Not } \\
\text { important }\end{array}$ & $\begin{array}{c}\text { Slightly } \\
\text { Important }\end{array}$ & $\begin{array}{l}\text { Moderately } \\
\text { Important }\end{array}$ & $\begin{array}{c}\text { Very } \\
\text { Important }\end{array}$ & $\begin{array}{l}\text { Extremely } \\
\text { Important }\end{array}$ \\
\hline $\begin{array}{l}\text { How I will feel during the } \\
\text { tests (e.g., x-ray, bone scan }\end{array}$ & & & & & \\
\hline $\begin{array}{l}\text { If the breast cancer will } \\
\text { come back }\end{array}$ & & & & & \\
\hline $\begin{array}{l}\text { How to prepare for my } \\
\text { treatment }\end{array}$ & & & & & \\
\hline When to examine my breas & & & & & \\
\hline $\begin{array}{l}\text { How I will feel after my } \\
\text { treatment }\end{array}$ & & & & & \\
\hline $\begin{array}{l}\text { Who I should call if I have } \\
\text { questions while I am still } \\
\text { getting treatment }\end{array}$ & & & & & \\
\hline $\begin{array}{l}\text { How breast cancer acts in th } \\
\text { body }\end{array}$ & & & & & \\
\hline $\begin{array}{l}\text { If there are groups where I } \\
\text { can talk with other people } \\
\text { with cancer }\end{array}$ & & & & & \\
\hline $\begin{array}{l}\text { If there are ways to prevent } \\
\text { treatment side effects }\end{array}$ & & & & & \\
\hline $\begin{array}{l}\text { How the illness may affect } \\
\text { my life over the next few } \\
\text { months }\end{array}$ & & & & & \\
\hline
\end{tabular}




\begin{tabular}{|l|c|c|c|c|c|}
\hline & $\begin{array}{c}\text { Not } \\
\text { important }\end{array}$ & $\begin{array}{c}\text { Slightly } \\
\text { Important }\end{array}$ & $\begin{array}{c}\text { Moderately } \\
\text { Important }\end{array}$ & $\begin{array}{c}\text { Very } \\
\text { Important }\end{array}$ & $\begin{array}{c}\text { Extremely } \\
\text { Important }\end{array}$ \\
\hline $\begin{array}{l}\text { If there will be changes in } \\
\text { the usual things I can do with } \\
\text { and for my family }\end{array}$ & - & & & & \\
\hline $\begin{array}{l}\text { If there is cancer anywhere } \\
\text { else in my body }\end{array}$ & - & - & & & \\
\hline $\begin{array}{l}\text { Who should I call if I have } \\
\text { questions after all the } \\
\text { treatments are over }\end{array}$ & $\bigcirc$ & $\bigcirc$ & & & \\
\hline
\end{tabular}

2. I am interested in learning about the types of information women with breast cancer need. Please read each of the following sentences and check the circle that best describes how important it was for you to have this information. (continue)

It was important for me to know:

\begin{tabular}{|c|c|c|c|c|c|}
\hline & $\begin{array}{c}\text { Not } \\
\text { Important }\end{array}$ & $\begin{array}{c}\text { Slightly } \\
\text { Important }\end{array}$ & $\begin{array}{l}\text { Moderately } \\
\text { Important }\end{array}$ & $\begin{array}{c}\text { Very } \\
\text { Important }\end{array}$ & $\begin{array}{l}\text { Extremely } \\
\text { Important }\end{array}$ \\
\hline $\begin{array}{l}\text { If it is known what causes } \\
\text { breast cancer }\end{array}$ & & & & & \\
\hline $\begin{array}{l}\text { How the tests (e.g., x-rays, } \\
\text { bone scans) are done }\end{array}$ & & & & & \\
\hline $\begin{array}{l}\text { Whey they need to test by } \\
\text { blood }\end{array}$ & & & & & \\
\hline $\begin{array}{l}\text { Who to talk with if I hear about } \\
\text { treatments other than surgery } \\
\text { radiations, or chemotherapy }\end{array}$ & & & & & \\
\hline $\begin{array}{l}\text { How the illness may affect my } \\
\text { life in the future }\end{array}$ & & & & & \\
\hline $\begin{array}{l}\text { What the results of my blood } \\
\text { tests mean }\end{array}$ & & & & & \\
\hline $\begin{array}{l}\text { Where my family can go if } \\
\text { they need help dealing with my } \\
\text { illness }\end{array}$ & & & & & \\
\hline $\begin{array}{l}\text { How to care for my wound or } \\
\text { incision }\end{array}$ & & & & & \\
\hline
\end{tabular}




\begin{tabular}{|c|c|c|c|c|c|}
\hline & $\begin{array}{c}\text { Not } \\
\text { Important }\end{array}$ & $\begin{array}{l}\text { Slightly } \\
\text { Important }\end{array}$ & $\begin{array}{l}\text { Moderately } \\
\text { Important }\end{array}$ & $\begin{array}{c}\text { Very } \\
\text { Important }\end{array}$ & $\begin{array}{l}\text { Extremely } \\
\text { Important }\end{array}$ \\
\hline $\begin{array}{l}\text { What to do if I become } \\
\text { concerned about dying }\end{array}$ & & & & & \\
\hline $\begin{array}{l}\text { If I can continue my usual } \\
\text { hobbies and sports }\end{array}$ & & & & & \\
\hline If I can wear a brassiere & & & & & \\
\hline $\begin{array}{l}\text { Where I can get help to deal } \\
\text { with my feelings about my } \\
\text { illness }\end{array}$ & & & & & \\
\hline $\begin{array}{l}\text { How to talk to family/friends } \\
\text { about my illness }\end{array}$ & & & & & \\
\hline $\begin{array}{l}\text { If I have side effects, how to } \\
\text { deal with them }\end{array}$ & & & & & \\
\hline $\begin{array}{l}\text { The possible side effects of my } \\
\text { treatment }\end{array}$ & & & & & \\
\hline $\begin{array}{l}\text { What side effects I should } \\
\text { report to the doctor/nurse }\end{array}$ & & & & & \\
\hline
\end{tabular}

3. I am interested in learning about the types of information women with breast cancer need. Please read each of the following sentences and check the circle that best describes how important it was for you to have this information. (continue)

It was important for me to know:

\begin{tabular}{|l|c|c|c|c|c|}
\hline & $\begin{array}{c}\text { Not } \\
\text { Important }\end{array}$ & $\begin{array}{c}\text { Slightly } \\
\text { Important }\end{array}$ & $\begin{array}{c}\text { Moderately } \\
\text { Important }\end{array}$ & $\begin{array}{c}\text { Very } \\
\text { Important }\end{array}$ & $\begin{array}{c}\text { Extremely } \\
\text { Important }\end{array}$ \\
\hline $\begin{array}{l}\text { If I am prone to infection } \\
\text { because of my treatment }\end{array}$ & $\bigcirc$ & & & \\
\hline $\begin{array}{l}\text { How long my wound/incision } \\
\text { will take to heal }\end{array}$ & $\bigcirc$ & $\bigcirc$ & & & \\
\hline $\begin{array}{l}\text { How long I will be receiving } \\
\text { treatment }\end{array}$ & $\bigcirc$ & $\bigcirc$ & & & \\
\hline $\begin{array}{l}\text { How I will feel after the tests } \\
\text { (e.g., x-rays, bone scans) }\end{array}$ & $\bigcirc$ & $\bigcirc$ & $\bigcirc$ & & $\bigcirc$ \\
\hline
\end{tabular}




\begin{tabular}{|c|c|c|c|c|c|}
\hline & $\begin{array}{c}\text { Not } \\
\text { Important }\end{array}$ & $\begin{array}{l}\text { Slightly } \\
\text { Important }\end{array}$ & $\begin{array}{l}\text { Moderately } \\
\text { Important }\end{array}$ & $\begin{array}{c}\text { Very } \\
\text { Important }\end{array}$ & $\begin{array}{l}\text { Extremely } \\
\text { Important }\end{array}$ \\
\hline $\begin{array}{l}\text { Where can I get help if I have } \\
\text { problems feeling as attractive } \\
\text { as I did before }\end{array}$ & & & & & \\
\hline $\begin{array}{l}\text { How the treatment works } \\
\text { against cancer }\end{array}$ & & & & & \\
\hline $\begin{array}{l}\text { If there are special arm } \\
\text { exercises to do }\end{array}$ & & & & & \\
\hline $\begin{array}{l}\text { The medical name for my type } \\
\text { off breast cancer }\end{array}$ & & & & & \\
\hline $\begin{array}{l}\text { If there are any physical } \\
\text { things I should not do }\end{array}$ & & & & & \\
\hline $\begin{array}{l}\text { If I'm going to need help } \\
\text { taking care of myself }\end{array}$ & & & & & \\
\hline How my treatment is done & & & & & \\
\hline $\begin{array}{l}\text { If the treatment will alter the } \\
\text { way I look }\end{array}$ & & & & & \\
\hline $\begin{array}{l}\text { How to tell if the cancer has } \\
\text { come back }\end{array}$ & & & & & \\
\hline $\begin{array}{l}\text { Which foods I can or cannot } \\
\text { eat }\end{array}$ & & & & & \\
\hline If I can take a bath or shower & & & & & \\
\hline $\begin{array}{l}\text { What types of treatment are } \\
\text { available }\end{array}$ & & & & & \\
\hline $\begin{array}{l}\text { Why the doctor suggested this } \\
\text { treatment plan for me }\end{array}$ & & & & & \\
\hline $\begin{array}{l}\text { The reasons my doctor } \\
\text { suggest certain tests (e.g., } \mathrm{x} \text { - }\end{array}$ & & & & & \\
\hline
\end{tabular}




\begin{tabular}{|c|c|c|c|c|c|c|}
\hline & & $\begin{array}{c}\text { Not } \\
\text { Important }\end{array}$ & $\begin{array}{c}\text { Slightly } \\
\text { Important }\end{array}$ & $\begin{array}{l}\text { Moderately } \\
\text { Important }\end{array}$ & $\begin{array}{c}\text { Very } \\
\text { Important }\end{array}$ & $\begin{array}{l}\text { Extremely } \\
\text { Important }\end{array}$ \\
\hline \multicolumn{7}{|c|}{ rays, bone scans) } \\
\hline \multicolumn{7}{|c|}{$\begin{array}{l}\text { How to prepare for the tests } \\
\text { (e.g., x-rays, bone scans) }\end{array}$} \\
\hline $\begin{array}{l}\text { What to do if I } \\
\text { uncomfortable } \\
\text { situations }\end{array}$ & social & & & & & \\
\hline \multicolumn{7}{|c|}{ If my illness is hereditary } \\
\hline \multicolumn{7}{|c|}{ When to have a mammogram } \\
\hline $\begin{array}{l}\text { If I can contin } \\
\text { social activitie }\end{array}$ & my usual & & & & & \\
\hline (bioffen) & (bioffen) & (bioffen) & (bioffen, & (bioffen) & & \\
\hline
\end{tabular}

Conduct your own online surveys University of Kansas Medical Center I Please contact Customer Support at 913-588-7995 if you have any problems using this survey.

\section{Appendix C}




\section{Breast Cancer Assessment Survey}

\section{Decision Scale 2}

1. Please indicate how strongly you agree or disagree to the following statements about the decisions you made after being diagnosed with breast cancer. Please check a circle from:

$\mathbf{1}=$ strongly agree to

$\mathbf{5}=$ strongly disagree as to how you felt about the choice.

\begin{tabular}{|c|c|c|c|c|c|}
\hline & $\begin{array}{l}\text { Strongly } \\
\text { Agree }\end{array}$ & Agree & $\begin{array}{l}\text { Neither Agree or } \\
\text { Disagree }\end{array}$ & Disagree & $\begin{array}{l}\text { Strongly } \\
\text { Disagree }\end{array}$ \\
\hline This decision is easy for me to make & & & & & \\
\hline I'm sure what to do in this decision & & & & & \\
\hline It's clear what choice is best for me & & & & & \\
\hline $\begin{array}{l}\text { I'm aware of the options I have in this } \\
\text { decision }\end{array}$ & & & & & \\
\hline I feel I know the pros of each option & & & & & \\
\hline I feel I know the cons of each option & & & & & \\
\hline $\begin{array}{l}\text { I am clear about how important the } \\
\text { pros are to me in this decision }\end{array}$ & & & & & \\
\hline $\begin{array}{l}\text { I am clear about how important the } \\
\text { cons are to me in this decision }\end{array}$ & & & & & \\
\hline $\begin{array}{l}\text { I am clear about which is more } \\
\text { important to me (the pros or the cons) }\end{array}$ & & & & & \\
\hline $\begin{array}{l}\text { I am making this choice without any } \\
\text { pressure from others }\end{array}$ & & & & & \\
\hline $\begin{array}{l}\text { I have the right amount of support } \\
\text { from others in making this choice }\end{array}$ & & & & & \\
\hline $\begin{array}{l}\text { I have enough advice about the } \\
\text { options }\end{array}$ & & & & & \\
\hline
\end{tabular}




\begin{tabular}{|c|c|c|c|c|c|}
\hline & $\begin{array}{l}\text { Strongly } \\
\text { Agree }\end{array}$ & Agree & $\begin{array}{l}\text { Neither Agree or } \\
\text { Disagree }\end{array}$ & Disagree & $\begin{array}{l}\text { Strongly } \\
\text { Disagree }\end{array}$ \\
\hline I feel I have made an informed & & & & & \\
\hline $\begin{array}{l}\text { My decision shows what is imp } \\
\text { to me }\end{array}$ & & & & & \\
\hline I expect to stick with my decisic & & & & & \\
\hline I am satisfied with my decision & & & & & \\
\hline
\end{tabular}

\begin{tabular}{|c|c|c|c|c|}
\hline (briffen) & (biofuten, & (hrifufen) & (biufung) & (hriften) \\
\hline
\end{tabular}

Powered by Vovici: Publish your own web survey today University of Kansas Medical Center I Please contact Customer Support at 913-588-7995 if you have any problems using this survey.

Used with permission from Dr. Annette O’Connor.

O’Connor, A. (1993). User-manual decisional conflict scale. Retrieved on June 4, 2009 from www.ohri.ca/decisionaid.

Appendix D

CONFIDENCE IN DECISION SCALE

\section{Breast Cancer Assessment Survey}




\section{Decision Scale 3}

1. Please rate your confidence in the decisions you made about treatment options after being diagnosed with breast cancer.

The scale is $\mathbf{0}$ to $\mathbf{1 0}$ :

0 indicating no confidence at all and

10 indicating complete confidence.

Check the circle (number) that corresponds to your confidence level.
$\bigcirc_{0} \bigcirc 1$
$\mathrm{O}_{2}$
$\bigcirc_{3} \bigcirc_{4}$
${ }_{4} \bigcirc_{5} \bigcirc_{6}$
${ }_{7}$
$\mathrm{O}_{8}$
$\bigcirc_{9} \bigcirc 10$

\begin{tabular}{|c|c|c|c|c|}
\hline (bifufon) & (briffen) & (briffan) & (hrifun & (briffan) \\
\hline
\end{tabular}

Powered by Vovici: Conduct your own online surveys University of Kansas Medical Center I Please contact Customer Support at 913-588-7995 if you have any problems using this survey.

Appendix E

SATISFACTION WITH DECISION INSTRUMENT 


\section{Breast Cancer Assessment Survey}

\section{Decision Scale 4}

1. You have made a decision about treatment options after the diagnosis of breast cancer. Please answer the following questions about your decision. Indicate how true the statement is for you AT THIS TIME. Use the following scale to answer the questions.

\begin{tabular}{|c|c|c|c|c|c|c|}
\hline & & $\begin{array}{l}\text { Strongly } \\
\text { Disagree }\end{array}$ & Disagree & $\begin{array}{l}\text { Neither Agree } \\
\text { nor Disagree }\end{array}$ & Agree & $\begin{array}{l}\text { Strongly } \\
\text { Agree }\end{array}$ \\
\hline \multicolumn{7}{|c|}{$\begin{array}{l}\text { I am satisfied that I am adequately } \\
\text { informed about the issues important to } \\
\text { my decision }\end{array}$} \\
\hline \multicolumn{7}{|c|}{$\begin{array}{l}\text { The decision I made was the best } \\
\text { decision possible for me personally }\end{array}$} \\
\hline \multicolumn{7}{|c|}{$\begin{array}{l}\text { I am satisfied that my decision was } \\
\text { consistent with my personal values }\end{array}$} \\
\hline \multicolumn{7}{|c|}{$\begin{array}{l}\text { I expect to successfully carry out or } \\
\text { continue to carry out the decision I } \\
\text { made }\end{array}$} \\
\hline \multicolumn{7}{|c|}{$\begin{array}{l}\text { I am satisfied that this was my decision } \\
\text { to make }\end{array}$} \\
\hline \multicolumn{7}{|c|}{ I am satisfied with my decision } \\
\hline (hisuten, & (hisuten, & \multicolumn{2}{|c|}{$\langle$ histan } & $\langle$ hidusen $\rangle$ & & \\
\hline
\end{tabular}

Conduct your own online surveys

University of Kansas Medical Center I Please contact Customer Support at 913-588-7995 if you have any problems using this survey.

\section{Appendix F}

\section{DECISION REGRET SCALE}




\section{Breast Cancer Assessment Survey}

\section{Decision Scale 5}

1. Please think about the first decision you made about treatment options after the diagnosis of breast cancer. Please indicate how strongly you agree or disagree with the following statements by checking the circling/number: 1 (strongly agree) to $\mathbf{5}$ strongly disagree in regards to your views about your decision.

\begin{tabular}{|c|c|c|c|c|c|}
\hline & $\begin{array}{l}\text { Strongly } \\
\text { Agree }\end{array}$ & Agree & $\begin{array}{c}\text { Neither Agree or } \\
\text { Disagree }\end{array}$ & Disagree & $\begin{array}{l}\text { Strongly } \\
\text { Disagree }\end{array}$ \\
\hline It was the right decision & & & & & \\
\hline I regret the choice that was $n$ & & & & & \\
\hline $\begin{array}{l}\text { I would go for the same choi } \\
\text { had to do it over again }\end{array}$ & & & & & \\
\hline The choice did me a lot of ha & & & & & \\
\hline The decision was a wise one & & & & & \\
\hline
\end{tabular}

Thank you again for taking the time to complete the questionnaires.

If you have any questions or concerns, please contact me:

Cheryl Spittler

913-449-9321 c

cspittler@kumc.edu

To complete the process, please click on the "Submit Survey" button.

\begin{tabular}{|c|c|c|c|c|}
\hline (hriffen, & (briffen) & (briffen) & (biofunen & (bifufen, \\
\hline
\end{tabular}

\section{Submit Survey}

Powered by Vovici survey software

University of Kansas Medical Center I Please contact Customer Support at 913-588-7995 if you have any problems using this survey.

Used with permission from Dr. Annette O’Connor. 
Brehaut, J.C., O’Connor, A.M., Wood, T.J., Hack, T.F., Siminoff, L., Gordon, E., \& Feldman-Stewart, D. (2003). Validation of a decision regret scale. Medical Decision Making. 23, 281-292.

Appendix G University of Kansas Medical Center 


\section{Breast Cancer Survivors Wanted for a Research Study on:}

\section{Exploring How Women Make Treatment Decisions After a Breast Cancer Diagnosis}

The purpose of this study is to assess information needs women have after being diagnosed with this disease, investigate how decisions about treatment options are made, and assess the personal responses to the decisions made. As a doctoral nursing student at the University of Kansas Medical Center, I am interested in learning how women diagnosed with breast cancer have made decisions about treatment options. I hope to provide healthcare providers with information needed to help women make informed and satisfied decisions after receiving a breast cancer diagnosis.

\section{Eligibility criteria includes:}

- Breast cancer survivor who has completed any type of treatment procedure such as chemotherapy, radiation, and any type of surgical procedure for at least 3 months and less than 5 years. If you are on anti-hormonal therapy: tamoxifen (Novaldex), raloxifene (Evista), anastrozole (Arimidex), exemestane (Aromasin), letrozole (Femara), you are eligible to participate in this study.

- Age 18 or older

- Have access to a computer, be able to perform simple computer functions and complete five questionnaires

- Be able to read, write, and speak English

Participation in the study includes:

- Completing a Participant Information Form on the computer (5 minutes)

- Completing 5 decision questionnaires on the computer (25 minutes)

- Possibly be selected to participate in a focus group at the breast cancer survivorship clinic session lasting 90-120 minutes

If you are interested in participating in this research study or have further questions please contact me: 
Cheryl Spittler RN, MSN, CEN, CPSN

913-449-9321

cspittler@kumc.edu

APPENDIX H

PARTICIPANT INFORMATION FORM 


\section{Breast Cancer Assessment Survey}

Please answer the following questions. Your answers to the questions will be kept confidential. Only the researcher will have access to this information.

Please fill in the blank the answer that applies to you.

1. What is your Name?

First Name

Last Name

2. What is your full address?

Street

City

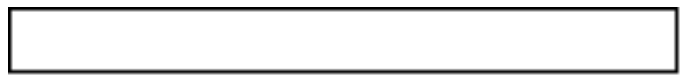

State

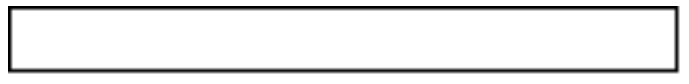

Zip

3. What is your e-mail address?

e-mail address

4. What is your ethnic origin/race?

Caucasian

African-American

Hispanic

Asian

Other: please

describe

5. What was your marital status at the time of your diagnosis?

Single

Married 
Widowed

Divorced

6. What is your marital status now?

Single

Married

Widowed

Divorced

7. What is the highest level of education you have completed?

High School

Associates Degree

Some College

Bachelors Degree

Some Graduate level

Masters Degree

Higher level

8. What is your employment status?

Unemployed

Part-time

Full-time

Retired

9. Describe your living location?

Urban

Suburban

Rural

Other: please

describe

10. What was your Menstrual Status at the time of your diagnosis?

Pre-Menopausal

Post-Menopausal

11. What is your Menstrual Status now?

Pre-Menopausal

Post-Menopausal 
12. Do you have a First-Degree Relative with cancer (Mother, Daughter, Sister)?

Yes

\section{No}

13. What was your tumor stage at the time of diagnosis?

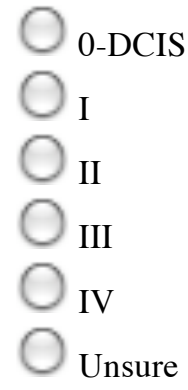

14. What is your tumor stage now?

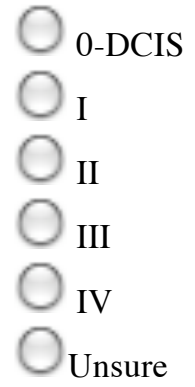

15. How many months since your breast cancer diagnosis?

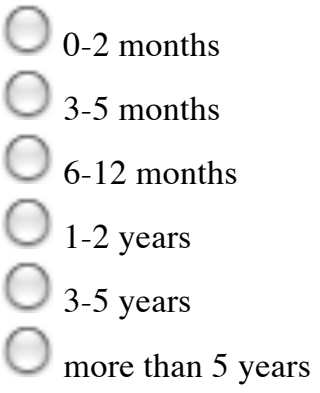

16. Please indicate all the treatments you have chosen? (check all that apply)

\section{Lumpectomy}

Mastectomy

Reconstruction

Tissue expanders

TRAM flap

Lattissmus dorsi flap 
Preventive mastectomy

Radiation

Chemotherapy

Hormonal Therapy

Other Therapies: please

describe

17. Are you currently disease free?

Yes

No

18. Are you currently being treated for active cancer?

Yes

No

19. Did you have any complications from any of your treatments? (check all that apply)

Infection

Bleeding

Scarring

Need for hospitalization

Unexpected surgery

Other: please

describe

20. What is your preferred learning style when receiving medical advice and information?

Know all possible options

Just need to know what is the best possible option for me

Somewhere between the 2 options above

21. Did you use the Internet to obtain information about treatment options?

Yes: please list sites (American Cancer Society, Komen Foundation, Breastcancer.org, General Google search, other)

No

22. Did the Internet information affect the treatment decisions you made? 
Yes

No

Didn't use Internet

\begin{tabular}{|c|c|c|c|}
\hline (bidten) & (bituten, & (bioften, & (bidtan) \\
\hline
\end{tabular}

Next Save

Conduct your own online surveys

University of Kansas Medical Center I Please contact Customer Support at 913-588-7995 if you have any problems using this survey. 


\section{Breast Cancer Assessment Survey}

Thank you for agreeing to participate in the "Exploration of How Women Make Treatment Decisions After A Breast Cancer Diagnosis" study.

Included in this link are the Participant Information Form, Consent Form, and five questionnaires.

Participation in the study is voluntary. I do need your consent to participate so please read the consent form and enter your name if you agree and are willing to take part in the study. It is anticipated that it will take you approximately 30 minutes to complete the packet. Please complete the whole survey once you begin the process.

1. The Participant Information Form provides me with some background information about you.

\section{The Consent Form}

\section{Five Questionnaires}

3.1 The Decision Scale \#1 is a 52-item questionnaire (TINQ-BC). Please check the item that best pertains to you. (takes about 15 minutes to complete)

3.2 The Decision Scale 2 is a 16-item survey (DCS). Please check the number that best represents your feelings. (takes about 5 minutes to complete)

3.3 The Decision Scale 3 is a one-item question that asks you to rate your confidence level in the decisions you have made about treatment options (Confidence). (takes less than one minute to complete)

3.4 The Decision Scale 4 is six-item questionnaire (SWD). Please check the value that best describes your feelings about the treatment decisions you have made. (takes less than one minute to complete)

3.5 The Decision Scale 5 is five-item survey (DRS). Please check the number that best explains your thoughts. (takes less than one minute to complete)

Thanks again for your willingness to participate in the study. If you have any questions please do not hesitate to call or e-mail me. I appreciate your time and attention.

Sincerely,

Cheryl Spittler, RN, PhD (c)

913-449-9321

cspittler@kumc.edu 


\section{Appendix J}

\section{QUALITATIVE INTERVIEW GUIDE}

\section{Grand Tour Questions:}

1. Tell me about the first things or questions that came to your mind after the diagnosis of breast cancer and the treatment options presented to you.

2. Who gave you your treatment options?

3. What range of treatment options were given to you?

\section{Main Questions:}

1. What type of information did you need to make an informed decision about surgical choices?

2. Were you satisfied with the explanation of risks and benefits of treatment options?

3. Did you feel you had the adequate amount of information to make an informed decision and were you able to comprehend the information given to you?

4. How much time did you have to make a decision about treatment options?

5. Who was involved in helping you make the decisions after being diagnosed with breast cancer?

6. Describe to me how you made your decision about treatment choices.

7. What types of personal feelings or values do you have that may have affected the decision you made?

8. What role did you want your treatment team to play in helping you make treatment decisions?

9. What information did you want the treatment team to give you to help you make medical decisions about the treatment options you chose?

\section{Probes:}

1. What type of information were you not given that you would identify as helpful in making an informed decision?

2. Who would you identify as your support systems?

3. Did you feel you had adequate support from your significant others or close friends?

4. What types of personal feelings or values do you have that affected the decision you made? 
5. Did you use the Internet, chat rooms, or other types of on-line sources to aid in your decision making?

6. Did you consider body image, sexuality, reproduction, and reconstruction as important issues when you made decisions about treatment options?

\section{Ending:}

1. Is there anything else I have not asked that you think would be beneficial for women to know after being diagnosed with breast cancer?

- Questions may be adjusted after the initial analysis the quantitative data. 


\section{Appendix K}

\section{Focus Group Follow-up E-mail}

\section{Dear}

I want to thank you again for participating in the focus group meetings. Now I am writing to ask your assistance in helping me clarify the findings from the focus group sessions. Could you please elaborate on the following questions for me? I want to capture "how" you made decisions and what considerations went your decisions. If you don't feel comfortable answering any of the questions then just leave them blank. Not responding to this request will be taken, as you do not want to participate in this additional step. Thanks for your time and help and I wish you the best. If you have any questions don't hesitate to e-mail or call me.

Thanks again!

Cheryl A. Spittler R.N., MSN, CEN, CPSN

cspittler@kumc.edu

$913-449-9321$

Focus Group Follow-up Questions

Please think about the time from when you were told you had breast cancer until the time your treatment decisions were made to answer the following questions.

1. How did your initial medical consultation experience after being diagnosed with breast cancer impact how you made your treatment decisions? How did conflicting opinions from physicians affect your decisions?

2. Now, about the time frame and the risks/benefits explanation. Did you have enough time to make an informed decision and were you satisfied with the explanations?

3. Who was involved in helping you make treatment decisions? Do you have any medical background or did you have friends or family members with medical backgrounds that gave you advice about treatment decisions?

4. Were there specific things you considered in "how" your treatment decisions were made? What if any of these were considered in "how" you made your treatment decisions: personal feelings, values, body image concerns, threat of dying, sexuality, reproductive issues, or reconstructions procedures?

5. Did family or friends experience with a breast cancer diagnosis affect "how" you chose treatment options?

Thanks for your help! 


\section{Appendix L}

\section{Coding Sheet}

Treatment considerations-Personal Thoughts and Feelings

Initial personal reactions:

Fog

Wow

Shocked

Shell-shocked

Overwhelmed

Taken off guard

Felt Naïve

Just one more thing to happen to me

Feeling I had a positive experience

Feeling I had a negative experience

First Impressions to treatment team:

Felt rushed

Didn't feel doctor understood my preferences, and didn't listen,

Didn't want a clinical feel, wanted a good bedside manner

Confusion about conflicting opinions and feeling uncertain about what course of action to

take

Didn't feel good about the doctor, setting, or recommended treatment options 


\section{Thoughts:}

Want "it" (cancer) out quickly

Thoughts of body image, sexuality, and reproduction concerns but not the primary focus

of treatment considerations

Knowing I was able to consider options on my own and make my own decisions

The need to gather information (from books, pamphlets, and internet) about possible considerations on my own.

\section{Feelings:}

Fear of dying

Fear of reoccurrence

Fear of the unknown

Had "gut feelings" about considerations "knew what I was going to do"

Treatment considerations- Decision aids:

Personal resources and strategies:

Finding the right doctor

Having medical friends

Making a game plan

Note-taking

Building and creating your own team

Having a family member or friend accompany you to appointments.

Having family experiences (with cancer) that helped me make decisions

Having personal experience (long-term breast health issues) allowed me to weigh options and consider the what ifs 
Spirituality

Support from family and friends about treatment considerations

Feeling comfort in talking with previous survivors about possible considerations

Being prepared for consultations (by doing my own research)

\section{Treatment team strengths:}

Being told this is not a death sentence

Collaboration between various health care providers

Given the entire range of options and feeling informed

Access to reliable informational resources provided by trusted health care providers

Having an advocate, navigator, or doctor/office staff to help direct care

Feeling trust in the doctor, specialists, medical team, and having a multi-disciplinary approach.

Given time-lines to consider options and given time to make decisions about treatment considerations

\section{Treatment considerations-Deterrents:}

Higher stage cancer diagnosis diminishes treatment option considerations

Sexuality concerns

Mixed information posted on the Internet

Lack of follow-up and support from groups known to be breast cancer advocates

Not being informed about potential complications or future "touch-up" surgeries

Not being allowed to consider treatment options

Not knowing about available resources initially but finding out about them after the fact 
Treatment considerations- Recommendations

Recommendations for future breast cancer patients:

Be proactive

Take charge

Educate yourself

Take time to absorb

Find breast cancers specialists

Write down questions

Ask questions

Take a tape recorder to consultation appointments

Take someone with you to appointments

Find advocates and support groups

Have the doctor recommend reputable websites on the Internet

Go with your gut feeling, do what is right for you

\section{Recommendations for Health Care Providers:}

Tell women the diagnosis is not a death sentence (when possible)

Give women time to make decisions

Give women permission to postpone or delay some treatment decisions

Give simple guidebooks as a reference

Give a comprehensive resource book that is up to date and from well respected sources

Tell women about lymphedema

Tell women about the potential for future surgeries during reconstruction 